\title{
Abdominal Aortic Aneurysm
}

\section{Aspects on how to affect mortality from rupture}

\author{
Jakob Hager
}

Division of Cardiovascular Medicine

Department of Medical and Health Sciences

Linköping University, Sweden

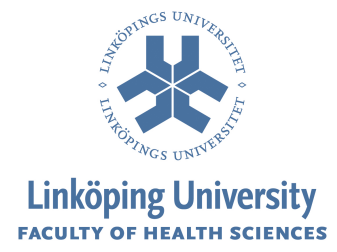

Linköping 2014 
(C) Jakob Hager, 2014

Cover picture: A ruptured Abdominal Aortic Aneurysm (rAAA) in a 79-year old man visualized on CT-scan.

One afternoon, he experienced sudden onset of shock and on arrival at the emergency department he was judged to have sepsis, despite no fever. On physical examination, he did not have any obvious abdominal pain. A CT-scan was performed to exclude any "surgical disease" - this however showed a 10 $\mathrm{cm}$ in diameter rAAA. By this time he had been in deep shock for more than four hours. He acutely underwent an uneventful open operation, but died less than three days later due to multiorgan failure.

Unfortunately this case illustrates a not too uncommon scenario and the poor prognosis of rAAA - especially if the correct diagnosis is delayed.

Printed in Sweden by LiU-Tryck, Linköping, Sweden, 2014

ISBN 978-91-7519-503-2

ISSN 0345-0082 
To my everything - my family Louise, Disa, Sixten and Anna!

"Säll är den som har till rättesnöre, att man bör nog tänka efter före." Ur "Samlade dikter 1967-1967"

Tage Danielsson 1928-1985 



\section{CONTENTS}

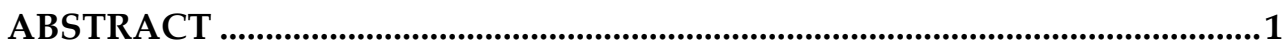

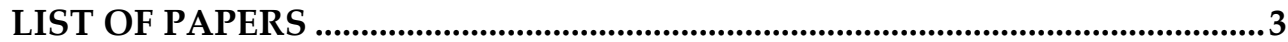

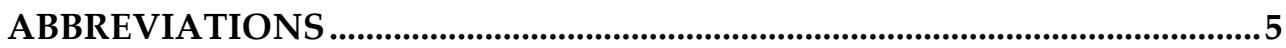

INTRODUCTION AND BACKGROUND ...........................................................

Aneurysms ...........................................................................................................

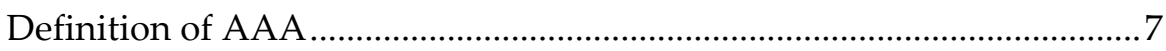

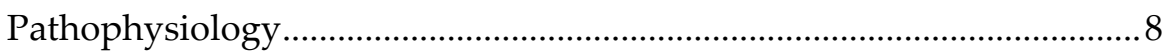

Prevalence and Epidemiology.............................................................

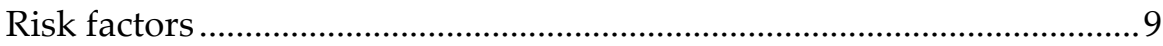

Ruptured Abdominal Aortic Aneurysm - rAAA............................................15

Symptoms and detection of AAA............................................................ 15

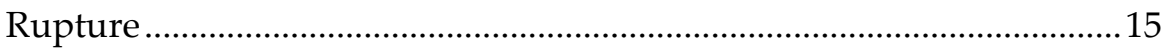

Surgical management of AAA/rAAA and indications for surgery ..........19

Surgical management ............................................................................19

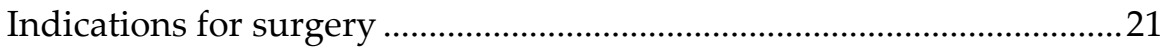

Surveillance and treatment other than surgical ..............................................22

Methods how to prevent mortality from rAAA ...............................................2

Reorganisation of health-care..................................................................... 24

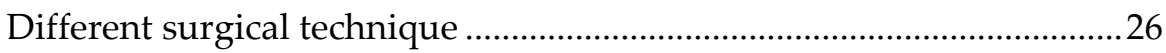

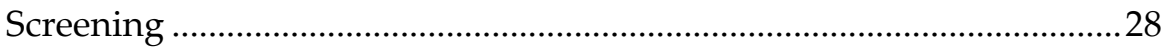

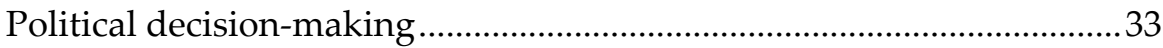

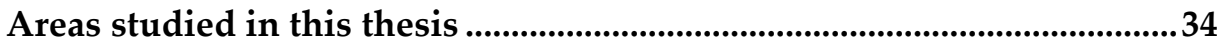

AIMS

SUBJECTS, MATERIAL AND METHODS ..........................................................39

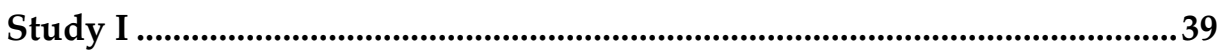

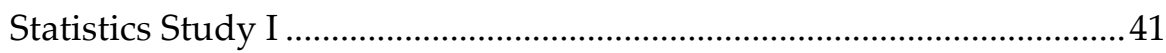

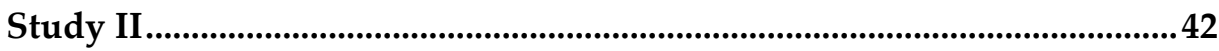




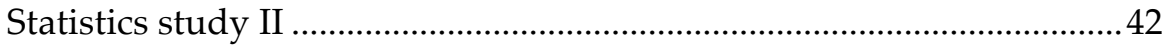

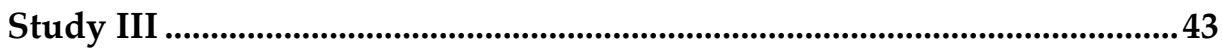

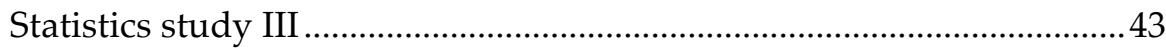

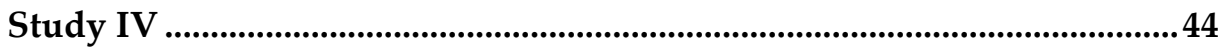

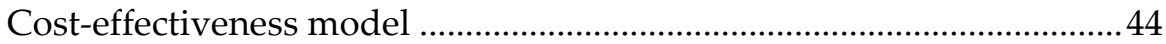

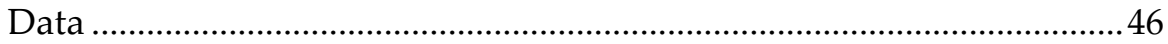

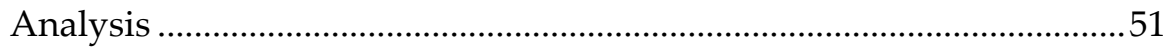

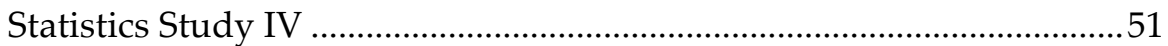

The ultrasound-examination and definition of an AAA ...........................52

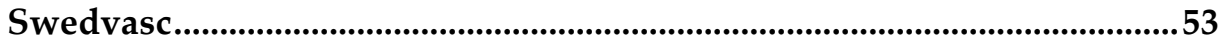

Statistical calculations and Ethics ..............................................................53

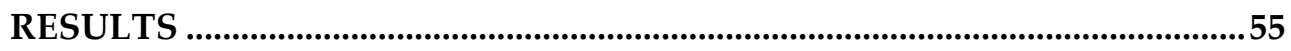

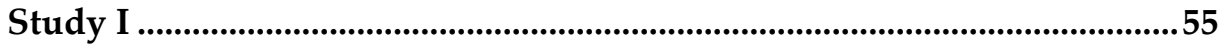

Study II ................................................................................................................5 58

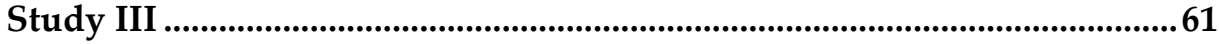

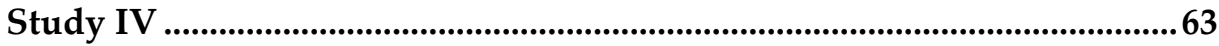

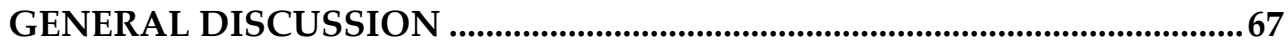

Centralisation of services for rAAA/AAA ................................................68

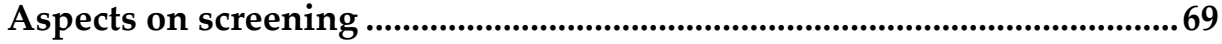

Risk factors among 70-year-old men........................................................70

Is screening at 70 years of age instead of 65 more effective? ..................72

Surveillance of sub-aneurysmal aortas? .............................................73

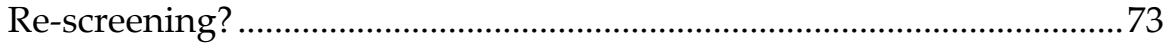

Still cost-effective to screen........................................................................... 74

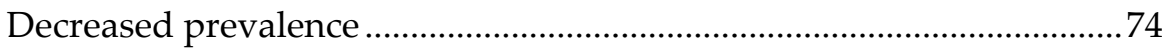

Higher attendance rate ...................................................................... 75

Decreased mortality, increased survival ..............................................75

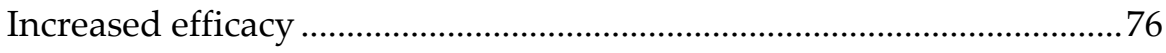

Incidental discovery of AAA .......................................................... 76

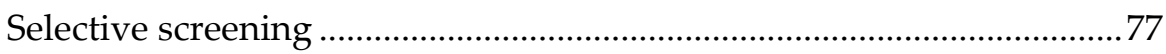

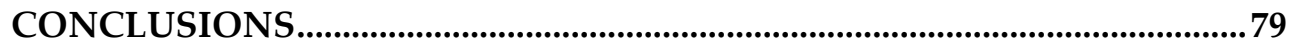

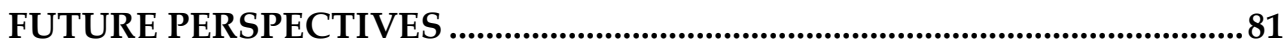


SUMMARY IN SWEDISH - SAMMANFATTNING PÅ SVENSKA ............83

Sammanfattning

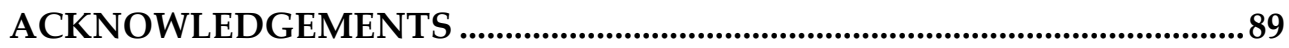

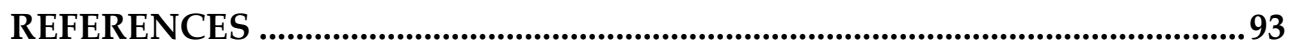

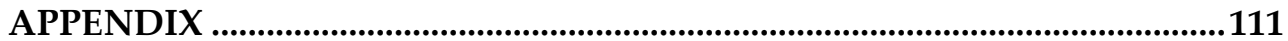




\section{ABSTRACT}

Abdominal Aortic Aneurysm (AAA) is a disease that mainly affects elderly men, and ruptured AAA (rAAA) is associated with a mortality of $>80 \%$. AAA seldom gives any symptoms prior to rupture.

The aims of this thesis were to investigate different aspects of how to affect mortality from rAAA.

In Study I, we identified 849 patients treated for rAAA during 1987-2004, and studied the 30-day survival after surgery, depending on whether they came directly to the treating hospital (one-stop) or were transferred via another hospital (two-stop). A two-stop referral pattern resulted in a $27 \%$ lower population-based survival rate for patients 65-74 years of age. However, the consequences would be small even if a one-stop referral pattern could be generally accomplished, due to the huge over-all mortality related to rAAA, hence an argument to find and treat AAA before rupture, e.g. by screening.

In Study II, we examined the AAA-prevalence and the risk factors for AAA among 70-year-old men. The screening-detected AAA-prevalence was $2.3 \%$, thus less than half the predicted. The most important risk factor was smoking.

In Study III, we compared the screening-detected AAA-prevalence, the attendance rate, and the rate of opportunistic detection of AAA, between almost 8000 65- and 6000 70-year-old men. There was no difference in the screening-detected prevalence; probably due to the fact that almost $40 \%$ of the AAAs among the 70-year-old were already known prior to screening, compared to roughly $25 \%$ in the 65 -year-old. The attendance rate was higher among the 65 -year-old men, $85.7 \%$ compared $84.0 \%$ in the 70 -year-old. Thus, there is no benefit of screening for AAA among 70- instead of 65-year-old men.

In Study IV, a cost-effectiveness analysis, we found that screening for AAA still appears to be cost-effective, despite profound changes in disease pattern and AAA-management.

In conclusion, we found that mortality from rAAA is not affected in any substantial way by different referral patterns and hence centralisation of services for AAA/rAAA is not a solution. A better alternative is to prevent rupture through early detection by screening. Screening 65-year-old men for AAA still appears to be cost-effective, despite profound changes in disease pattern and AAA-management during the last decade. Screening 70- instead of 65-year-old men will not increase the efficacy of screening. 


\section{LIST OF PAPERS}

I. Population-based Survival Rate with a One- or Two-stop Referral Pattern for Patients with Ruptured Abdominal Aortic Aneurysms Jakob Hager, Fredrik Lundgren International Angiology 2013 October; 32(5): 492-500

II. Lower Prevalence than Expected when screening 70-year-old Men for Abdominal Aortic Aneurysm Jakob Hager, Toste Länne, Per Carlsson, Fredrik Lundgren European Journal of Vascular \& Endovascular Surgery 46 (2013): 453-459

III. No Benefit of Screening for Abdominal Aortic Aneurysm among 70Instead of 65-year-old Men Jakob Hager, Toste Länne, Per Carlsson, Fredrik Lundgren Submitted

IV. Changing Conditions but same Conclusion: Cost-effective to Screen for Abdominal Aortic Aneurysm among 65-year-old Men, Based on Data from an Implemented Screening Programme Jakob Hager, Martin Henriksson, Per Carlsson, Toste Länne, Fredrik Lundgren

Submitted

Reprints have been made with the permission of the publishers. 


\section{ABBREVIATIONS}

AAA

ACE

ADAM

ARR

BMI

BP

CAESAR

CHD

CI

CMT

COPD

CPP

CT

CVD

DM

DREAM

eEVAR

EpC

EVAR

EVAR1

EVAR2

HDL

HR

ICD

ICER

ICU

IMPROVE
Abdominal Aortic Aneurysm

Anevrysme de l'aorte abdominale: Chirurgie versus Endoprothese

The Aneurysm Detection and Management Veterans Affairs Cooperative Study

Absolute Risk Reduction

Body Mass Index $\left(\mathrm{kg} / \mathrm{m}^{2}\right)$

Blood Pressure

The Comparison of Surveillance Versus Aortic Endografting for Small Aneurysm Repair-study

Coronary Heart Disease

95\% Confidence Interval

The Centre for Medical Technology assessment

Chronic Obstructive Pulmonary Disease

Cost Per Patient

Computed Tomography

Cerebro Vascular Disease

Diabetes Mellitus

The Dutch Randomized Endovascular Aneurysm Repair-study

Emergency EVAR

The Epidemiological Centre at the Swedish National Board of Health and Welfare

Endovascular Aneurysm Repair

The United Kingdom Endovascular Aneurysm Repairtrial 1

The United Kingdom Endovascular Aneurysm Repairtrial 2

High-Density Lipoprotein

Hazard Ratio

International Classifications of Diseases

Incremental Cost-Effectiveness Ratio

Intensive Care Unit

The Immediate Management of the Patient with Rupture: Open Versus Endovascular repair 
ITI

LELE

MASS

MMP

MRI

NAAASP

NHS

NICE

NNS

OR

OAR

OTO

QALY

QoL

OVER

PIVOTAL

rAA

rAAA

RCT

RR

RRR

Swedvasc

UKSAT

USG

USPSTF
Inner To Inner

Leading Edge to Leading Edge

The Multicentre Aneurysm Screening Study

Matrix Metalloproteinases

Magnetic Resonance Imaging

The NHS AAA Screening Programme

The National Health Service

The National Institute for Health and Care Excellence

Number Needed to Screen

Odds Ratio

Open Aortic Repair

Outer To Outer

Quality Adjusted Life-year

Quality of Life

The Open Versus Endovascular Repair-study

The Positive Impact of Endovascular Options for treating Aneurysms Early

ruptured Aortic Aneurysm

ruptured Abdominal Aortic Aneurysm

Randomised Controlled Trial

Relative Risk

Relative Risk Reduction

The Swedish National Registry for Vascular Surgery

The United Kingdom Small Aneurysm Trial

Ultrasound/Ultrasonography

The US Preventive Services Task Force 


\section{INTRODUCTION AND BACKGROUND}

\section{Aneurysms}

The word aneurysm is derived from the Greek word " $\alpha v \varepsilon v \varrho v \sigma \mu \alpha$ " aneurusma - meaning, "a widening". An aneurysm is usually defined as a localized dilatation of an artery having at least a 50\% increase in diameter compared to the expected normal diameter of the artery in question (Johnston et al. 1991). The most common location of an aneurysm is in the aorta below the renal arteries, the infrarenal aorta - an abdominal aortic aneurysm (AAA). Other common locations for aneurysms are the iliac, the femoral and the popliteal arteries and if an individual has an aneurysm in one location he or she often has one in other locations as well, for example $85 \%$ of those with an aneurysm in the femoral artery have an AAA, and for those with a popliteal artery aneurysm, 62\% have an AAA (Moll et al. 2011). Among men with an AAA, $14 \%$ have a femoral or popliteal artery aneurysm (Diwan et al. 2000).

Intracranial arterial aneurysms and AAA result from different underlying disease processes and exhibit different rupture potentials, yet share many histopathological and biomechanical characteristics (Humphrey, Taylor 2008).

The normal development of an aneurysm is to progress exponentially in diameter, with subsequent risk of rupture (Limet, Sakalihassan \& Albert 1991). It is estimated that $2 \%$ of all deaths may be related to rup1tured AAA (rAAA) (Nordon et al. 2011).

A true aneurysm includes all three layers of the vessel wall; the intima, the media and the adventitia. A pseudo-aneurysm or a "false" aneurysm represents a hematoma contained by the surrounding tissue, and is the result of localized arterial trauma and has the appearance of an arterial aneurysm on examination (Rutherford 2000).

\section{Definition of AAA}

There are several different definitions of an AAA, but the most commonly accepted is that the abdominal aortic diameter below the renal arteries is 30 mm or more (McGregor, Pollock \& Anton 1975), and this is almost always a 
width of more than two standard deviations compared to the normal aorta in both men and women. This definition may seem rather rigid since the body size, and hence the "normal" aorta, displays large variations between different individuals, as well as between men and women. The normal diameter of the infrarenal aorta in elderly men is 15-24 mm (Liddington, Heather 1992) and it increases with age, weight and height and is also larger in men than in women, if not corrected for differences in body surface area (Sonesson et al. 1994).

Other definitions than the " $\geq 30 \mathrm{~mm}$ in diameter-definition" of an AAA has been proposed, for example the aortic diameter below the renal arteries being at least 1.5 times larger than the expected normal aorta or the presence of a localised swelling infra-renally or the infra-renal aortic diameter being $\geq 5$ $\mathrm{mm}$ larger than the diameter at the level of the renal arteries (Sterpetti et al. 1987, Collin et al. 1988, Johnston et al. 1991, Lanne, Sandgren \& Sonesson 1998, Singh et al. 2001), but in contemporary literature the $30-\mathrm{mm}$ limit is now almost exclusively used.

\section{Pathophysiology}

Previously AAA was considered to be an advanced manifestation of atherosclerotic disease. However, in recent years it has become increasingly clear that AAA rather is a focal representation of a systemic disease entity of its own in the vascular system. Histologically, AAA is characterized by destruction of elastin and collagen in the media and adventitia, smooth muscle cell loss with thinning of the medial wall, infiltration of lymphocytes and macrophages, and neovascularisation (Lopez-Candales et al. 1997). Inflammation is a common underlying feature of both aneurysm disease and atherosclerosis, but atherosclerosis primarily affects the intima and media whereas aneurysm disease typically affects the media and adventitia (Ailawadi, Eliason \& Upchurch 2003).

It has also been said that patients with AAA have a greater risk of developing inguinal and postoperative hernias as well as diastasis of the rectus abdominis muscle (Nordon et al. 2011). Well-performed studies regarding these issues have however questioned this - for example Henriksen et al. found no association between inguinal hernia and AAA (Henriksen et al. 2013), and Israelsson has studied the importance of suture technique and concluded that the rate of incisional hernias is similar in patients with AAA as in other surgical procedures (Israelsson 1999). 


\section{Prevalence and Epidemiology}

The prevalence of AAA increases with age (Singh et al. 2001, Kent et al. 2010), for example the prevalence of AAA (defined as $\geq 30 \mathrm{~mm}$ ) was more than doubled when comparing men aged 80-83 years with men 65-69 years old $(10.8 \%$ vs. $4.8 \%)$ in a screening-study examining 12,203 men (Jamrozik et al. 2000).

AAA and rAAA is about six times more common among men than women (Scott, Bridgewater \& Ashton 2002, Choksy, Wilmink \& Quick 1999). The reason for this is not clear but hormonal and genetic factors and different exposure to risk factors may be of importance (Blanchard 1999).

In men 64-80 years old, the prevalence of AAA, in large screening studies performed around the turn of the century, has been between 4.0 and $7.7 \%$ and the corresponding figure for women of similar age is 1.3\% (Ashton et al. 2002, Norman et al. 2004, Lindholt et al. 2005, Ashton et al. 2007, Scott, Bridgewater \& Ashton 2002). For 65-year-old men specifically, the prevalence has previously been calculated to be $4.9 \%$ (Henriksson, Lundgren 2005a).

Until the mid-nineties the prevalence of AAA steadily rose (Von Allmen, Powell 2012). However, in recent years when large screening-programmes have been initiated (see also page 28 , Screening) the prevalence has decreased substantially among 65 -year-old men, now being around only $1.7 \%$, i.e. only one-third of what has previously been found (Conway et al. 2012, Svensjo et al. 2011). In the National Health Services AAA Screening Programme (NAAASP) in England, the prevalence 2011-12 was 1.5\% for the 65-year-old men examined (NAAASP). Also for women the prevalence has decreased in a similar way, now being only $0.4 \%$ among 70 -year-old women (Svensjö, Björck $\&$ Wanhainen 2012). The main reason for this large declination probably is the pronounced decrease in cigarette smoking during the last decades. Smoking is indisputably the major affectable risk factor for AAA (Svensjo et al. 2011, Conway et al. 2012, Norman, Spilsbury \& Semmens 2011, Sandiford, Mosquera \& Bramley 2011, Anjum, Powell 2012).

\section{Risk factors}

Risk factors for AAA are associated with development, expansion and rupture - the most devastating complication of all. The main risk factors that have been studied in relation to AAA are: smoking, hypertension, diabetes mellitus, alcohol, obesity, low HDL (High-Density Lipoprotein) -levels, physical activity 
and diet. Age, sex and family history are also of major importance for AAAdevelopment, but these are often called associated or predisposing factors, rather than risk factors.

\section{Smoking}

The strongest risk factor for AAA that is possible to affect is tobacco smoking (Lederle, Nelson \& Joseph 2003, Badger et al. 2008). The excess prevalence for AAA associated with smoking, accounts for $75 \%$ of all AAAs $\geq 4 \mathrm{~cm}$ (Lederle et al. 2000a) and the etiological fraction, i.e. the excess prevalence associated to smoking has been suggested to be $71 \%$ (Svensjo et al. 2011). In one study on almost 40,000 US men, the Hazard Ratio (HR) for AAA among men who were heavy smokers ( $>25$ cigarettes a day) was 15.2 (95\% Confidence Interval (CI) 9.9-23.3) compared to never smokers (Wong, Willett \& Rimm 2007).

Smoking seems to be the only modifiable risk factor affecting all three aspects in the evolution of an AAA; development, expansion and rupture (Brown, Powell 1999, Brady et al. 2004). Current smokers were 7.6 (CI 3.3-17.8) times more likely to have an AAA than a non-smoker (Wilmink, Quick \& Day 1999). To date no certain causative link has been proven between smoking and AAA formation (Nordon et al. 2011), but besides being part of the atherosclerotic process, smoking affects elastin degradation in the vascular wall by promoting the expression of proteolytic systems (Matrix Metalloproteinases (MMPs), elastase, plasmin, cysteine proteases and lipooxygenase) and at the same time smoking attenuates the activity of the inhibitors of these systems, which all together contributes to the development of an AAA (Kakafika, Mikhailidis 2007).

Smoking is the only know risk factor that actually increases expansion rate of an AAA (MacSweeney et al. 1994, Brown, Powell 1999, Lindholt et al. 2001, Brady et al. 2004, Sweeting et al. 2012). Sweeting et al. found that the mean expansion-rate of AAA was $2.21 \mathrm{~mm} /$ year, and smoking increased this by 0.35 $\mathrm{mm}$ /year. They also found that the risk of rupture at a given diameter is doubled among smokers, thus confirming previous results from the United Kingdom Small Aneurysm Trial (UKSAT) (UKSAT participants 2000).

Whether the duration rather than the level of exposition is the most important for AAA-development is not completely clear. Varludaki et al. found the level of exposition to be the most important, but another author Wilmink et al. - found duration to be more significant (Vardulaki et al. 2000, Wilmink, Quick \& Day 1999). Forsdahl et al. found both duration and number of cigarettes smoked being important, which seems to be the most reasonable 
standpoint (Forsdahl et al. 2009). Wilmink et al. found that the Relative Risk (RR) of AAA increased by $4 \%$ (CI 2-5\%) for each year of smoking (Wilmink, Quick \& Day 1999). After quitting smoking there is a slow decrease in the risk of developing an AAA, and also growth-rate may be reduced in an already established AAA (MacSweeney et al. 1994).

There is no full-proof evidence that passive smoking is of importance in relation to AAA, but it is certain that common environmental factors affect the incidence of AAA (Powell 2003), e.g. passive smoking.

Svensjö et al. found the Odds Ratio (OR) for the risk factor "Ever smoked" being 20.3 (CI 2.7-152.7 (sic!)) for AAA among women, indicating that women might be more sensitive to smoking than men, where the OR is substantially lower - for example Lederle et al. found a 5.1 OR (CI 4.1-6.2) for "ever smoking" (> 100 cigarettes during lifetime) among AAA $\geq 4.0 \mathrm{~cm}$ in the Aneurysm Detection and Management Veterans Affairs Cooperative Study (ADAM), where 97.3\% were men (Svensjö, Björck \& Wanhainen 2012, Lederle et al. 2000a). The aortic wall stiffness was increased in female but not in male smokers, thus also supporting that women are more sensitive to smoking than men (Sonesson et al. 1997)

In the UKSAT $92 \%$ of the men with an AAA were "ever-smokers" and the corresponding figure for ADAM, was 94\% (UKSAT Participants 2002, Lederle et al. 2002b).

Finally, but very important when dealing with patients with AAA, smoking also decreases long-term overall survival (UKSAT participants 2000).

\section{Family History}

Having a first-degree relative with AAA increases the risk of having AAA (Bengtsson et al. 1992, Lederle et al. 2000a). In the Life Line Screening ${ }^{1}$ cohort, $8.0 \%$ of those having an AAA (in a population of 3 million people studied), had a positive family history, compared to $2.5 \%$ in those without, $\mathrm{p}<0.0001$, OR 3.80 (CI 3.66-3.95) (Kent et al. 2010). In a Swedish study the RR of developing AAA for first-degree relatives to persons diagnosed with AAA, was approximately doubled, OR 1.9 (CI 1.6-2.2) compared to persons with no

${ }^{1}$ Life-Line Screening Inc (LLS, Independence, Ohio, USA) is a company offering screening-tests "preventing complications of cardiovascular disease and sudden stroke" to self-referred individuals who pays for the test out of pocket. Before screening, individuals complete a 36-item questionnaire. 
family history. In that study neither the gender of the index person or the firstdegree relative, influenced the risk of AAA (Larsson et al. 2009).

Frydman et al. found that $30 \%$ of the siblings to AAA patients had an "enlarged aorta" (5\% ectasia ${ }^{2}$ and $25 \%$ aneurysmal), $43 \%$ of the male and $16 \%$ of the female siblings. The incidence of an "enlarged aorta" was $45 \%$ in brothers of female index patients, $42 \%$ in brothers of male patients, $23 \%$ in sisters of female patients and $14 \%$ of sisters in male index patients (Frydman et al. 2003). In a study using data from the Swedish Twin Registry, a $24 \%$ probability that a monozygotic twin of a person with AAA had the disease, was found, OR 71 (CI 27-183 (sic!)), and for dizygotic twins the probability was 4.8\%, OR 7.6 (CI 3.0-19) (Wahlgren et al. 2010).

Despite these clear hereditary relationships there are no robust genetic studies showing causative gene mutations (Nordon et al. 2011, Björck, Wanhainen 2013).

\section{Hypertension}

Nordon et al. in a recent review claimed; "any association seems weak" regarding the potential association between AAA and increased blood pressure (BP) (Nordon et al. 2011).

However, Varludaki et al. in a study among more than 5000 subjects, found that a raised diastolic BP increased the risk of having an AAA by between 30 and $40 \%$, depending on how elevated BP was defined, and this risk increased linearly. But, surprisingly, raised systolic BP did not significantly increase the risk of having an AAA and hypertension did not increase expansion of an already existing AAA (Vardulaki et al. 2000). Further, Sweeting et al. in a meta-analysis of more than 15,000 people found that rupture rates increased with higher BP (defined as mean arterial BP (per 10 $\mathrm{mm} \mathrm{Hg}$ )) with a HR of 1.32 (CI 1.11-1.56) (Sweeting et al. 2012). In another study including almost 40,000 US men, the HR for developing AAA, when having self reported hypertension was 1.53 (CI 1.22-1.92), $\mathrm{p}=0.0002$ (Wong, Willett \& Rimm 2007). Finally, Forsdahl et al. found that hypertension (defined as systolic $\mathrm{BP}>160 \mathrm{~mm} \mathrm{Hg}$, diastolic $\mathrm{BP}>95 \mathrm{~mm} \mathrm{Hg}$ or ever use of antihypertensive medication) was associated with increased AAA risk, but interestingly, only in women (Forsdahl et al. 2009).

\footnotetext{
${ }^{2}$ Ectasia is usually defined as the arterial dilatation being less than $50 \%$ above the normal(Rutherford 2000), but in this study it was defined as the infrarenal aortic diameter being $>1.5$ to $<2.0$ times larger than the suprarenal aortic diameter.
} 


\section{Diabetes Mellitus}

Diabetes Mellitus (DM) has been suggested to have a negative association, i.e. being protective, to AAA, despite its strong association to atherosclerosis (Lederle et al. 1997). In a review, Shantikumar et al. found a reduced rate of DM among people with AAA compared to those without, OR 0.65 (CI 0.600.70, $\mathrm{p}<0.001$ ) (Shantikumar et al. 2010).

Brady et al. found a slower growth rate of established AAA, among patients with DM (Brady et al. 2004). This was confirmed in two other studies, the first, a meta-analysis by Sweeting et al., were it was found that DM diminished the calculated growth rate of AAA-diameter of $2.21 \mathrm{~mm}$ per year, by $0.51 \mathrm{~mm}$ per year (Sweeting et al. 2012) and the other by De Rango et al. who found that the progression rate of small AAA (by $>5 \mathrm{~mm}$ in 36 months) was 63\% lower in patients with DM (De Rango et al. 2012).

One explanation for such negative association might be the reduced wall stress in the aorta (mainly due to a thicker aortic wall) seen among patients with DM (Astrand et al. 2007).

\section{Alcohol, low HDL, obesity, physical activity and diet}

Alcohol in the form of wine in moderate doses shows a significant inverse association in relation to vascular risk (Di Castelnuovo et al. 2002). However, there is a positive trend between alcohol consumption and the risk of AAA (Wong, Willett \& Rimm 2007). Alcohol has a favourable effect on HDL-levels, the so-called "good cholesterol" (Brinton 2012), but a bit confusing, low HDLlevels is an independent risk factor for AAA (Singh et al. 2001). The mechanisms behind these findings remain unclear (Nordon et al. 2011).

Obesity has to some extent also been associated with AAA - Golledge et al. found that waist circumference and waist-to-hip ratio were independently associated to AAA, OR 1.14 (CI 1.06-1.22) and OR 1.22 (OR 1.09-1.37) respectively and that the association was stronger for AAA $\geq 40 \mathrm{~mm}$ (Golledge et al. 2007). This is in consonance with the findings by Stackelberg et al. (Stackelberg et al. 2013). They estimated that the risk of AAA increased by 15\%, RR 1.15 (OR 1.05-1.26) per 5-cm increment of waist circumference up to the level of $100 \mathrm{~cm}$ for men and $88 \mathrm{~cm}$ for women, but a bit surprisingly, they could not confirm any association between Body Mass Index (BMI) and the risk of AAA. A positive relation between BMI and AAA has however previously been described (Wong, Willett \& Rimm 2007). 
Kent et al. too, found a relation between excess weight and increased risk of having an AAA, and in addition they discovered that exercise, and consumption of nuts, vegetables, and fruits were associated with reduced risk (Kent et al. 2010). 


\section{Ruptured Abdominal Aortic Aneurysm - rAAA}

\section{Symptoms and detection of AAA}

An AAA most often gives no symptoms at all. It is sometimes discovered by the patient himself or by his partner, noticing a pulsating mass in the abdomen. Occasionally a physician discovers it by physical examination, while palpating the abdomen. Fink et al. found that when looking for AAA on physical examination, the sensitivity for finding one was $68 \%$ (CI 60-76\%) with a specificity of $75 \%$ (CI 68-82\%) (Fink et al. 2000). The sensitivity increased with the size of the AAA, e.g. for AAA with diameter 3.0-3.9 cm the sensitivity was $61 \%$ and for AAAs $\geq 5.0 \mathrm{~cm}$ it was $82 \%$. The sensitivity decreased with increased abdominal girth; for abdominal girth $<100 \mathrm{~cm}$ the sensitivity was $91 \%$ and $\geq 100 \mathrm{~cm}$ it was $53 \%$. Three factors were independently associated with sensitivity of discovering an AAA: 1 . AAA-diameter, OR 1.95 per $\mathrm{cm}$ increase (CI 1.06-3.58); 2. Abdominal girth, OR 0.90 per $\mathrm{cm}$ increase (CI 0.87$0.94) ;$ and 3. The examiners assessment "that the abdomen was not tight", OR 2.68 (CI 1.17-6.13). However, in this study the physicians knew that they were looking for an AAA, so in real clinical life when physicians are palpating the abdomen as part of a general examination, the detection rate most probably is substantially lower. Kiev et al. for example found that of 145 patients with an AAA, clinical detection was less than $30 \%$ on admission, and if the AAA was less than $4.5 \mathrm{~cm}$ in diameter it was "rarely" discovered on physical examination (Kiev, Eckhardt \& Kerstein 1997).

Before screening for AAA was introduced, most often an AAA was discovered incidentally by radiological means, for example with Magnetic Resonance Imaging (MRI), Computed Tomography (CT) or Ultrasound/Ultrasonography (USG), when investigating for other abdominal diseases.

\section{Rupture}

As the diameter of an AAA increases, so does the risk of rupture. A ruptured AAA (rAAA) is one of the most catastrophic conditions seen at emergency departments with an overall total mortality of at least 80\% (Drott et al. 1992, Bengtsson, Bergqvist 1993, Choksy, Wilmink \& Quick 1999, Reimerink et al. $2013 b)$. It is estimated that $1 \%$ of the deaths in men older than 65 years of age 
are caused by rAAA (SBU, The Swedish Council on Health Technology Assessment). Of those reaching hospital alive, $87.5 \%$ were alive after two hours, with a median survival time (without treatment) of 10 hours and 45 minutes after admission. The total median time from onset of symptoms to death was 16 hours and 38 minutes (Lloyd et al. 2004).

The risk of rupture increases exponentially with diameter (Limet, Sakalihassan \& Albert 1991), according to the law of Laplace, which states that wall tension increases with diameter. When following 198 patients with large AAA (diameter $\geq 5.5 \mathrm{~cm}$ ), who refused or were unfit for elective repair, Lederle et al. found that the one-year incidence of "probable" rupture (the autopsy rate was only $46 \%$ ) was $9.4 \%$ for AAA with diameters $5.5-5.9 \mathrm{~cm}$, $10.2 \%$ for AAA of $6.0-6.9 \mathrm{~cm}$ and $32.5 \%$ for AAA $\geq 7.0 \mathrm{~cm}$ (Lederle et al. 2002a). In another study, the mean size when rupture occurred was $8.1 \mathrm{~cm}$, and only in $7.4 \%$ of the 68 cases, rupture occurred in AAAs $<6 \mathrm{~cm}$ in diameter (Choksy, Wilmink \& Quick 1999). Powell et al. found that the pooled RR for rupture per 100 person-years for AAA being 5.0-5.9 cm in diameter was 10.3 (CI 7.5-14.3) and for AAA $\geq 6.0 \mathrm{~cm} 27.0$ (CI 21.1-34.7) (Powell et al. 2008).

The median age when rupture occurred, in a study with the autopsy rate of $85 \%$, was 73 years in men and 83 in women (Bengtsson, Bergqvist 1993), compared to 76 years in men and 80 years in women in the study by Choksy et al. (Choksy, Wilmink \& Quick 1999). The mean age for both men and women increased from 73 to 79 years between 1986 and 1994. Interestingly, 12.6\% of all ruptures occurred in men $<65$ years, which is bit lower than what was found in The Swedish National Registry for Vascular Surgery (Swedvasc) 2006 , were $19 \%$ of the men operated on for rAAA were younger than 65 years (Wanhainen, Svensjo \& Mani 2008).

In the UKSAT, the risk of rupture was associated with female sex, HR 3.0 (CI 2.0-4.5) compared to men, larger initial aneurysm diameter, current smoking and higher mean BP (Brown, Powell 1999). Another study regarding women, found that the RR for rupture in an AAA with diameter 5.0-5.9 cm was four times greater in women than in men, RR 4.0 (CI 1.2-13.0), and if the AAA was $\geq 6.0 \mathrm{~cm}$ in diameter the RR was 1.6 times greater for women compared to men (Brown, Zelt \& Sobolev 2003). Also one third of rAAA that results in death in the USA occur in women, and $40 \%$ of the AAA-related deaths are in women, despite that AAA is six times more common in men (Vouyouka, Kent 2007, Mureebe et al. 2008, Kent et al. 2010). Further, 30-day mortality after intervention for rAAA was $7.7 \%$ higher among women compared to men when studying the Medicare beneficiary database 1995-2006 
(Mureebe et al. 2010). Hence, AAA seems to be a potentially more dangerous disease in women.

When rupture occurs, it is estimated that one third, 32\% (CI 27-37), of the patients die before reaching hospital and of those that reach hospital alive, only in 60\% (CI 53-67) intervention is attempted (Reimerink et al. 2013b). 53\% (CI 48-59) of those who were subject to intervention died perioperatively. In Swedvasc the mortality rate after intervention for rAAA 2011-12 was 27\% after 30 days and $32 \%$ after 90 days (Hager 2013).

An AAA may rupture in mainly five different ways (Sakalihasan, Limet \& Defawe 2005):

1. Free rupture into the abdominal cavity - which usually is dramatic and most often associated with death at the scene.

2. Rupture of the posterolateral wall of the AAA into the retroperitoneal space - most patients who reach hospital alive have this type of rupture. Often a small tear can temporarily seal the rupture and the initial blood loss might be small, however this initial event systematically is followed by a larger rupture - and subsequent death if the patient has not been treated.

3. Anecdotally, the first "small" rupture (see above) may become definitely contained and become a chronic pulsatile extra-aortic hematoma - a pseudoaneurysm.

4. Very rarely the AAA ruptures into the duodenum, presenting as a massive gastrointestinal bleeding.

5. Rupture may finally occur into the vena cava - this often presents as lower extremity oedema, high output congestive heart failure and the presence of a continuous murmur located abdominally.

A meta-analysis from 2002 demonstrated a gradual decrease in operative mortality rate of rAAA repair during the years 1955-1998, with the pooled estimate for the overall operative mortality rate being $48 \%$. The operative mortality over time also demonstrated a constant reduction of $3.5 \%$ per decade (Bown et al. 2002). During the period 1995-2006 the hospitalization for rAAA decreased in the USA from 23.2 to 12.8 per 100,000 Medicare beneficiaries, as did repairs of rAAA (15.6 to 8.4 per 100,000, p<0.0001) (Mureebe et al. 2008). No change was observed in elective AAA-repairs. Also, in this study the perioperative mortality rate improved slightly during the studied period. However, a more recent meta-analysis including 60,822 patients treated by Open Aortic Repair (OAR) 1991-2006, found a mortality rate of 49\% (thus, almost the same as in the study by Bown et al.), without any change during 
the studied years. One explanation for this discrepancy could be the increased age of the patients undergoing surgery for rAAA (Hoornweg et al. 2008). 


\section{Surgical management of AAA/rAAA and indications for surgery}

\section{Surgical management}

The treatment of AAA/rAAA is primarily surgical. There are two principally different methods of AAA-repair, Open Aortic Repair (OAR) and EndoVascular Aortic Repair (EVAR).

\section{Open Aortic Repair}

During OAR, with the patient under general anaesthesia, the abdomen most often is entered via a long midline incision, and the transabdominal route is used. An alternative way to enter the abdomen is via a wide transverse incision, slightly to the patients left. A retroperitoneal approach may also be used.

Once the abdomen is opened the first step is to gain proximal control by dissecting and clamping the neck of the AAA. Distal control can be achieved in two principal ways, either by clamping the iliac arteries or by inserting Foley-catheters into the iliac vessels, and inflating the balloons, once the AAA is opened. A graft made of Polyethylene terephthalate (Dacron ${ }^{\circledR}$ ) or expanded Poly Tetra Fluoroethylene (ePTFE (Gore-Tex®)) is sutured to the inside of the AAA with so-called in-lay technique. The duration of the operation is typically two hours, and if the postoperative course is event-free, the patient can be discharged from hospital in 5-7 days.

\section{EndoVascular Aortic Repair}

EVAR was invented by Volodos 1986 and made known by Parodi 1991 (Volodos' et al. 1986, Parodi, Palmaz \& Barone 1991). With the patient either under general anaesthesia or using local anaesthetics only, access to the aorta is gained through the femoral arteries, in which self-expandable metal nettubes - stents - covered with conventional graft fabric ("stent-grafts") are inserted via introducer-sheaths. The stent-grafts are placed across the interior of the AAA and fixated to the normal aorta above and normal iliac arteries below, thus excluding blood-flow and thereby pressure from the wall of the 
AAA. Where to deploy the stent-graft is determined using fluoroscopic guidance. Also for EVAR, the typical duration of the operation is two hours, but patients are normally discharged in 3-4 days, thus often less than when treated with OAR.

\section{OAR or EVAR?}

Three randomized controlled trials (RCT) have compared OAR with the EVAR-technique in patients fit for elective surgery: The United Kingdom Endovascular Aneurysm Repair-trial 1 (EVAR1), The Dutch Randomized Endovascular Aneurysm Repair-study (DREAM) and The Open Versus Endovascular Repair-study (OVER) (EVAR trial participants 2005, Prinssen et al. 2004, Lederle et al. 2009). These studies reported an early perioperative mortality benefit for EVAR versus OAR, EVAR1: $1.8 \%$ vs. $4.3 \%(\mathrm{p}=0.02)$ (The United Kingdom EVAR Trial Investigators, 2010), DREAM: $1.2 \%$ vs. $4.6 \%$ $(\mathrm{p}=0.10)$ (Prinssen et al. 2004) and OVER: 0.5\% vs. 3.0\% $(\mathrm{p}=0.004)$ (Lederle et al. 2009). However, already after one to three years there was no difference between EVAR and OAR in terms of total mortality or AAA-related mortality. Also, the rates of graft-related complications and reinterventions were higher with EVAR and overall costs were higher. There was also a risk of late ruptures among the EVAR-treated patients in all three studies (The United Kingdom EVAR Trial Investigators, 2010, Blankensteijn et al. 2005, Lederle et al. 2012).

Another RCT - Anevrysme de l'aorte abdominale: Chirurgie versus Endoprothese (ACE) - started after the results of EVAR1, DREAM and OVER had been published. They compared mortality and major adverse effects after EVAR and OAR in patients with AAA anatomically suitable for EVAR and at low- to intermediate-risk for OAR (Becquemin et al. 2011). With a median follow-up of three years there was no difference in the cumulative survival free rate of death or rates of major events between OAR and EVAR. Neither did in-hospital mortality nor the percentage of minor complications differ. However, in the EVAR-group, the reintervention rate was higher $(2.4 \%$ vs. $16 \%, \mathrm{p}<0.0001)$ with a trend towards a higher AAA-related mortality $(0.7 \%$ vs. $4.0 \%, \mathrm{p}=0.12)$.

A recent meta-analysis, which besides the four above mentioned RCTs also included data from the US Medicare and Swedvasc databases confirmed that there is no long-term survival benefit for patients treated by EVAR compared to OAR, and that there are significantly higher risks of reintervention and aneurysm rupture after EVAR (Stather et al. 2013). 
In Sweden 2012, 45\% of the 1269 patients treated electively due to AAA, were treated with OAR while 55\% had EVAR (Hager 2013).

\section{Indications for surgery}

Intuitively one might think that as soon as an AAA is discovered, it should be surgically treated, regardless the size. However, a small AAA seldom or never ruptures, growth of an AAA is often slow and above all - the surgical treatment itself is not free of serious risk, at worst death.

Four RCTs have addressed this problem - for OAR the UKSAT and the ADAM study (UKSAT Participants 2002, Lederle et al. 2002b) and for EVAR, the Comparison of Surveillance Versus Aortic Endografting for Small Aneurysm Repair (CAESAR) and the Positive Impact of Endovascular Options for treating Aneurysms Early (PIVOTAL) (Cao et al. 2011, Ouriel et al. 2010). These studies with a combined total of 3314 patients compared long-term survival in patients with AAAs of diameter $4.0-5.5 \mathrm{~cm}$ that received immediate repair versus routine ultrasound surveillance. These studies together with a recent Cochrane review concluded that there is no advantage of early repair (either with OAR or EVAR) for AAA of this size and suggest that surveillance best favours these patients (Filardo et al. 2012).

Rapid growth of an AAA has been regarded as a possible indication for surgical treatment even if the diameter of the AAA is $<5-5.5 \mathrm{~cm}$ (Limet, Sakalihassan \& Albert 1991, UKSAT Participants 1998). However, Sharp et al. followed 277 patients at six-monthly intervals and concluded that rapid increase in AAA diameter was not an indication for elective AAA repair (Sharp, Collin 2003).

Higher rupture-rates have been observed among AAA-patients with relatives having the same disease (Verloes et al. 1995), but in modern recommendations - family history in itself, is not considered to be an indication for surgery (Chaikof et al. 2009, Moll et al. 2011).

So to conclude - surgical treatment of an AAA should be evaluated when the risk of rupture is greater than the risk of the treatment - i.e. practically at a diameter of $5.5 \mathrm{~cm}$ or larger for men. For women, in whom the risk of rupture at a given size is larger compared to men as discussed above, an AAA $>5 \mathrm{~cm}$ in diameter is often considered being justified as indication for surgical treatment, and the same might go for younger fit men with low operative risk (Norman, Powell 2007, Chaikof et al. 2009, Moll et al. 2011). 


\section{Surveillance and treatment other than surgical}

Once an AAA is discovered, the patient is usually referred to a vascular surgeon, who decides whether the patient shall be surveyed, treated or deferred from surgery. A reasonably fit patient with an AAA $<5-5.5 \mathrm{~cm}$ in diameter is normally included in a surveillance-programme, where USGexaminations are performed at regular intervals. In a typical surveillance programme the patient is examined once a year as long as the diameter of the $\mathrm{AAA}$ is $<4.0 \mathrm{~cm}$. If the diameter is larger, examinations are carried out twice a year.

Recently a meta-analysis has concluded that screening intervals safely may be increased substantially - if the lower $95 \%$ prediction limit of the estimates in the meta-analysis were applied (to acknowledge that the populations in the studies included may have had different growth and rupture rates), surveillance intervals could be extended to once every second year for AAAs 3.0-3.9 cm in diameter, once a year for AAAs 4.0-4.9 cm and twice a year for AAAs 5.0-5.4 cm (RESCAN Collaborators et al. 2013). If and when the AAA grows to $>5-5.5 \mathrm{~cm}$ the patient should be evaluated for surgical intervention and a CT-scan performed, to exclude concomitant aneurysms in the thoracic aorta, any other major diseases (e.g. neoplasms) and to get a picture of the extent of the AAA in preparation for OAR or EVAR.

For AAA-patients that are very old, have generalized malignant diseases, grave dementia or are generally frail, surgical intervention should be dissuaded. De Martino et al. studied 309 patients with an AAA $<6.5 \mathrm{~cm}$ considered to be unfit for OAR by the operating surgeon and found that they may not benefit from EVAR either, despite the lesser surgical trauma (De Martino et al. 2013). These patients had higher rates of cardiac $(7.8 \%$ vs. $3.1 \%$, $\mathrm{p}<0.01)$ and pulmonary $(3.6 \%$ vs. $1.6 \%, \mathrm{p}<0.01)$ complications and worse survival rates at 5 years $(61 \%$ vs. $80 \%$, log rank p<0.01), compared to those deemed fit for OAR.

Besides surveilling patients with an AAA $<5.0-5.5 \mathrm{~cm}$ in diameter, fit for surgery, most important is that they quit smoking (if applicable). As mentioned above, smoking is the only known risk factor that actually affects expansion and it also increases the risk of rupture. Further, intensive smoking cessation therapy may cost-effectively increase long-term survival and decrease the need for AAA repair (Mani et al. 2011) and in addition, the risk of complications (especially wound infections and respiratory complications) perioperatively seems to be decreased by smoking cessation at least four weeks prior to surgery (Lindstrom et al. 2008, Wong et al. 2012). 
Patients should preferably be referred to appropriate management for hypertension, diabetes mellitus and other atherosclerotic risk factors in order to be in optimal shape before a possible intervention (Chaikof et al. 2009, Moll et al. 2011). Statins should be prescribed as they decrease all-cause mortality and cardiovascular mortality after surgery for AAA (Kertai et al. 2004) and also reduce the risk of cardiac morbidity and mortality by half, within 30 days of surgery (Schouten et al. 2009). Previously it has been thought that statins would reduce growth-rate of AAA (Schouten et al. 2006, Schlösser et al. 2008), but a more recent and larger study indicates that this is not the fact (Ferguson et al. 2010), and the same conclusion is drawn in a meta-analysis (Twine, Williams 2011).

If the patient is obese (BMI > 30), he or she should be encouraged to lose weight in order to decrease the risk of postoperative mortality and the risk of wound-infections (Kennedy et al. 2010). And finally, physical exercise can be recommended as it probably is of benefit perioperatively (Jack, West \& Grocott 2011).

Due to the risk of AAA among relatives, the patient should also be informed to encourage all their first-degree relatives over the age of 50-55 years to be investigated regarding AAA (Kent et al. 2004, Chaikof et al. 2009).

There are limited evidence that antibiotic medication (roxithromycin) may have a slight protective effect in retarding the expansion rates of small AAAs, however a recent Cochrane review does not recommend this for the moment as it is unclear if antibiotic medication results in fewer referrals to AAA surgery (Rughani, Robertson \& Clarke 2012). 


\section{Methods how to prevent mortality from rAAA}

As described in the previous section, the natural course of an AAA often is that it goes undetected until it maybe eventually ruptures - a condition associated with a mortality rate of at least $80 \%$, despite what is done once this occurs.

How can we prevent this from happening? Do our potential interventions have any effect? In this section reorganisation of health-care, other treatment options, screening and political decision-making, as possible actions in order to decrease mortality from rAAA, will be discussed.

\section{Reorganisation of health-care}

\section{Centralisation}

Already 1979 Luft et al. found that mortality after high-risk operations decreased at hospitals performing larger volumes (Luft, Bunker \& Enthoven 1979). Regarding AAA, several studies have indicated that high-volume centres and surgeons with a high caseload of elective and acute aortic surgery achieve better results in terms of mortality (Dueck et al. 2004, Holt et al. 2007a, Cho et al. 2008).

Dimick et al. found that having abdominal aortic surgery at a high-volume hospital was associated with a $37 \%$ reduction in mortality, OR 0.63 (CI $0.42-$ 0.92) $\mathrm{p}=0.02$, and that this was due to decreased RR of mainly pulmonary and cardiac complications at the high-volume hospitals (Dimick et al. 2002, Dimick et al. 2003). The gain in mortality at high-volume hospitals has also been found not to be due to case-mix, i.e. low-volume units performing more difficult cases. On the contrary - high-volume hospitals either do more difficult cases (Holt et al. 2007b) or there is no difference concerning case-mix (Eckstein et al. 2007).

Holt et al. quantified critical volume thresholds per institution in a metaanalysis from 2007. They found that regarding mortality, the weighted OR was 0.66 (CI 0.65-0.67) for elective AAA-repair and 0.78 (CI 0.73-0.82) for rAAArepair at high-volume institutions vs. low-volume. The threshold for critical volume was stated to be $43 \mathrm{AAA}-$ and 15 rAAA-procedures per year respectively (Holt et al. 2007a). Another study from the same year published corresponding results - the perioperative mortality rate was $90 \%$ higher at 
hospitals performing 1-9 AAA-operations per year, compared to those performing > 50 AAA-operations annually, OR 1.90 (CI 1.12-3.22) (Eckstein et al. 2007). As a comparison, in Sweden 2012, eleven hospitals performed at least $46 \mathrm{AAA} / \mathrm{rAAA}$ procedures and 18 hospitals performed less, whereof six performed $<20$ procedures during this year (Hager 2013).

Cho et al. studied the effect of surgeon-volume regarding OAR for rAAA and found that high-volume surgeons, defined as $>20$ average annual AAAcases per year, had a higher 30 -day survival rate $(78.4 \%$ vs. $57.9 \%, \mathrm{p}=0.024)$ (Cho et al. 2008). It has also been stated that specialist vascular surgeons have approximately half the mortality when performing surgery for AAA/rAAA compared to general surgeons (Rosenthal et al. 2005) and evidence suggests that surgeon volume is likely to account for about half the effect on outcome, of for example surgery for AAA (Holt, Michaels 2007).

So, there is evidence speaking for centralisation of AAA-surgery. However, the patients themselves may be prepared to trade off small increases in operative risk in exchange for access to local service (Shackley, Slack \& Michaels 2001).

\section{Changing referral patterns}

The main disadvantage with centralisation is that the patient has to be moved to a greater or lesser extent. For elective surgery this is not a big issue, but for emergency surgery, e.g. surgery for rAAA, where every hour of delay is of importance, this may have negative consequences.

Vogel et al. evaluated the differences between transferred and nontransferred patients treated at a tertiary care centre with OAR for rAAA (Vogel et al. 2005). They found that the overall 30-day or in-hospital mortality rates for the nontransferred and transferred groups were $69 \%$ and $65 \%$ respectively, with no statistical difference. The mortality rate within 24 hours of surgery was significantly higher in patients who were not transferred $41 \%$ vs. $10 \%(p<0.05)$, maybe reflecting the fact that patients in a really bad state on arrival at the transferring hospital were not transferred at all.

Corresponding results were found in another study (Hames et al. 2007). However, death during the 24 first hours was more common among the transferred patients, compared to nontransferred, $40 \%$ vs. $33 \%, \mathrm{p}<0.05$. This might be explained by the fact that in the study by Vogel et al., the time for reaching the operating room was shorter for nontransferred patients - 1.8 hours vs. 3.2 hours in the study of Hames et al. Thus, the explanation might be that if a patient in the extremities is to survive, he has to be operated 
immediately. In other words - if a patient survives the first one-two hours, he probably survives a couple more, but how many is of course unknown.

Another more recent study investigating this problem reaches the same conclusion - i.e. no difference in mortality between the transferred and nontransferred group $25.6 \%$ vs. $18.2 \%$, $\mathrm{p}=0.41$ (Azizzadeh et al. 2009).

Hafez et al. studied the problem in a different way - they found it advantageous to be handled by a one-stop referral pattern, i.e. the patient is treated at the hospital were he primarily seeks medical care, even if this involves further travel, compared to a two-stop referral pattern, i.e. being transported from the hospital were the patient seeks primary care, to a hospital performing surgery for AAA (Hafez et al. 2009).

An American study concluded that rural hospitals face a disproportionate burden of rAAA and are more likely to transfer patients with rAAA without performing repair, compared to urban hospitals (Maybury, Chang \& Freischlag 2011). However, they did not demonstrate a survival disadvantage for patients with rAAA admitted to rural hospitals, but then only operative mortality rate was studied.

Finally, in a Swedish study by Zdanowski et al. the vascular surgeon travelled out into the periphery and operated the patient at the hospital where the patient sought care initially, a hospital where there were no specialist vascular surgeons (Zdanowski et al. 2002). They found that the mortality was higher if the operation was delayed more than 45 minutes, but concluded that if the rAAA-patient was in shock and operated by a vascular specialist surgeon at the peripheral hospital the outcome was "fully acceptable".

The main problem with these and other studies is that only patients with rAAA who actually are operated on are studied, giving the operative mortality rate. Hence, neither the number of patients with rAAA who die on their way to hospital following rupture, nor the number actually being operated on of those reaching hospital alive, is taken into account.

\section{Different surgical technique}

Standard treatment for rAAA has been OAR. Since the mortality of rAAA despite improvements in perioperative care, still is around $50 \%$, hope has been that EVAR as a less invasive method to treat AAA, would reduce the high operative mortality rate when applied in the treatment of rAAA.

In 2007 a Cochrane Review was published to highlight this problem (Dillon et al. 2007). At that point there were no RCTs identified, comparing 
emergency EVAR (eEVAR) with OAR for rAAA, and the authors' conclusion was that evidence from completed studies suggested that eEVAR was feasible in selected patients, with outcomes comparable to best OAR in the treatment for $\mathrm{AAAA}$.

Since then, a number of systematic reviews and meta-analyses and two RCTs (where one was single centre and stopped after 32 patients, thus more regarded as a pilot study (Hinchliffe et al. 2006)), have been published (Sadat et al. 2008, Rayt et al. 2008, Veith et al. 2009, Antoniou et al. 2013, Reimerink et al. 2013a).

Sadat et al. identified 23 studies, whereof only one RCT (Hinchliffe et al. 2006) - the single-centre RCT that halted after 32 included patients - and included these in a systematic review and meta-analysis. They found a significant reduction in mortality in favour of eEVAR, pooled OR 0.62 (CI 0.52$0.75), \mathrm{p}<0.0001$. Despite this they concluded; "because of the heterogeneity and bias in the outcomes these results should be interpreted with caution" (Sadat et al. 2008). Along the same line Rayt et al. two years later, also doing a systematic review and meta-analysis, in their conclusion stated; "Mortality from EVAR for rAAA appears to be lower... However, the high level of publication bias cannot be ignored and may actually indicate higher mortality rates" (Rayt et al. 2008).

Veith et al. tried another approach; they examined the collected experience using EVAR for rAAA from 49 centres around the world. They found that centres performing eEVAR for rAAA whenever possible, did so in a mean of $49.1 \%(28-79 \%)$ of the cases, with a significant reduction in 30-day mortality compared to OAR for these patients. They concluded that in at least some patients eEVAR is better than OAR for treating patients with rAAA provided they have favourable anatomy (for example a long-enough neck to anchor the proximal part of the stent-graft, and wide-enough, not to tortuous, iliacarteries to be able to insert the introducer-sheaths), adequate skills, facilities and protocols available; and that optimal strategies, techniques, and adjuncts are employed (Veith et al. 2009).

In 2013 Antoniou et al. in another meta-analysis selected 41 studies, analysing the risk-adjusted observational studies and RCTs. They found the OR for in-hospital mortality for the EVAR-treated rAAA-patients to be 0.58 (CI 0.46-0.73) $\mathrm{p}<0.01$, compared to OAR (Antoniou et al. 2013). They proposed an EVAR-first policy in the non-elective setting.

In the only completed RCT, 116 out of 520 patients with rAAA, were fit for both EVAR and OAR and thus were randomized to either method (Reimerink et al. 2013a). The authors found no significant difference in combined 30-day 
mortality- and severe complication-rate between eEVAR and OAR, 21\% and $25 \%$ respectively, Absolute Risk Reduction (ARR) was $4.4 \%$ (CI $-11 \%$ to $+20 \%$ ). 59 patients were randomised to OAR and 57 to eEVAR and of the 57 eEVARcases, ten were converted to OAR. Two hundred and forty (46\%) of the 520 rAAA patients had an anatomy not suitable for EVAR, and thus were not included in the study.

The first large-scale randomised trial comparing eEVAR with OAR for rAAA, The Immediate Management of the Patient with Rupture: Open Versus Endovascular repair (IMPROVE) has just finished recruiting the planned 600 patients (IMPROVE 2013). In a retrospective analysis of 141 patients treated in a high volume AAA centre performing eEVAR prior to the start of IMPROVE, whereof 89 were treated before and 52 were treated under the trial protocol, Ambler et al. found that the survival benefit for eEVAR over OAR seen before the trial started $(\mathrm{p}=0.020)$ was lost after starting randomisation $(\mathrm{p}=0.963)$ (Ambler et al. 2013). They also found that the 30-day mortality of $11 \%$ for eEVAR before IMPROVE had started, increased to $29 \%$ after randomisation to the trial started, however $p=0.407$. The authors concluded that the change in observed survival during the IMPROVE trial highlights the need for randomised rather than cohort data for national decision-making.

To conclude - eEVAR might be related to a lower mortality for rAAA when it can be utilised. However, in almost half of the patients with rAAA it is not possible to perform standard EVAR, so OAR will still have to be a part of the vascular surgeons toolbox. And even if the logistics are as optimal as in the study of Reimerink et al. 2013, in which the mortality-rate was considered to be surprisingly low - even under these circumstances still almost one fourth of those operated die. Another problem with eEVAR is that it requires even greater centralisation, because the treating clinic needs a certain volume of EVAR-cases annually, to keep an updated consignation-storage of stent-grafts and, of course, the knowledge and experience on how to use them. In addition, up to now, there is no fully convincing evidence that eEVAR should be better than OAR as standard treatment for rAAA.

\section{Screening}

The idea with screening is to look for not yet known diseases or risk factors among individuals in a population. The purpose is to prevent morbidity and mortality in a population without known disease. 
In 1968 Wilson and Jungner on commission of The World Health Organisation (WHO) formulated ten criteria, since then updated several times, most recently 2008 (Wilson, Jungner \& World Health Organization 1968, Andermann et al. 2008).

The ten criteria are:

1. The screening program should respond to a recognized need.

2. The objective of screening should be defined at the outset.

3. There should be a defined target population.

4. There should be a scientific evidence of screening program effectiveness.

5. The program should integrate education, testing, clinical services and program management.

6. There should be quality assurance, with mechanisms to minimize potential risk of screening.

7. The program should ensure informed choice, confidentiality and respect for autonomy.

8. The program should promote equity and access to screening for the entire target population.

9. Program evaluation should be planned from the outset.

10. The overall benefits of screening should outweigh the harm.

In the developed world, ultrasound screening for AAA in risk populations fulfils these criteria (Bergqvist, Bjorck \& Wanhainen 2013).

A number of studies concerning screening for AAA with USG have been performed but the main knowledge regarding this issue comes from four randomized population-based studies that have evaluated ultrasound screening of men for AAA; two from England - the Multicentre Aneurysm Screening Study (MASS) and the Chichester trial, one from Denmark - the Viborg trial and one from Western Australia (Thompson et al. 2012, Ashton et al. 2007, Lindholt et al. 2010, Norman et al. 2004). Up to 2008 four systematic reviews and meta-analyses were performed to evaluate the benefit of screening (Fleming et al. 2005, Cosford, Leng 2007, Takagi, Kawai \& Umemoto 2007, Lindholt, Norman 2008), and in 2010 additionally one was published (Takagi et al. 2010).

Ultrasound (USG) is the preferred tool used for screening for AAA since it has a very high sensitivity and specificity and also a high reproducibility (Lederle, Walker \& Reinke 1988, Lindholt et al. 1999). In addition it is cheap, noninvasive and only related to minor discomfort for the examined subject, if any. There are no known medical risks associated with USG. With the modern USG-machines, with the size of an ordinary laptop computer, it is also possible 
to use in a community setting. Finally it is relatively easy to learn and it is possible to train any interested health-care worker how to use it (Moll et al. 2011).

\section{The four RCTs}

The Chichester trial was the first RCT of AAA-screening (Ashton et al. 2007). It included 6040 men aged 65-80 years (median age 72 years) during the years 1988-1991. The attendance rate was $74 \%$ and the prevalence of AAA was $7.7 \%$. At the 5-year follow-up the relative risk reduction (RRR) regarding mortality was $42 \%$ (CI 22-58) and at 10-year follow-up $21 \%$. However, in the 15 -year follow-up the main finding was that the AAA-related mortality was reduced by only $11 \%$, HR 0.89 (CI $0.60-1.32$ ). This reduced benefit was attributed to increasing age and frailty of participants with regard to surgery. There was no effect on all-cause mortality, OR 1.01 (CI 0.95-1.07). The authors concluded a lasting benefit of screening even after 15 years.

The Danish Viborg trial included 12,639 64-73 year-old men (mean-age 67.8 years) during 1994-1998 with an attendance rate of $76.6 \%$ and an AAAprevalence of $4.0 \%$ (Lindholt et al. 2010). At the 14-year follow-up the RRR of the AAA-related mortality was 66\%, HR 0.34 (CI 0.20-0.57) and the RRR in allcause mortality of $2 \%$ was not significant, HR 0.98 (CI 0.93-1.03). The incremental cost-effectiveness ratio (ICER), i.e. the ratio of the change in costs to incremental benefits of screening, was estimated at $€ 157$ per life year gained and the cost per quality-adjusted life-year (QALY) gained was $€ 179$. This study represents the longest follow-up used for economic evaluation and the authors concluded that screening reduces AAA-related mortality and is cost-effective.

The Western Australia study included 41,000 men 65-83 years old (meanage 72.6 years) during 1996-98 (Norman et al. 2004). The attendance rate was $70 \%$ and the AAA-prevalence was $7.2 \%$. The follow-up was 3.6 years and the main finding was that the age-standardized mortality for those attending screening was $60 \%$ compared to the control group (7.48 vs. 18.91 deaths per 100,000 man-years). Benefit was mainly in men aged 65-75 years, where the mortality ratio was 0.19 (CI $0.04-0.89$ ). Reduction in all-cause mortality was $2 \%$, but as in the Chichester and Viborg trials not significant, HR 0.98 (CI 0.941.03). The authors concluded that there was no benefit in screening all men aged 65-83 years and they suggested screening the group of 65-74-years old.

The MASS is the largest of the four screening studies concerning AAA done (Thompson et al. 2012). It enrolled patients 1997-1999 and invited 67,770 
men in the age 65-74 years (mean-age 69.2 years). The attendance rate was $80 \%$ and the prevalence of AAA was $4.9 \%$. The main findings at the 13-year follow up were; that there was a RRR in AAA-related death of $42 \%$ (CI 31-51\%) and a slight decrease in all-cause mortality of 3\% (CI 1-5) among the screened men. Regarding cost-effectiveness, the ICER was $£ 7600$ (CI $£ 5100-£ 13,000)$ per life year gained and the cost per QALY at 10 years of follow-up was $£ 9400$ (CI $£$ $6300-£ 16,000)$. In the 13-year follow-up there was a slight decrease of benefit compared to earlier years of follow-up because of the occurrence of rAAA in those with an aorta originally screened normal. 216 men needed to be invited to screening to save one death from rAAA over 13 years. The authors concluded that screening for AAA will reduce AAA-related mortality by half in the long term.

\section{The systematic reviews and meta-analyses}

Up to 2008 four meta-analyses were done to, among other things, evaluate the effect on all-cause mortality when screening men for AAA. As mentioned above, there was no significant benefit of screening on all-cause mortality in the Chichester, Viborg and Western Australia trials. In two of the metaanalyses (Cosford, Leng 2007, Lindholt, Norman 2008) it was claimed that there was a positive effect on all-cause mortality, however, these trials suffered from errors due to misinterpretation of the data from the Western Australia trial, using unadjusted deaths from this trial (Lederle 2008). When taking the methodological ambiguities from the Western Australia trial in consideration, Takagi et al. actually found a marginally not significant effect on all-cause mortality, pooled OR 0.95 (CI 0.95-1.00), when using only long-term (> 10 years) follow-up data (Takagi et al. 2010).

When including the 13-year follow up data from MASS (Thompson et al. 2012), Takagi et al. however found a reduced all-cause mortality of $2.7 \%$, fixedeffects OR 0.973 (CI 0.950-0.997) $\mathrm{p}=0.025$ (Takagi et al. 2013). The numbers needed to be invited to screening, to save one all-cause death over 10 years was estimated to be 156, in other words, each 10,000 men invited to screening for AAA saved 64 all-cause deaths. Since AAA-related deaths only account for approximately $2 \%$ of the all-cause deaths, the reduction in AAA-related mortality may not directly contribute to the reduction in all-cause mortality. The explanation might instead be a result from life-style changes (e.g. changed diet, quitting smoking, and increasing exercise) or better treatment of $\mathrm{BP}$, and other cardiovascular risk factors among the participants screened (Takagi et al. 2013). Previous findings of e.g. Freiberg et al. points in this direction - they 
found that infrarenal aortic diameters $>2.0 \mathrm{~cm}$ are associated with a significant increased risk of future cardiovascular events and total mortality (not AAArelated), suggesting that increased aortic diameter is another measure of subclinical atherosclerosis (Freiberg et al. 2008). Thus, better control of BP, advice regarding smoking and maybe treatment with lipid-lowering medication, might very well be enough to decrease over-all mortality in a screened population.

Regarding mortality from rAAA, the number needed to screen (NNS) for AAA to avoid one death in rAAA is 238 , with corresponding figures for colorectal- and breast-cancer being 671 and 1339 respectively (Dabare et al. 2012).

\section{Ethics and dilemmas regarding screening}

Although the obvious advantages with a screening-program for AAA outlined above, including the lower all-cause mortality in the group invited to screening, one major disadvantage with screening is that individuals, who previously have considered themselves healthy, suddenly are labelled with a potentially lethal disease. This may create anxiety and other negative effects on quality of life (QoL). Both the MASS and Viborg-studies have reported on this - the effects are usually mild and in those subjects who do not have an AAA, the impaired QoL most often resolves within a few months after screening. In cases with an AAA treated conservatively, QoL is impaired permanently and progressively, however, in those with an AAA, which is treated, the decline in QoL is reversed by the treatment (Ashton et al. 2002, Lindholt et al. 2000). In another study regarding men diagnosed with an AAA, followed for one-year, the men appeared to appreciate having their AAA diagnosed and felt secure being under superintendence, although there were feelings of disillusionment and thoughts about the consequences of the defect as well as the treatment (Berterö, Carlsson \& Lundgren 2010).

Another dilemma with screening-detected AAA is that the treatment for AAA is associated with a not negligible risk of mortality as discussed above, although the risk related to surgery for a screening-detected AAA seems to be lower than the risk with an incidentally found AAA, for reasons not clear (Lindholt, Norman 2011).

Further, screening leads to an increased workload for the vascular unit, both in terms of administrating the screening-process itself, surveilling those with an AAA found and the doubled amount of elective procedures for AAA required - although this is counteracted by the fact that the burden of surgery 
for ruptures is reduced (Cosford, Leng 2007, Thompson et al. 2009). Also, an acute operation for rAAA, besides being an obvious physical risk for the patient, often in addition is a psychologically demanding event for the patient and his relatives, as well as for the whole operating team (Liss, Lundgren 2005).

So, in summary screening for AAA has been shown to decrease AAArelated mortality cost-effectively (Henriksson, Lundgren 2005a, Wanhainen et al. 2005), and also to have a small but significant positive effect on all-cause mortality.

As a consequence, screening-programmes for AAA are now being launched around the world; in Sweden 2011 it was estimated that $>90 \%$ of 65 year-old Swedish men were invited to screening (Wanhainen, Bjorck 2011), in England screening on a national basis was introduced 2009 via NAAASP (NAAASP) and in the USA screening for AAA is part of the Medicareprogramme since 2007 (U.S. Preventive Services Task Force 2005).

However, in the light of rapidly decreasing prevalence-rates, discussed on page 9, Prevalence and Epidemiology, question remains whether screening in the $21^{\text {st }}$ century is effective. Should screening of younger men, with re-screening of sub-groups, e.g. men with $25-29 \mathrm{~mm}$ aortas be considered? Or is it more effective to screen older men, as the prevalence increases with age or is selective screening, e.g. screening only ex- or current smokers, the most effective approach?

\section{Political decision-making}

Since smoking is the main risk factor for AAA, accounting for at least $70 \%$ of the etiological fraction for AAA (Lederle et al. 2000a, Svensjo et al. 2011), the most logical way to effectively reduce the incidence of AAA in the long run would of course be to ban tobacco smoking. Three foresighted countries have to date been forerunners in this issue, namely Ireland, New Zealand and Finland, where the governments, as a target, have declared a total ban of cigarettes by the year 2025, 2025 and 2040, respectively.

Forbidding smoking would in a couple of decades reduce the greatest part of the problem with rAAA, and as a "side-effect" it would also have other immensely positive effects on public health; however, this issue is beyond the scope of this thesis. 


\section{Areas studied in this thesis}

In this thesis regarding aspects on how to prevent mortality from rAAA, the following areas are the ones on which I have chosen to focus further.

Regarding potential positive effects of reorganisation of health care in terms of changing referral patterns and/or centralisation, the decisive problem when studying patients with rAAA, is that up until now only patients who where indeed operated on have been studied, giving the operative mortality rate (Hoornweg et al. 2008). Since we have such a low autopsy-rate, we do not know how many patients with rAAA that die immediately at the moment of rupture or prior to reaching hospital, and neither do we know how many of those surviving rupture initially, that actually are transferred (if needed) to a hospital were AAA-surgery can be performed. In addition, we do not know how many of those reaching the AAA-operating hospital alive, either directly or transferred via another hospital, that are in fact operated on. Hence, we do not really know if and to what extent it is of benefit for the rAAA-related mortality, to transport patients with rAAA from the hospital where the patient seeks care primarily, to an AAA-operating hospital and extending this argument still further, if centralisation of services for rAAA is of any benefit at all.

As mentioned previously the AAA-prevalence among 65-year-old men today is far less than half of what was expected from earlier screening-studies and in addition seemingly in declination, mainly due to changing smoking habits (Lederle 2011). Since we know that the AAA-prevalence increases with age, a possible way to find more AAAs, thus increasing the clinical efficacy of screening, would be to screen older men (Lederle et al. 2000a, Anjum, Powell 2012, Conway et al. 2012, Von Allmen, Powell 2012).

Also re-screening the whole male population has been discussed, since some of the men who have a normal aorta at 65-years of age, still develop AAA later in life (Lederle et al. 2000b, Sogaard, Laustsen \& Lindholt 2012a, Von Allmen, Powell 2012).

Almost a decade ago, before screening for AAA was generally accepted, two independent health-economic evaluations from Sweden showed that screening was cost-effective (Henriksson, Lundgren 2005a, Wanhainen et al. 2005). Henriksson and Lundgren estimated the expected use of resources, life expectancy and QALY over a lifetime perspective by modelling the natural history of the disease and the influence of a screening-programme on this, for a cohort of 65-year-old men. Since then, results from completed and on-going screening studies and programmes have been published, among other things 
revealing that the prevalence is considerably lower, the attendance rate is higher, the rate of opportunistic detection is greater, the costs associated with surgery have changed, e.g. due to shorter ICU-stay and increased use of EVAR, operative mortality rate has decreased and general survival (not related to AAA) in the population has increased (Svensjo et al. 2011, Darwood et al. 2012, Thompson et al. 2012, Mani et al. 2008). Although previous studies have indicated that screening for AAA appears cost-effective and that the results are robust to changes in input parameters, updated analyses in a different context are warranted due to changed circumstances and the availability of data from screening programmes in healthcare practice. 


\section{AIMS}

The overall aim of this thesis was to study aspects on how to affect mortality from rAAA. The specific aims were:

I. To evaluate if the population-based survival rate for patients with rAAA differed between age- and sex-adjusted groups managed by a one- or two-stop referral pattern (Study I).

II. To determine the contemporary screening-detected prevalence of AAA among previously unscreened 70-year-old men, and to define potential risk factors and their association to AAA in this age group (Study II).

III. To determine whether the screening-detected AAA-prevalence differ between 65- and 70-year-old men in such a way that increasing the screening-age or rescreening the whole population after five years, would increase the clinical effectiveness by revealing more AAA, thus preventing rAAA with more saved life-years as a result (Study III).

IV. To evaluate if screening for AAA among 65-year-old men on a general basis still is cost-effective (Study IV). 


\section{SUBJECTS, MATERIAL AND METHODS}

\section{Study I}

If you really want to now what people die from, a one hundred per cent autopsy-rate is required. However, in Sweden 2007, the autopsy-rate was only $12 \%$ (The National board of health and welfare, Centre of epidemiology, Official statistics of Sweden 2009). To get around this problem, we applied a new way of studying the mortality from rAAA in this population-based retrospective study.

Instead of just studying the operative-mortality rate, as is the common way to present results dealing with e.g. mortality after surgery, we started with what is known from the following four registries; Swedvasc, the Swedish Population register, the Register for Diagnosis in In-patient Care and the Register for Causes of Death and studied the survival-rate after OAR for rAAA with reference to the background population, instead of the operativemortality rate (Swedvasc, Statistics Sweden a, The National Board of Health and Welfare, Sweden).

We identified ten regions in Sweden were a one- and two-stop referral pattern prevailed, Figure 1 and Figure 2.

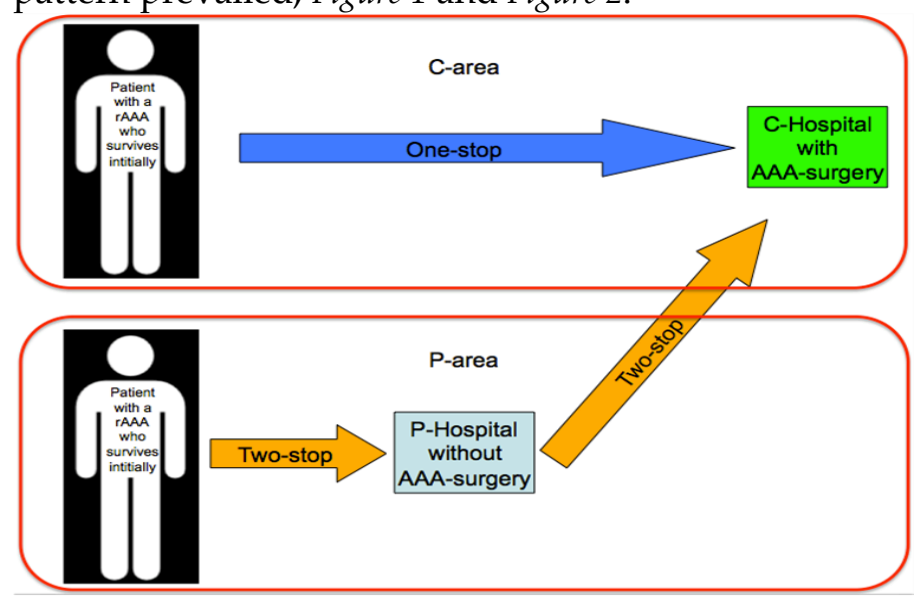

Figure 1. The principle of "one-stop" and "two-stop" referral patterns and the relations to the $C$ - and P-areas. 


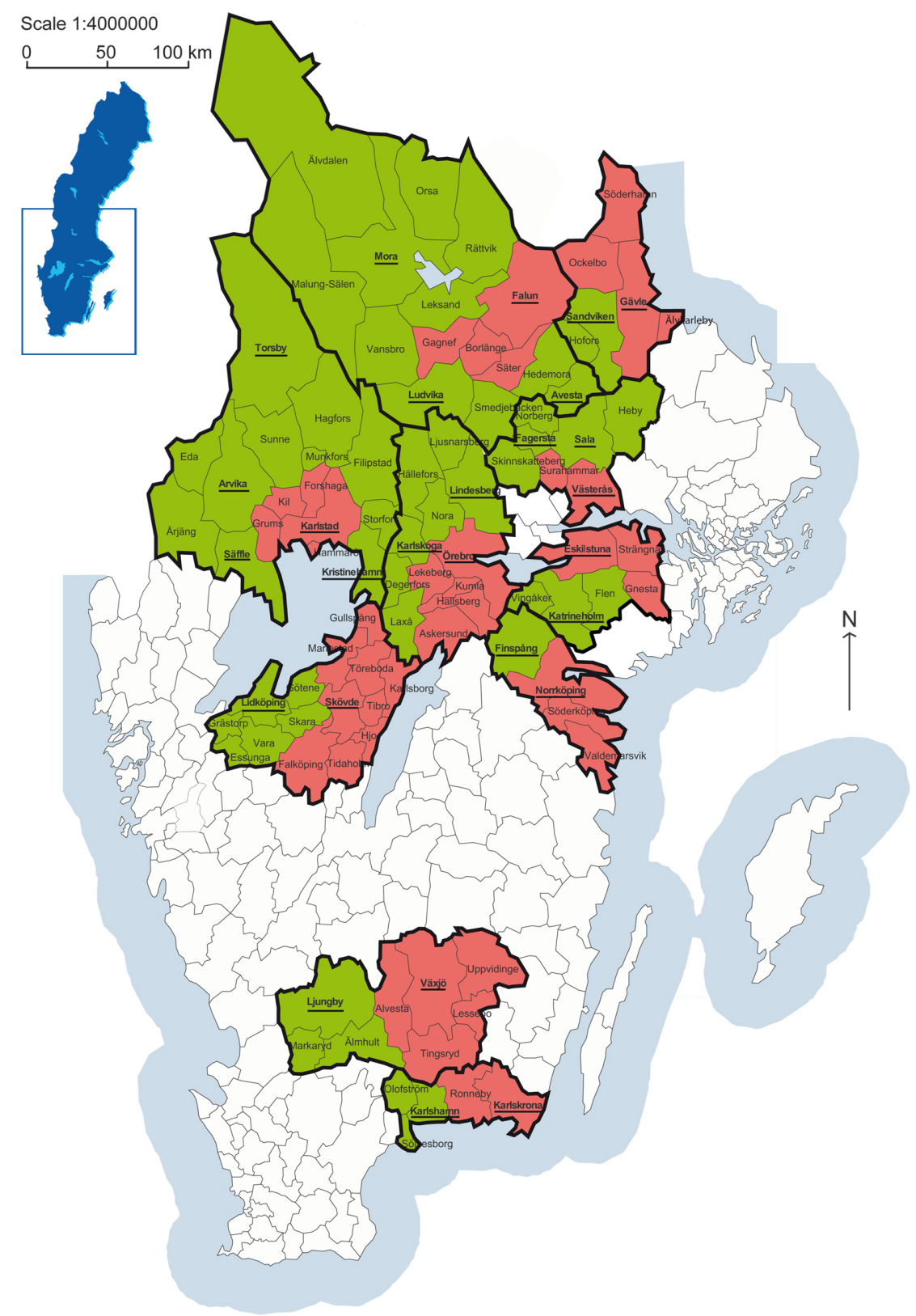

Figure 2. The ten studied regions. The areas served by a central (C-) hospital are red and the areas served by a peripheral ( $P$-) hospital are green. The names of the hospitals are underlined and bold. In a peripheral area, there may be several peripheral hospitals, e.g. the region of Falun. Picture created by Ida Severin, Identx, Linköping, Sweden. 
In each region only one hospital ( $\mathrm{C}$ - central) served the population within that hospital's catchment area (C-area) with surgery for both rAAA and other abdominal emergencies. Besides this hospital there were one or more hospitals ( $\mathrm{P}$ - peripheral) serving the population in their respective catchment areas ( $\mathrm{P}$ areas), with all forms of emergency abdominal surgery except for surgery for rAAA. Hence, all patients in the P-area with abdominal pain sought medical care at their local P-hospital and were evaluated and most often taken care of there. However, patients found to have rAAA, were referred to the C-hospital and consequently had an extra stop during their referral for aneurysm surgery, i.e. a two-stop referral pattern. One C-hospital could serve more than one P-hospital/area in this aspect. Patients who lived within the C-hospital's catchment area (C-area) sought medical care at the C-hospital directly and consequently had no extra stop before surgery for rAAA, i.e. a one-stop referral pattern.

From the Swedvasc-registry we extracted all patients $\geq 45$ years of age, treated for rAAA with OAR in Sweden 1987-2004, and with help from the Epidemiological Centre (EpC) merged them with the Swedish Population register, the Register for Diagnosis in In-patient Care and the Register for Causes of Death. We finally included 849 patients who at the time of operation were living in any of the ten regions studied. There were no eEVAR done during this period in any of these regions.

These patients were categorised according to three age groups (45-64, 6574 and $75+$ years of age), sex, which region the lived in at the time of surgery, whether the hospital where they primarily sought medical care for abdominal issues served a peripheral (without service for rAAA) or a central hospital (with service for rAAA) and finally whether they survived one-month or not.

For each region, area (peripheral or central), year of study, sex, and age group, we collected the population-size from the Swedish Population register, and then plotted all patients in spreadsheets and clarified whether they survived one-month or not, Paper I, Table III.

\section{Statistics Study I}

We used Poisson regression (Faraway 2006) to model the number of patients surviving rAAA, from each area and for each and every year studied. This regression was adjusted for; region (thus taking into consideration possible differences in for example prevalence, decision to operate, referral patterns, ambulance organisation, individual surgical skill, ICU-resources and quality 
of aftercare); area (central or peripheral, i.e. a one- or two-stop referral pattern); age group and sex. The population-size of each area for each year was used as an offset-term and thus the regression was adjusted for the background population. Furthermore the interaction between area and age group or sex was tested.

Logistic regression (Collett 2003a) was used to model the mortality rate after surgery for rAAA. This regression was also adjusted for region, area, age group and sex, and again the interaction between area and age group or sex was tested.

In this way survival after $r A A A$ was modelled with reference to the population in each area (population-based survival-rate) and mortality after $r A A A$ with reference to the number of patients operated on from each area (operative-mortality rate).

\section{Study II}

In this population-based screening study, all men $(n=5623)$ in Östergötland, Sweden becoming 70 years old (born 1938-40), during 2008-2010, were identified through the National Population Registry and without any exclusion criteria, they were invited to an USG examination of the infra-renal aorta. We used a decentralized way of screening in that the examination was carried out at two of the three hospitals in the County Council and in addition at seven district health care centres.

Also weight and height were measured at the examination and by means of a Health Questionnaire (Appendix) issues regarding heredity concerning AAA, smoking habits, medication and the presence or absence of a number of diseases, directly or indirectly related to AAA, were recorded. These data were self-reported.

From local databases men born 1938-40 with an already known AAA under surveillance were identified and with aid of Swedvasc-data, all men in our cohort who already had been treated for an AAA, were identified. These men were excluded from the study.

\section{Statistics study II}

Chi-square test with continuity correction was used for testing the risk factors in the univariate analysis, and when the validity of the chi-square test was in 
question (too small expected numbers in any cell of the 2x2-table) the result was checked with Fisher's test (Petrie, Sabin 2005). Univariate analyses for testing differences in continuous variables were made with t-test (Petrie, Sabin 2005). Logistic regression was used for the multivariable risk factor analysis and variables with a p-value $<0.1$ from the univariate chi-square test were entered into the multivariable logistic regression (Collett 2003a). The different risk factors were entered as being present or absent in the logistic regression.

The relative risk of differences in Body Mass Index (BMI) for the prevalence of AAA was calculated by exponentiation of the predicted Log Odds (from logistic regression) to Odds, by transforming Odds to probabilities, and finally the quotient of the probabilities of the two BMIs of interest.

The expected point prevalence for 70-year-old men was calculated by using data from previous studies concerning men $\geq 66$ years of age by means of a multiple linear regression analysis weighted for the number of men in each study used, Paper II, Table 1 (Petrie, Sabin 2005).

\section{Study III}

In this population-based screening study, all men ( $\mathrm{n}=7951)$ in Östergötland, Sweden becoming 65 years old during the years 2007-2009 (born 1942-44), were compared to the 70-year-old men in Study II, in terms of attendance rate, prevalence and incidental detection of AAA. They were previously not screened for AAA, and they were also identified through the National Population Registry, and invited to an ultrasound examination of the infra renal aorta the year they became 65. The details concerning the screening process are described in Paper II.

Also among the men born 1942-44, those with an already known or already treated AAA were identified from local databases and Swedvasc, respectively and excluded from the cohort.

\section{Statistics study III}

Chi-square test was used for testing differences between categorical data in the two study cohorts (Petrie, Sabin 2005). Differences between continuous data were performed with Wilcoxon's rank sum test (Hollander, Wolfe 1973) 


\section{Study IV}

This health-economic modelling study evaluated lifetime costs and health outcomes in terms of life-years and QALYs of a screening strategy representing current clinical practice and a no-screening strategy. With the screening strategy all 65-year-old men in the general population were invited to an ultrasound scan. Men with an AAA 30-54 mm were put under surveillance and elective repair was considered if the AAA exceeded $54 \mathrm{~mm}$.

In the no screening strategy there was no active search for AAA and management was based on opportunistic detection. A previously reported cost-effectiveness model was updated with recent data collected alongside an implemented screening program in Sweden together with published sources (Henriksson, Lundgren 2005a). In the base-case analysis, a healthcare perspective was taken and costs and health outcomes were discounted by $3.0 \%$ annually (NICE). Costs were in 2013 prices and were converted to euros $(€)$ using the exchange rates: $1 €=9$ (SEK) Swedish kronor.

\section{Cost-effectiveness model}

The model developed by Henriksson \& Lundgren has been described in detail previously (Henriksson, Lundgren 2005b). In summary the model was designed to estimate disease progression and utilisation of resources for the investigated strategies; inviting to screening or not inviting to screening.

Since the model was constructed, some attention has been focusing on the aorta with sub-aneurysmal (25-29 mm) dilatation (Wild et al. 2013). Wild et al. studied eight screening programmes from this aspect and found that the aortic diameter in $67.7 \%$ of 1696 men and women with a mean-age of 66 years and an aorta between $25-29 \mathrm{~mm}$ in diameter, in five years time progressed to $\geq 30 \mathrm{~mm}$ in diameter. Based on this information a sub-aneurysmal aorta state was included in the Markov model, implying that AAAs 25-29 mm could grow larger than $29 \mathrm{~mm}$ with a subsequent risk of rupture. For the men with an aorta $<25 \mathrm{~mm}$ at the age of 65 we ruled out development of AAA for life, compared to the former model where this limit was $<30 \mathrm{~mm}$. For men with an aorta between 30-39 $\mathrm{mm}$, the surveillance interval was once a year and for men with an aorta $\geq 40 \mathrm{~mm}$, twice a year, according to current clinical practice. We thus have seven core health states in the current model, Figure 3; no-AAA, sub-aneurysmal aorta (25-29 mm), small AAA (30-39 mm), medium AAA (40- 
$54 \mathrm{~mm}$ ), large AAA (>54 mm), post surgery (representing the survival prognosis after surgery) and the dead state. Note that individuals with an AAA may or may not be diagnosed in the model as indicated by Figure 3.

In a Markov structure, hypothetical individuals reside in one of a set of mutually exclusive health states at each and every point of time. During annual Markov cycles individuals can transition from one health state to another with the probability of moving between these states being determined by transition probabilities (as shown by the arrows in Figure 3). Each health state is associated with costs and health outcomes, and these are accumulated and summarized for the cohort of hypothetical individuals at the end of the analysis. The key difference between the investigated strategies (i.e. "Screening" and "No screening" respectively) is that more individuals will be diagnosed with an AAA in the first cycle when the screening program is carried out. Furthermore, the cost of the invitation to screening and the ultrasound investigation will be attributed to the screening strategy in the first cycle of the model.

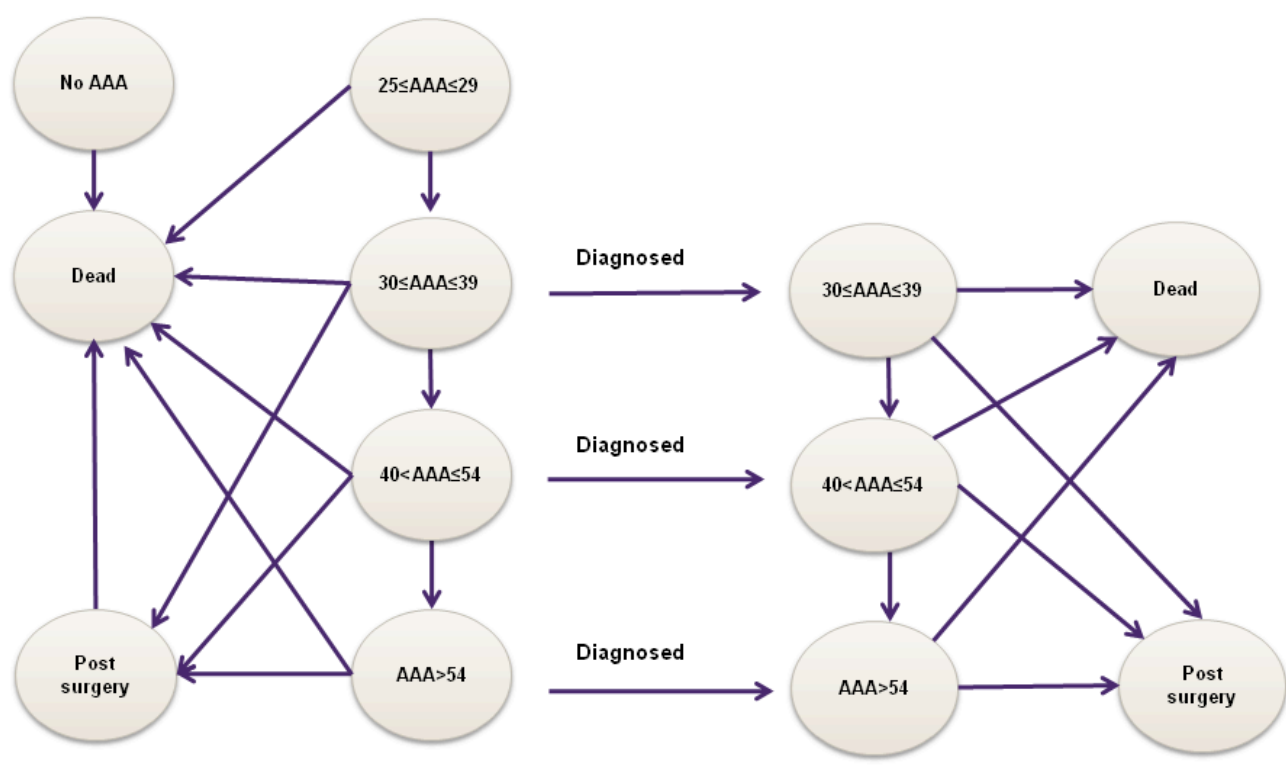

Figure 3. Model Structure. Note that the Dead and the Post surgery states are identical in the diagnosed and non-diagnosed parts of the model - they have been drawn twice to simplify the graphical representation. 
We assumed sensitivity and specificity to be $100 \%$ for the ultrasound screening investigation (Beales et al. 2011). Also the attendance rate concerning surveillance was assumed to be $100 \%$, in accordance to the experience from the ultrasound technicians inviting to and performing the surveillance-scans. Men with an AAA $\geq 55 \mathrm{~mm}$, who were not fit for intervention, were not followed further, according to clinical practice.

The results of the model show the total accumulated healthcare costs and health outcomes for two cohorts of 65-year-old men - one invited to screening and one not. Incremental cost-effectiveness ratios (ICERs) are presented as cost per life-year and cost per QALY gained with a screening program compared with no screening.

\section{Data}

The evidence and data sources used in the analysis are discussed below and summarized in Table 1.

Table 1. Parameters and transition rates.

\begin{tabular}{|c|c|c|c|}
\hline Parameter & Point estimate & Distribution & Reference \\
\hline Prevalence & & & (Paper III) \\
\hline $25-29 \mathrm{~mm}$ & 0.042 & Dirichlet ${ }^{1}$ & \\
\hline $30-39 \mathrm{~mm}$ & 0.014 & Dirichlet $^{1}$ & \\
\hline $40-54 \mathrm{~mm}$ & 0.004 & Dirichlet $^{1}$ & \\
\hline$>54 \mathrm{~mm}$ & 0.001 & Dirichlet $^{1}$ & \\
\hline \multicolumn{4}{|l|}{ Growth } \\
\hline $25-29 \mathrm{~mm}$ to $30-39 \mathrm{~mm}$ & 0.176 & Beta $(1011,684)^{2}$ & (Wild et al. 2013) \\
\hline $30-39 \mathrm{~mm}$ to $40-54 \mathrm{~mm}$ & 0.115 & Beta $(16,36)^{3}$ & $\begin{array}{c}\text { (Collin, Heather \& Walton } \\
\text { 1991) } \\
\text { (UKSAT Participants }\end{array}$ \\
\hline $40-54 \mathrm{~mm}$ to $>54 \mathrm{~mm}$ & 0.158 & Beta $(283,283)^{4}$ & $\begin{array}{l}\text { 1998, Lederle et al. } \\
\text { 2002b) }\end{array}$ \\
\hline \multicolumn{4}{|l|}{ Rupture } \\
\hline $30-39 \mathrm{~mm}$ & 0.005 & Beta $(1,183)$ & $\begin{array}{c}\text { (Law, Morris \& Wald } \\
\text { 1994) }\end{array}$ \\
\hline $40-54 \mathrm{~mm}$ & 0.016 & Beta $(1,62)$ & $\begin{array}{c}\text { (Law, Morris \& Wald } \\
1994)\end{array}$ \\
\hline$>54 \mathrm{~mm}$ & 0.248 & Beta $(56,98)^{5}$ & (Noronen et al. 2013) \\
\hline
\end{tabular}

Opportunistic detection

All AAA sizes

0.0023

Beta $(64,5559)^{6}$

(Paper III) 


$\begin{array}{cccc}\begin{array}{c}\text { Operation (probabilities) } \\ \text { Reach acute operation when rupture }\end{array} & 0.394 & \text { Beta }(190,292) & \text { (Reimerink et al. 2013b) } \\ \text { Elective repair when AAA > 54 detected } & 0.854 & \text { Beta }(672,115) & \text { (Thompson et al. 2012) }\end{array}$

\begin{tabular}{|c|c|c|c|}
\hline \multicolumn{4}{|l|}{ Attendance rate } \\
\hline Attending the ultrasound investigation & 0.857 & Beta $(6813,1138)$ & (Paper III) \\
\hline \multicolumn{3}{|l|}{ Mortality elective operation } & \multirow[t]{5}{*}{ (Swedvasc) } \\
\hline $65-59$ years & 0.017 & Lognormal $^{7}$ & \\
\hline $70-74$ years & 0.022 & Lognormal $^{7}$ & \\
\hline $75-79$ years & 0.034 & Lognormal $^{7}$ & \\
\hline 80 years or over & 0.056 & Lognormal $^{7}$ & \\
\hline \multicolumn{3}{|l|}{ Mortality acute operation } & \multirow{5}{*}{ (Swedvasc) } \\
\hline $65-59$ years & 0.149 & Lognormal $^{7}$ & \\
\hline $70-74$ years & 0.191 & Lognormal $^{7}$ & \\
\hline $75-79$ years & 0.264 & Lognormal $^{7}$ & \\
\hline 80 years or over & 0.381 & Lognormal $^{7}$ & \\
\hline \multicolumn{4}{|c|}{$\begin{array}{l}\text { Joint distribution for proportion with No AAA, } 25-29 \mathrm{~mm}, 30-39 \mathrm{~mm}, 40-54 \mathrm{~mm} \\
(6383,286,92,27,8) \text {. } \\
\text { 2Distribution is for a } 4.7 \text { year probability. } \\
{ }^{3} \text { Distribution is for a } 3 \text { year probability. } \\
{ }^{4} \text { Distribution is for a } 4 \text { year probability. } \\
{ }^{5} \text { Distribution is for a } 19 \text { month probability. } \\
{ }^{6} \text { Distribution is for a } 5 \text { year probability. } \\
{ }^{7} \text { Lognormal based on logistic regression. Details available from the authors. }\end{array}$} \\
\hline
\end{tabular}

\section{Prevalence, growth and risk of rupture}

Parameters required to model AAA disease progression include prevalence, AAA growth rates and risk of rupture. The prevalence of AAA among 65year-old men was based on approximately 6800 ultrasound investigations performed in the recently implemented screening program in the County Council of Östergötland (Paper III). Notably, the prevalence of AAAs $30 \mathrm{~mm}$ or larger observed in this clinical setting was substantially lower $(1.9 \%)$ compared with previous estimates (4.9\%) (Henriksson, Lundgren 2005a). The prevalence of sub-aneurysmal aortas $(25-29 \mathrm{~mm})$ was $4.2 \%$.

The proportion of AAA annually growing into the next size group was similar for the three AAA sizes smaller than $55 \mathrm{~mm}$, Table 1 (Wild et al. 2013, Collin, Heather \& Walton 1991, UKSAT Participants 1998, Lederle et al. 2002b)

The estimated annual risk of rupture was low for AAAs smaller than 55 $\mathrm{mm}$. For $\mathrm{AAA} \geq 55$ recent data suggested an annual risk of approximately $25 \%$ (Noronen et al. 2013). According to a recent review (Reimerink et al. 2013b), two studies reported the proportion of patients reaching surgery if rupture 
occurs (Acosta et al. 2006, Hafez et al. 2009). Synthesising data from these two studies yielded an estimated probability of reaching surgery of $39 \%$.

\section{Mortality after surgery}

The mortality rates after acute and elective surgery were based on data made available by the Swedvasc registry (Swedvasc) and were defined as deaths occurring within 90 days of surgery. The data included 4510 surgical procedures among men 65 years or older, performed during 2008-2012 (5 years) of which $29 \%$ were acute procedures. Mortality rates were estimated for different age groups in order to account for the fact that mortality risk increase with age, Table 1. The long-term survival rate after surgery, i.e. the prognosis after the 90 days defined as surgical mortality, was based on procedures reported to Swedvasc during 1998-2012 (15 years), with mortality status followed up until July 2013.

In total, 9397 patients were alive 90 days after surgery and available for analysis. Survival analyses were performed on these data and a Weibull model was used to estimate a parametric survival function including age as a covariate (Collett 2003b). The results indicated that the long-term post surgery mortality rate was substantially higher than mortality in the normal population despite the exclusion of 90-day mortality (which was accounted for when estimating surgical mortality). The predicted survival curve for 65-year old men based on the Weibull model was compared with the Kaplan-Meier estimate of the 65-year old patients in the sample indicating that the Weibull model provided a reasonable fit to estimate annual mortality probabilities, Figure 4 (Petrie, Sabin 2005). 


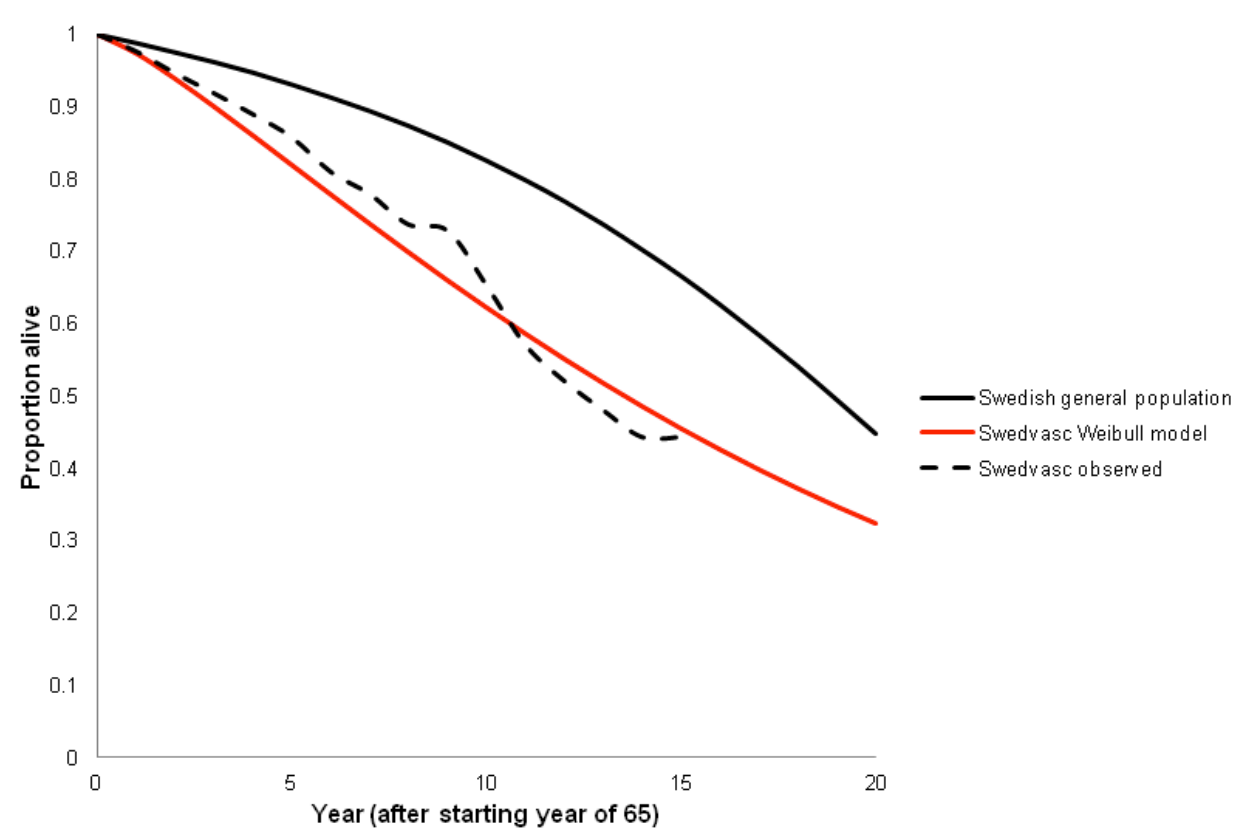

Figure 4. Estimated survival in the AAA-population.

For comparison, the survival curve for 65-year-old men in the general population is also depicted in Figure 4. In the decision-analytic model we applied the annual mortality probabilities from the Weibull model as long as those were higher than the annual mortality rates of the general population (approximately 15 years) and thereafter switched to the general population estimates.

\section{Long-term mortality}

Non-AAA related mortality was retrieved from life tables of the general population in Sweden (Statistics Sweden b). For patients with an AAA the excess mortality was estimated using the estimated long-term mortality post surgery as outlined in the previous section. 


\section{Attendance rate to screening, opportunistic findings and elective repair}

The rate of attending an invitation to screening was based on the screening programme in the County Council of Östergötland, Sweden and was 85.7\% (Paper III).

From the same data source the annual rate of opportunistic detection of AAAs was estimated to be less than $0.1 \%$ (Paper II and III).

From the final follow-up of the MASS we retrieved the overall turndown rate (contradictions and refusals) for elective surgery to estimate the proportion of patient undergoing elective repair when an AAA $>54 \mathrm{~mm}$ was detected (by screening or opportunistically) (Thompson et al. 2012).

\section{Costs}

The calculated costs associated with screening and surveillance of AAA, were based on resources used in the screening program in the County Council of Östergötland, Table 2. The costs of surgery were estimated from the comprehensive cost per patient (CPP) database in the County Council of Östergötland. The mean costs of 11 acute and 37 planned procedures performed in men aged 65 or older during 2012 were used.

Table 2. Costs and quality of life.

\begin{tabular}{|c|c|c|c|}
\hline Parameter & Point estimate & Distribution & Reference \\
\hline \multicolumn{4}{|l|}{ Costs of screening program (€) } \\
\hline Invitation to screening & 5.2 & Deterministic & 1 \\
\hline Screening examination & 17 & Deterministic & 1 \\
\hline Ultrasound surveillance & 34 & Deterministic & 1 \\
\hline \multicolumn{4}{|l|}{ Costs of surgery $(€)$} \\
\hline Elective surgery & 20185 & Gamma(14, 1421) & $\mathrm{CPP}^{2}$ \\
\hline Acute surgery & 33288 & $\operatorname{Gamma}(20,1705)$ & $\mathrm{CPP}^{2}$ \\
\hline Quality of life & & & $\begin{array}{c}\text { (Burström \& Rehnberg } \\
\text { 2006) }\end{array}$ \\
\hline QALY-weight $65-69$ years & 0.83 & $\operatorname{Beta}(2278,467)$ & \\
\hline Decrement $70-74$ years $^{3}$ & 0.02 & Gamma(100, 0.0002) & \\
\hline Decrement $75-79$ years $^{3}$ & 0.02 & Gamma(100, 0.0002) & \\
\hline Decrement 80 and over ${ }^{3}$ & 0.05 & Gamma(100, 0.0005) & \\
\hline
\end{tabular}




\section{Quality of life}

There is little evidence suggesting that a detected AAA would have a substantial impact on quality of life (Berterö, Carlsson \& Lundgren 2010). Moreover, evidence suggests that patients undergoing surgery return to normal quality of life within 6 months (Coughlin et al. 2013). Therefore, quality of life estimates of the general population were used for all individuals in the base case analysis (Burström \& Rehnberg 2006).

A decrement in quality of life associated with higher age was incorporated. Alternative scenarios investigated the impact on the costeffectiveness results of including decrements in quality of life due to a detected AAA and post surgery.

\section{Analysis}

The model was analysed using probabilistic sensitivity analysis. Probability distributions were defined for relevant model inputs, reflecting the volume and quality of information available. The uncertainty in model inputs was then propagated through the model so that the final results reflect the uncertainty in the estimated cost-effectiveness rather than single model inputs (Briggs, Claxton \& Sculpher 2006). One-way and multi-way sensitivity scenarios were also performed in order to investigate the importance of methodological uncertainty (e.g. different discount rates) and uncertainty due to assumptions that cannot be adequately captured in the probabilistic analysis. An alternative scenario also included private costs to individuals when attending the screening program.

\section{Statistics Study IV}

The Weibull and Kaplan-Meyer analysis were performed using Stata Statistical Software, Version 12, Stata Corporation LP, College Station, Texas, USA. The decision-analytical model was programmed and analysed in Microsoft ${ }^{\circledR}$ Excel, Microsoft Corporation, Redmond, Washington, USA. 


\section{The ultrasound-examination and definition of an AAA}

The ultrasound-examinations in Studies II and III were carried out by an experienced technician, using a portable ultrasound machine - GE Vivid i from General Electric Health Care, Waukesha, Wisconsin, USA - with a 4C-RS probe (1.8-6.0 MHz). All together nine dedicated technicians, working in pairs, specialized in USG-examinations of the peripheral arterial tree, performed the scans. Fasting was not demanded and the standard position was supine. If the aorta was difficult to visualize other positions were used and/or the other technician tried to visualize the aorta. If the aorta still could not be visualized the subject was invited for a new attempt, now during fasting condition.

An AAA was defined as the infra-renal aortic diameter being $\geq 30 \mathrm{~mm}$. The aorta was scanned with the probe in the transverse (horizontal) position and then in the sagittal (vertical) position. The greatest antero-posterior (AP) diameter of the aorta was measured according to the "leading-edge-toleading-edge" (LELE) principle (Singh et al. 1998).

There are principally three ways to measure the aortic diameter with USG; the LELE, the Inner To Inner- (ITI) and Outer To Outer- (OTO) wall techniques.

The LELE-method is based on the fact that the most distinct USGreflection (echo) is obtained at the boundaries between an echo-lucent and echo-dense layer (leading edge) as opposed to when the USG-wave passes from an echo-dense to an echo-lucent layer (far edge) (Wanhainen 2011). What is measured is thus the distance between the outer anterior wall and the inner posterior wall. This method is the most used in Scandinavia. Globally, the OTO-method is the most commonly used, and in e.g. the MASS the ITImethod was the one used. Also in the NAAASP the ITI-method is used (NAAASP ). When studying 60 random images of aortas between 1.4 and 7.1 $\mathrm{cm}$, and comparing OTO vs. ITI, Hartshorne et al. found that the ITI-method was more reproducible, particularly in the assessment of large AAA (Hartshorne et al. 2011). To date there is no study published comparing the three methods used.

In the UKSAT the repeatability of measurement of aneurysm diameter was \pm 2 mm (UKSAT Participants 1998). 


\section{Swedvasc}

The Swedish National Registry for Vascular surgery, Swedvasc, started 1987 as a local vascular registry in southern Sweden (Swedvasc). Since 1994 all Swedish hospitals with a vascular service are affiliated to Swedvasc. It has been validated and found to accurately reflect the activity of Swedish vascular surgeons (Troëng, Malmstedt \& Björck 2008).

We have used data from Swedvasc for all four studies in this thesis.

\section{Statistical calculations and Ethics}

In Study I, II and III calculations and statistical analyses were performed in the R-language from the R-Project for Statistical Computing (The R-project for Statistical Computing) and Microsoft ${ }^{\circledR}$ Excel, Microsoft Corporation, Redmond, Washington, USA was used as a database.

The Regional Ethical Review Board in Linköping approved Study I, II and III. No ethical approval was needed for Study IV. 


\section{RESULTS}

\section{Study I}

The population-based survival-rate for patients from the peripheral areas was $14 \%$ lower than that for the central areas, with adjusted population-based survival-rate ('peripheral areas'/'central areas') $=0.86$ (CI 0.72-1.02), $\mathrm{p}=0.084$. The interaction between area and age group was statistically significant, $\mathrm{p}=0.029$, in that the middle-aged (65-74 years) patients in the peripheral areas had the worst outcome. No corresponding interaction was seen for area and sex, Table 3.

Table 3. Adjusted ${ }^{1}$ rate-ratios comparing one-month survival rate (population-based survival rate) after rAAA from one- and two-stop referral areas ('two-stop'/'one-stop') in the whole material as well as interaction with age group or sex, respectively. The model was based on Poisson regression.

\begin{tabular}{|c|c|c|c|c|c|}
\hline & & Rate Ratios ${ }^{2}$ & $\mathrm{Cl}$ & $p$-value & \multirow{2}{*}{$\begin{array}{c}\text { Test of } \\
\text { interaction }\end{array}$} \\
\hline \multicolumn{2}{|c|}{ Total } & 0.86 & $0.72-1.02$ & 0.084 & \\
\hline \multirow{3}{*}{ Age group } & $45-64$ & 1.37 & $0.93-2.02$ & 0.11 & \multirow{3}{*}{$\begin{array}{c}\text { Chisq }=7.11 \\
d f=2 \\
\text { p-value }=0.029\end{array}$} \\
\hline & $65-74$ & 0.73 & $0.56-0.95$ & 0.021 & \\
\hline & $75+$ & 0.82 & $0.62-1.08$ & 0.15 & \\
\hline \multirow[b]{2}{*}{ Sex } & Female & 0.81 & $0.48-1.36$ & 0.43 & \multirow{2}{*}{$\begin{array}{c}\text { Chisq }=0.05 \\
d f=1 \\
\text { p-value }=0.82\end{array}$} \\
\hline & Male & 0.87 & $0.72-1.04$ & 0.12 & \\
\hline
\end{tabular}

${ }^{1}$ Poisson regression with the number of one-month survivors adjusted for region, area, age group, sex, and interaction between age group or sex with area. The population-size in each area with respect to age group and sex was used as an offset term.

${ }^{2}$ A value $<1$ equals better results for "one-stop-referral" compared to "two-stopreferral". 
The operative mortality rate was $32 \% ; 28 \%$ for patients from the peripheral areas and $34 \%$ for patients from the central areas, OR 0.87 (CI 0.57-1.31), $\mathrm{p}=0.49$. There were no interactions between area and age group or sex, Table 4 .

Table 4. Adjusted ${ }^{1}$ odds ratios comparing one-month operative mortality rate after $r A A A$ from one-and two-stop referral areas ('two-stop'/'one-stop') in the whole material as well as interaction with age group or sex, respectively. The model was based on logistic regression.

\begin{tabular}{|c|c|c|c|c|c|}
\hline & & Odds Ratio ${ }^{2}$ & $\mathrm{Cl}$ & $p$-value & \multirow{2}{*}{$\begin{array}{c}\text { Test of } \\
\text { interaction }\end{array}$} \\
\hline \multicolumn{2}{|c|}{ Total } & 0.87 & $0.57-1.31$ & 0.49 & \\
\hline \multirow{3}{*}{ Age group } & $45-64$ & 0.39 & $0.12-1.22$ & 0.11 & \multirow{3}{*}{$\begin{aligned} \text { Chisq } & =2.52 \\
d f & =2 \\
\text { p-value } & =0.28\end{aligned}$} \\
\hline & $65-74$ & 0.73 & $0.55-2.11$ & 0.82 & \\
\hline & $75+$ & 0.92 & $0.51-1.67$ & 0.79 & \\
\hline \multirow[b]{2}{*}{ Sex } & Female & 1.15 & $0.48-2.77$ & 0.76 & \multirow{2}{*}{$\begin{aligned} \text { Chis } q & =0.05 \\
d f & =1 \\
\text { p-value } & =0.48\end{aligned}$} \\
\hline & Male & 0.80 & $0.50-1.28$ & 0.35 & \\
\hline
\end{tabular}

${ }^{1}$ Logistic regression with one-month mortality adjusted for operating region, area, age group, sex, and interaction between age or sex with area.

${ }^{2}$ A value $<1$ equals better results for "one-stop-referral" compared to "two-stopreferral". 
The total number of survivors after rAAA, 30 days postoperatively, in our sample of 849 patients was 579 , Table 5.

Table 5. Observed number of survivors with respect to area (central/one-stop referral pattern or peripheral/two-stop referral pattern) and age group and expected number of survivors, where observed survivors are adjusted by using the rate ratios of the Poisson regression, Table 3.

\begin{tabular}{|c|c|c|c|c|}
\hline & & $\begin{array}{c}\text { Observed survivors } \\
\text { (Central areas, } \\
\text { One-stop referral) }\end{array}$ & $\begin{array}{l}\text { Observed survivors } \\
\text { (Peripheral areas, } \\
\text { Two-stop referral) }\end{array}$ & $\begin{array}{c}\text { Expected survivors } \\
\text { (Peripheral areas, } \\
\text { Adjusted }^{1} \text { ) }\end{array}$ \\
\hline \multirow{3}{*}{$\begin{array}{l}\text { Age } \\
\text { group }\end{array}$} & $45-64$ & 58 & 47 & 34 \\
\hline & $65-74$ & 170 & 84 & 115 \\
\hline & $75+$ & 140 & 80 & 98 \\
\hline \multicolumn{2}{|c|}{ Sum } & 368 & 211 & 247 \\
\hline
\end{tabular}

When comparing the actual number of survivors in the peripheral areas with the expected number, had they come from a central area (by using the rate ratios from the Poisson regression, Table 3), we found that 615 (36 more survivors) should have survived i.e. a $6.2 \%$ higher survival rate with a onestop referral pattern for the regions studied. The whole study represented $11,338,139$ person-years and in the year 2004 there were 3,905,529 persons, $\geq 45$ years of age in the whole of Sweden. If we assume similar circumstances in the rest of Sweden, this would at most represent $(3,905,529 / 11,338,139)$ x $36 \approx 12$ more survivors over one year with a one-stop referral pattern, as in the central areas, compared to the two-stop referral pattern as in the peripheral areas.

In 2004, 308 patients were operated on for rAAA in the whole of Sweden. After 30 days 213 of these where alive, i.e. the one-month mortality was $31 \%$. The difference in number of survivors, with respect to the two referral patterns would represent some $12 / 213 \times 100=5.6 \%$ when applied to the whole of Sweden.

\footnotetext{
${ }^{1}$ Observed survivors/Rate ratio
} 


\section{Study II}

Altogether 5623 70-year-old men were invited to screening. The attendance rate was $84.0 \%$ and of the 4721 that attended, six men were excluded, three due to poor visibility on US-examination and three due to that they already had a known AAA under surveillance. The final screening cohort was 4715.

The mean aortic diameter was $19.7 \mathrm{~mm} .93 .4 \%$ of the men had an aortic diameter $<25 \mathrm{~mm}$ and $4.3 \%$ had a diameter of $25-29 \mathrm{~mm}$. Eleven $(10.3 \%)$ of the 107 men with a screening-detected AAA had an aneurysm of $>54 \mathrm{~mm}$ in diameter, thus requiring evaluation for surgical treatment. Of the 107 AAAs, the vast majority - $93(87 \%)$ were $<40 \mathrm{~mm}$ in diameter.

The screening detected AAA-prevalence was $2.3 \%(n=107)$, which is less than half the predicted from previous studies, Figure 5.

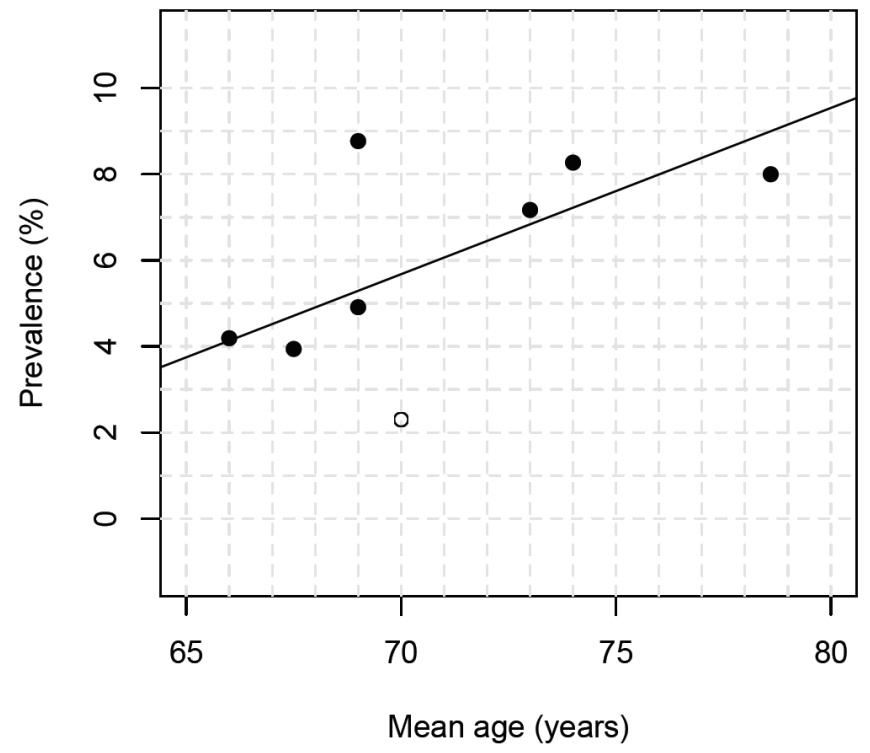

Figure 5. The predicted prevalence for 70-year old men was 5.7\%, using data from previous studies (filled circles, from left to right: ADAM (Lederle et al. 2000a), Lindholt (Lindholt et al. 2005), MASS (Ashton et al. 2002) (below), Simoni (Simoni et al. 1995) (above), Norman (Norman et al. 2004), Bengtsson (Bengtsson et al. 1991, Bengtsson, Sonesson \& Bergqvist 1996) and Ljungberg (Ljungberg et al. 2011), respectively) concerning men $>65$ years of age (Paper II, Table 1), weighted for the number of men in each study, $r=0.91$, $p=0.003$. The prevalence in this study was $2.3 \%$ (unfilled circle), thus less than half the predicted, $p=0.0014$. 
Adding the 48 men who already had been treated for an AAA/rAAA and the 16 men with non-screening detected AAA, to the screening detected AAAs, the total known prevalence was at least 3.0\% (171/5623), ergo, sixty-four $(37.4 \%)$ of the AAAs were already known or previously treated in this cohort.

In Paper II, Table 2 the results from the univariate analysis testing for potential risk factors for AAA are shown. The most significant risk factors were "Current smoker", "CHD" (Coronary Heart Disease - defined as having had myocardial infarction or angina pectoris) and "Renal disease", all reaching p-values $<0.001$. For those individuals who were "Ex smokers" the prevalence of AAA was $2.5 \%$ and for those who were "Current smokers" the prevalence was $5.5 \%$, compared to $0.65 \%$ among those who had "Never smoked".

An increased BMI was found among the men with an AAA, $\mathrm{p}<0.01$, compared to those without. From a logistic regression analysis on BMI and AAA we found that two BMI-steps, e.g. from 25 to $27 \mathrm{~kg} / \mathrm{m}^{2}$, which in a man who is $1.77 \mathrm{~m}$ tall and weighs $83 \mathrm{~kg}$ is slightly more than $6 \mathrm{~kg}$, increased the probability of having an AAA by the RR $19.0 \%$.

Ten risk factors (excluding medication) had a p-value $<0.1$ in the univariate analysis and these were tested in a multivariable logistic regression analysis, Table 6.

Table 6. Multivariable logistic regression analysis of variables associated with the presence of an AAA. Variables with a p-value< 0.1 in the univariate analysis (Paper II, Table 2), were included in the multivariable analysis. The number of complete observations used in the analysis is 3872 (of 4715 in the screening cohort). rAA=ruptured Aortic Aneurysm, $C O P D=C h r o n i c$ Obstructive Pulmonary Disease, $C V D=$ Cerebro Vascular Disease, $C H D=$ Coronary Heart Disease.

\begin{tabular}{|c|c|c|c|}
\hline Risk factor & Odds ratio & $\mathrm{Cl}$ & $\mathrm{p}$-value \\
\hline Previous rAA-surgery & 12.4 & $2.1-74.8$ & $p<0.01$ \\
\hline Never smoked & \multicolumn{3}{|c|}{--- Reference --- } \\
\hline Ex smoker & 3.3 & $1.7-6.6$ & $p<0.001$ \\
\hline Current smoker & 8.9 & $4.2-18.6$ & $p<0.001$ \\
\hline Renal disease & 3.2 & $1.2-8.4$ & $p<0.05$ \\
\hline COPD & 2.1 & $1.1-3.9$ & $p<0.05$ \\
\hline CVD & 2.0 & $1.1-3.6$ & $p<0.05$ \\
\hline Claudication & 2.0 & $0.7-5.6$ & $p=0.18$ \\
\hline $\mathrm{CHD}$ & 1.7 & $1.0-3.0$ & $p=0.053$ \\
\hline Hyperlipidaemia & 1.2 & $0.8-2.0$ & $p=0.37$ \\
\hline Cancer & 0.4 & $0.1-1.1$ & $p=0.079$ \\
\hline
\end{tabular}


The two risk factors "Ex smoker" and "Current smoker" remained the strongest risk factors, OR 3.3 (CI 1.7-6.6) and 8.9 (CI 4.2-18.6) respectively, $\mathrm{p}<0.001$ for both. Also the risk factors "Renal disease", COPD and CVD remained associated with AAA.

When we included BMI in the multivariable analysis, no major changes with respect to the association between AAA and the other risk factors occurred. We did not include BMI in the final multivariable analysis, since overweight in itself is not a disease - only when BMI $>30$, the patient is regarded as having the disease (obesity). However, we found that in the patients who were not obese, quite small changes in BMI were associated with changes in risk for AAA. 


\section{Study III}

In Figure 6 the study-population in Study III is illustrated.

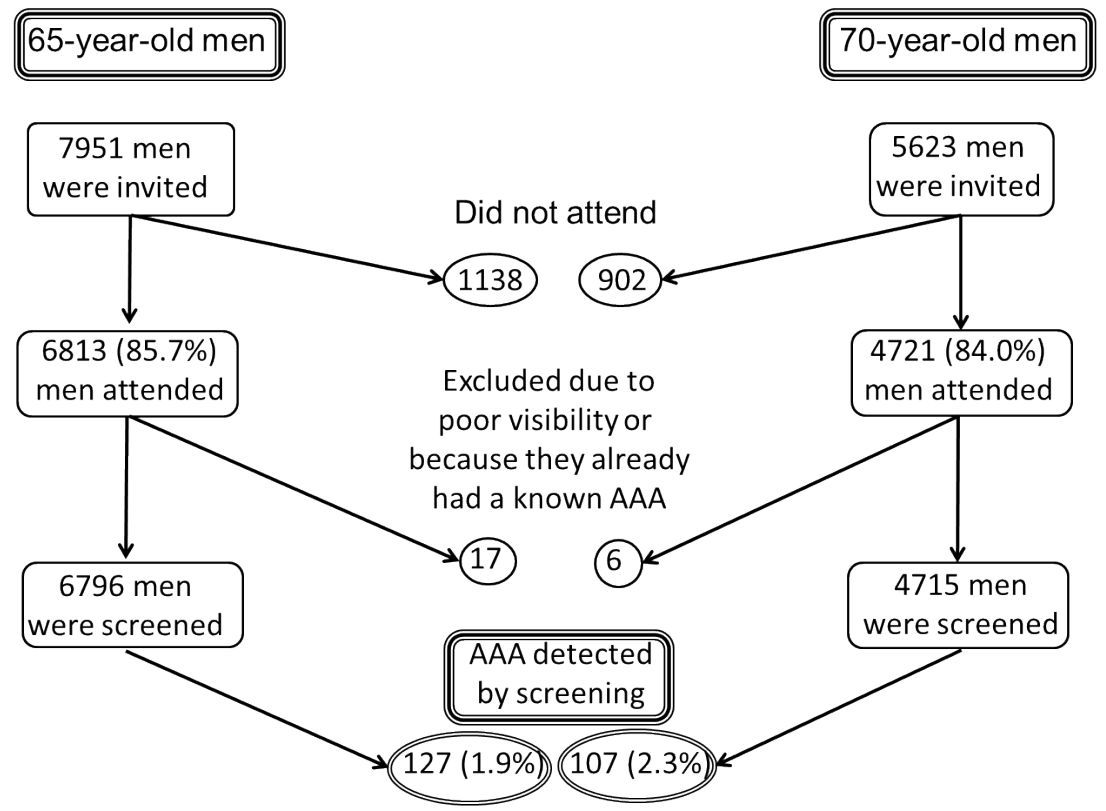

27 men were already treated and 12 men were already under surveillance.

48 men were already treated and 16 men were already under surveillance.

Figure 6. Exclusion/inclusion-process for screened 65- and 70-year-old men.

There were 7951 and 5623 men in Östergötland, Sweden becoming 65 and 70 years old, during the years 2007-2009 and 2008-2010 respectively. Of these, $85.7 \%$ and $84.0 \%$ attended respectively, $\mathrm{p}<0.01$.

As shown in Paper III, Table 1 there were no significant differences between the two groups regarding the distribution of the aortic diameter. The median diameter for all aortas $\geq 25 \mathrm{~mm}$ among 65- and 70-year-old men was exactly the same - $27 \mathrm{~mm}(25-32 \mathrm{~mm})^{1}, \mathrm{p}=0.41$. For AAA (i.e. aortic diameter $\geq$ $30 \mathrm{~mm})$, the median diameter was $36 \mathrm{~mm}(32-42 \mathrm{~mm})^{1}$ for 65 -year-old men and $36 \mathrm{~mm}(32-40 \mathrm{~mm})^{1}$ for 70-year-old men, again no significant difference was found, $\mathrm{p}=0.69$.

${ }^{1}\left(1^{\text {st }}\right.$ and $3^{\text {rd }}$ quartile $)$ 
Table 7 shows the prevalence of AAA among the 65- and 70-year-old men.

Table 7. Prevalence of AAA when screening 65- and 70-year-old men.

\begin{tabular}{|c|c|c|c|c|c|}
\cline { 2 - 7 } \multicolumn{1}{c|}{} & $\begin{array}{c}65 \text {-year old } \\
\text { men }\end{array}$ & $\mathrm{Cl}$ & $\begin{array}{c}70 \text {-year } \\
\text { old men }\end{array}$ & $\mathrm{Cl}$ & $\mathrm{p}$-value \\
\hline Screening-detected AAA (n) & 127 & - & 107 & - & - \\
\hline Screening-detected AAA (\%) & 1.9 & $1.6-2.2$ & 2.3 & $1.9-2.7$ & $\mathrm{p}=0.15$ \\
\hline AAA > 54 mm (n (\% of AAA)) & $10(7.9)$ & - & $11(10.3)$ & - & - \\
\hline AAA known prior to screening (n) & $39^{1}$ & - & $64^{2}$ & - & - \\
\hline $\begin{array}{c}\text { Proportion of AAA known without } \\
\text { screening (\%) }\end{array}$ & $23.5^{3}$ & $17.0-29.9$ & $37.4^{4}$ & $30.2-44.7$ & $\mathrm{p}<0.01$ \\
\hline $\begin{array}{c}\text { Total known AAA-prevalence in } \\
\text { the population (\%) }\end{array}$ & $2.1^{5}$ & $1.8-2.4$ & $3.0^{6}$ & $2.6-3.5$ & $\mathrm{p}<0.001$ \\
\hline
\end{tabular}

The screening-detected AAA-prevalence was $1.9 \%$ and $2.3 \%$ respectively, $\mathrm{p}=0.15$. Thirty-nine and 64 AAA were already known prior to screening among the 65 - and 70 -year-old men, respectively. Thus, $23.5 \%$ and $37.4 \%$ of all known AAAs in the two populations were already known at the time of screening, $\mathrm{p}<0.01$. The total known AAA-prevalence in the two age groups was $2.1 \%$ and $3.0 \%$ respectively, $\mathrm{p}<0.001$.

\footnotetext{
${ }^{1} 27$ men already treated for AAA and 12 already under AAA-surveillance.

${ }^{2} 48$ men already treated for AAA and 16 already under AAA-surveillance.

${ }^{3} 39 /(127+39)$

${ }^{4} 64 /(107+64)$

${ }^{5}(127+39) / 7951$

${ }^{6}(107+64) / 5623$
} 


\section{Study IV}

The results of the base-case analysis of screening compared to no screening for AAA are summarized in Table 8.

Table 8. Base case results.

\begin{tabular}{lrrr}
\hline & Screening & No Screening & Difference \\
\hline Costs $(€)$ & & & \\
Healthcare costs (mean per invited man) & & & \\
Screening costs & & 0 & 20 \\
Surveillance & 7 & 0 & 7 \\
Elective surgery & 156 & 3 & 153 \\
$\quad$ Acute surgery & 123 & 199 & -76 \\
Total healthcare costs & $\mathbf{3 0 5}$ & $\mathbf{2 0 2}$ & $\mathbf{1 0 3}$
\end{tabular}

\section{Outcomes}

Clinical (10-year rates per 10,000 men)

Rupture

43

Elective surgery

Death from elective surgery

AAA-related death

Death by all causes

Health (mean per invited man)

Life-years

QALYs

\section{Cost-effectiveness}

Cost $(€)$ per life-year gained with screening

${ }^{1}$ Invitation and ultrasound investigation.

The screening program was associated with an incremental healthcare cost per invited man of $103 €$ compared to no screening program. The cost of screening (invitation and ultrasound investigation) and subsequent surveillance accounted for approximately $27 €$ of the incremental costs. Costs due to elective repair increased with $153 €$, whereas costs due to acute surgery decreased with $76 €$ with the screening program. The gain in QALYs per invited individual with a screening program was 0.0244 , leading to a cost per QALY gained with a screening program of $4231 €$. The gain in life-years per invited individual was 0.0314 with a corresponding cost per life-year gained of $3252 €$. 
The results of the probabilistic analysis are presented in Figure 7 and Figure 8 and in conclusion indicate a high probability that the cost per QALY gained with a screening program is below conventional threshold values of a QALY for screening programmes.

In Figure 7 the incremental cost in $€$ of screening, related to the incremental effect in terms of QALYs gained, is displayed. The result of each simulation in the model is displayed as a dot. The cluster of dots is the result of 10,000 simulations. If the cluster of dots ends up in the northwest quadrant, this means that the method (in our case screening for AAA among 65-year-old men) is related to increased cost but less effect in terms of gain in QALYs. If the cluster ends up in the southeast quadrant the method is less costly and more effective. Our result - with the cluster in the northeast quadrant, thus means that there is a gain in QALYs at a certain cost - $103 €$ per 0.0244 QALYs, see Table 8.

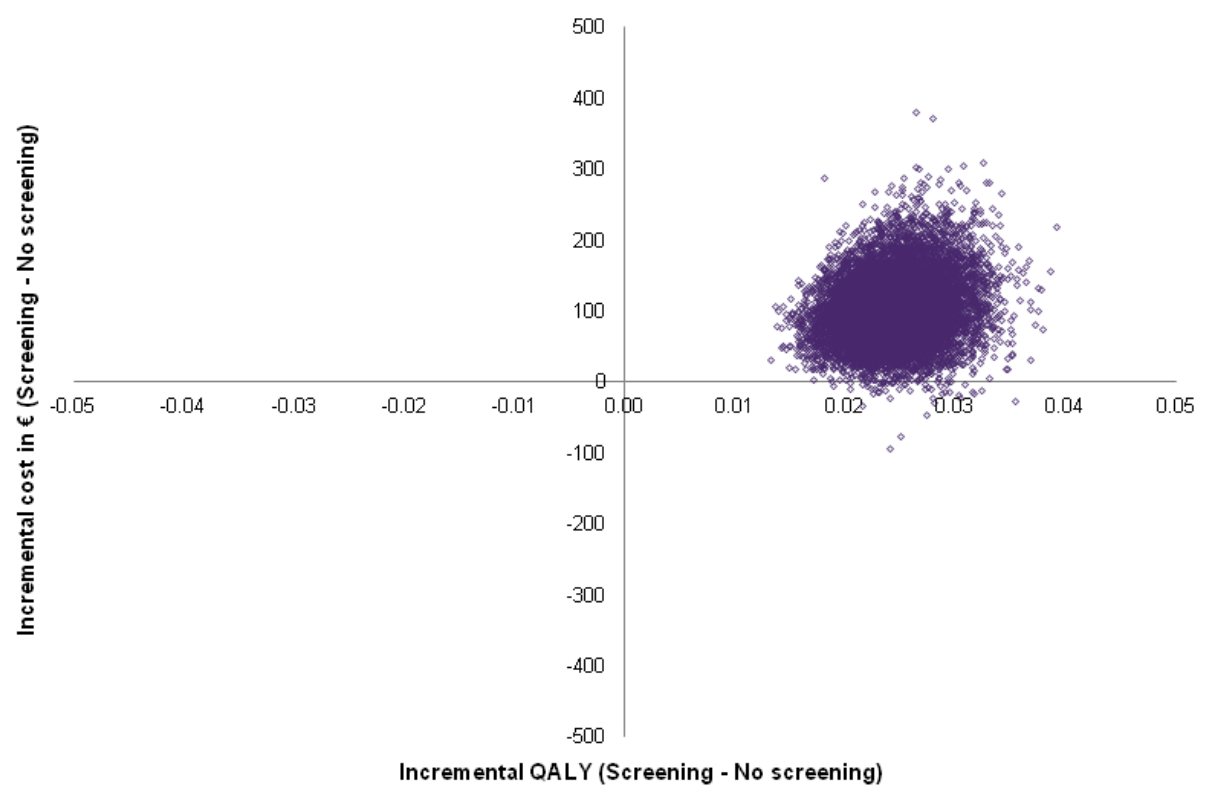

Figure 7. Cost-effectiveness plane. 
In Figure 8 the probability that the method is cost-effective at a certain cost is displayed. For example, if the accepted cost per QALY is set at a maximum of $5000 €$ per QALY, there is a $50 \%$ probability that the method is cost-effective. Hence, if the accepted cost is a maximum of $10,000 €$ per QALY, the probability that the method (i.e. screening for AAA) is cost-effective is $100 \%$. In our study the cost per QALY gained was $4231 €$ (see Table 8 ).

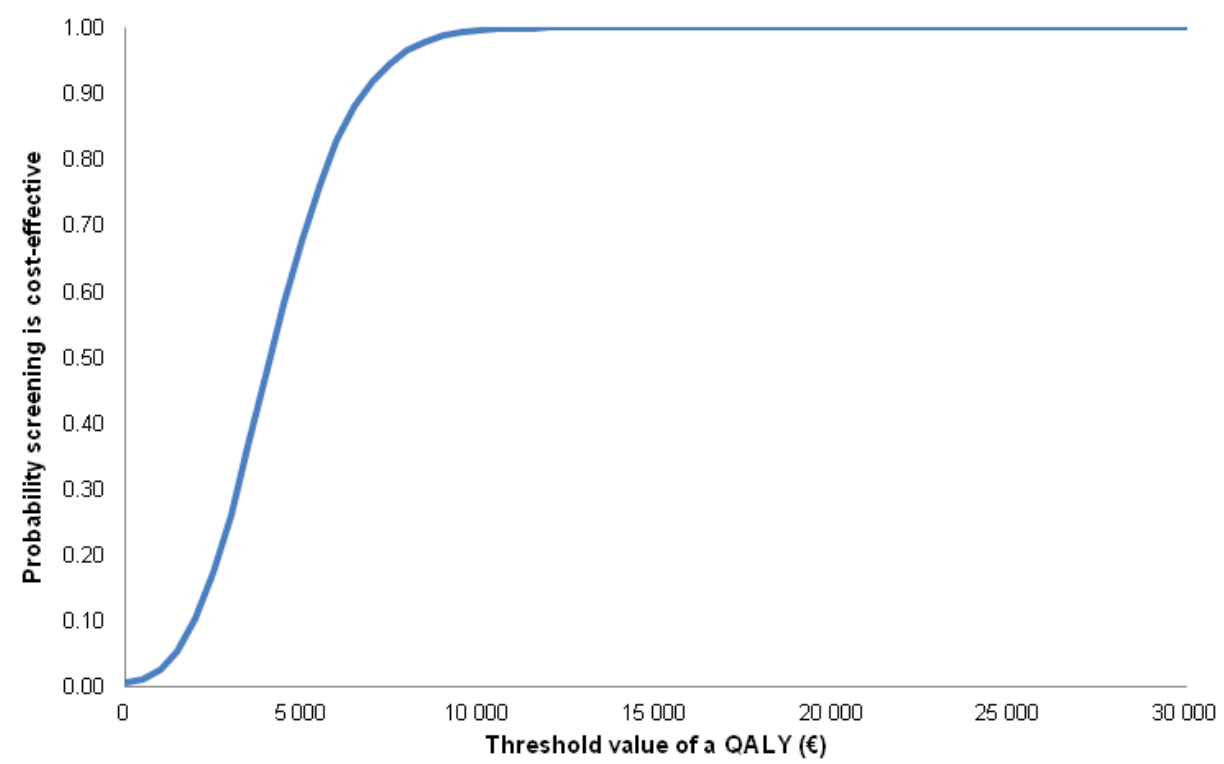

Figure 8. Cost-effectiveness acceptability curve for the screening strategy.

The results of alternative scenarios showed small differences in the point estimates of the incremental cost effectiveness ratios and did not alter the conclusion from the base-case analysis, Table 9.

Table 9. Alternative scenarios.

\begin{tabular}{lrrr}
\hline Scenario & $\begin{array}{r}\text { Incremental } \\
\text { cost }(\boldsymbol{\epsilon})\end{array}$ & $\begin{array}{r}\text { Incremental } \\
\text { QALY }\end{array}$ & ICER (€) \\
\hline Base case analysis & 103 & 0.0244 & 4231 \\
Inclusion of private costs & 113 & 0.0244 & 4614 \\
$5 \%$ discount rate (costs and QALYs) & 97 & 0.0188 & 5162 \\
3\% discount rate (costs), 0\% discount rate (QALYs) & 103 & 0.0388 & 2669 \\
0.10 decrement in QALY-weight due to diagnosis of & & & \\
AAA & 103 & 0.0107 & 9702 \\
0.10 decrement in QALY-weight post surgery & 103 & 0.0190 & 5446 \\
\hline
\end{tabular}




\section{GENERAL DISCUSSION}

In an effort to investigate aspects on how to affect mortality from rAAA, we have performed four studies of three different types. In the first study, which was population-based and retrospective, we studied whether different patterns of referral, affect survival after rAAA. As shown, the populationbased survival rate was lower for 65-74 year old patients with a two-stop referral pattern (Paper I). Since the numerical effect was quite small, probably due to the fact that mortality related to rAAA is so immense, this study indirectly is an argument for continued and maybe expanded AAA-screening.

However, as the prevalence of AAA for 65-year-old men in a contemporary setting is considerably lower than what has been expected, a number of questions arise. For example, is 65 years of age the optimal age when to screen? In order to elucidate this question, we performed two population-based screening studies, where the prevalence and risk factors among 70-year-old men were determined (Paper II), and the differences in terms of prevalence; attendance rate; opportunistic detection; and aortic diameters, between 65- and 70-year-old men were compared (Paper III).

Finally, to evaluate whether screening under current clinical practice still is cost-effective, we performed a health-economic modelling study using data from our own implemented screening programme, Swedvasc and other recently published studies (Paper IV).

In this chapter I will interpret the results and try to put them into the context of contemporary knowledge. 


\section{Centralisation of services for rAAA/AAA}

Previous studies have shown that high-volume centres and specialist surgeons with a high case-load of elective and acute aortic surgery achieve better results in terms of operative mortality, as discussed on page 24, Centralisation. Numerous reorganisations of health care have been implemented during the last decades, thus centralisation of services for vascular surgery has already occurred in Sweden as well as in parts of the rest of the developed world.

So, if a patient is struck by rAAA, he should optimally be treated as fast as possible, since any delay increases mortality - already two hours after the rAAA-patients arrival at hospital, almost $15 \%$ of them were dead, and the median total time from onset of symptoms to death was less than 17 hours without treatment (Lloyd et al. 2004).

A two-stop referral pattern, which means longer time from rupture to treatment, decreases the survival rate after rAAA (Paper I). Nevertheless, the effect is rather small. At most $5.6 \%$ more survivors would be generated if a one-stop referral pattern could be generally applied. In numerical terms this would save approximately 12 lives per year in the whole of Sweden. This rather small difference is probably due to the huge overall mortality from rAAA.

What options are there for future improvement? Sweden is a vast, sparsely populated country and will not be able to maintain fully trained and experienced round-the-clock on-call rAAA-surgery-teams for the whole population. In many cases patients with rAAA have to be transferred. Centralisation of all emergency health care would of course avoid the problems of a two-stop referral pattern, but would the Swedish population accept travelling great distances for basic medical care as e.g. appendectomy?

Emergency ultrasound is a fast and accurate method for identifying patients with AAA (Moore et al. 2008). Using portable ultrasound equipment in ambulances, or even more simple, teaching medical orderlies in ambulances to evaluate patients in regard of the typical symptom-triad for rAAA (circulatory shock; abdominal or back pain; and a palpable pulsating mass in the abdomen), might help avoiding unnecessary transports to hospitals not performing surgery for rAAA. This would in turn shorten the time from rupture to operation, and hence make a one-stop referral strategy possible. However, for the moment ultrasound equipment in ambulances are, at least in Sweden, not available and unfortunately only $25 \%$ of the rAAA-patients present with the typical triad (Donnelly, London 2009). 
Thus, changing referral patterns or increasing centralisation does not seem to be the solution on how to decrease mortality from rAAA, indirectly supporting continued and expanded use of AAA-screening.

\section{Aspects on screening}

When screening programmes for AAA in men were launched in Sweden and England, a screening age of 65 years was chosen. In the four large screening studies the mean-age for the screened was between 67.8 and 72.6 years, and for the largest study, MASS, the mean age was 69.2 years, thus considerably higher than 65 years, see page 30, The four RCTs. However, in a meta-analysis of studies specifically reporting the prevalence in 65-year-old men, a prevalence of $4.9 \%$ was calculated, and hence choosing 65 years as an age when to screen, seems reasonable (Henriksson, Lundgren 2005a).

Nevertheless, contemporary prevalence among 65-year-old men is now reported to be substantially lower, only 1.6-1.7\% (Conway et al. 2012, Svensjo et al. 2011).

Since the prevalence of AAA increases with age, a possible way to find more AAAs would be to screen older men, which also has been suggested by several authors (Anjum, Powell 2012, Davis, Harris \& Earnshaw 2013, Rudarakanchana, Powell 2013, Von Allmen, Powell 2012).

However, the screening detected AAA-prevalence among 70-year-old men was only $2.3 \%$, which is less than half the predicted (Paper II). Further, almost $40 \%$ of the patients with AAA in this age group were already known by other means than screening.

When evaluating a screening programme, a high attendance rate is crucial. We experienced a higher attendance rate among both 65- and 70-year-old men $-85.7 \%$ and $84.0 \%$ respectively (Paper III and II) - compared to the four major screening trials, were the attendance rate was between 70 and $80 \%$, see page 30, The four RCTs. The fact that we utilized a partly decentralized screening method and that the examination was free of charge might have contributed to this. The attendance rate, in a study by Zarrouk et al., was lower in areas with low socioeconomic status, whereas AAA-prevalence in these areas was higher (Zarrouk et al. 2013). Despite the high attendance rate in our study, the screening detected prevalence among 70-year-old men was lower than ever reported previously for this age. 


\section{Risk factors among 70-year-old men}

As in other screening-studies, we found smoking to be the most important risk factor for AAA, with OR being 3.3 (CI 1.7-6.6) and 8.9 (CI 4.2-18.6), for "Ex-" and "Current smokers", respectively. Since smoking has declined steeply over the last decades, Figure 9, this probably is the main explanation for the decreasing prevalence of AAA, see page 9 Prevalence and Epidemiology.

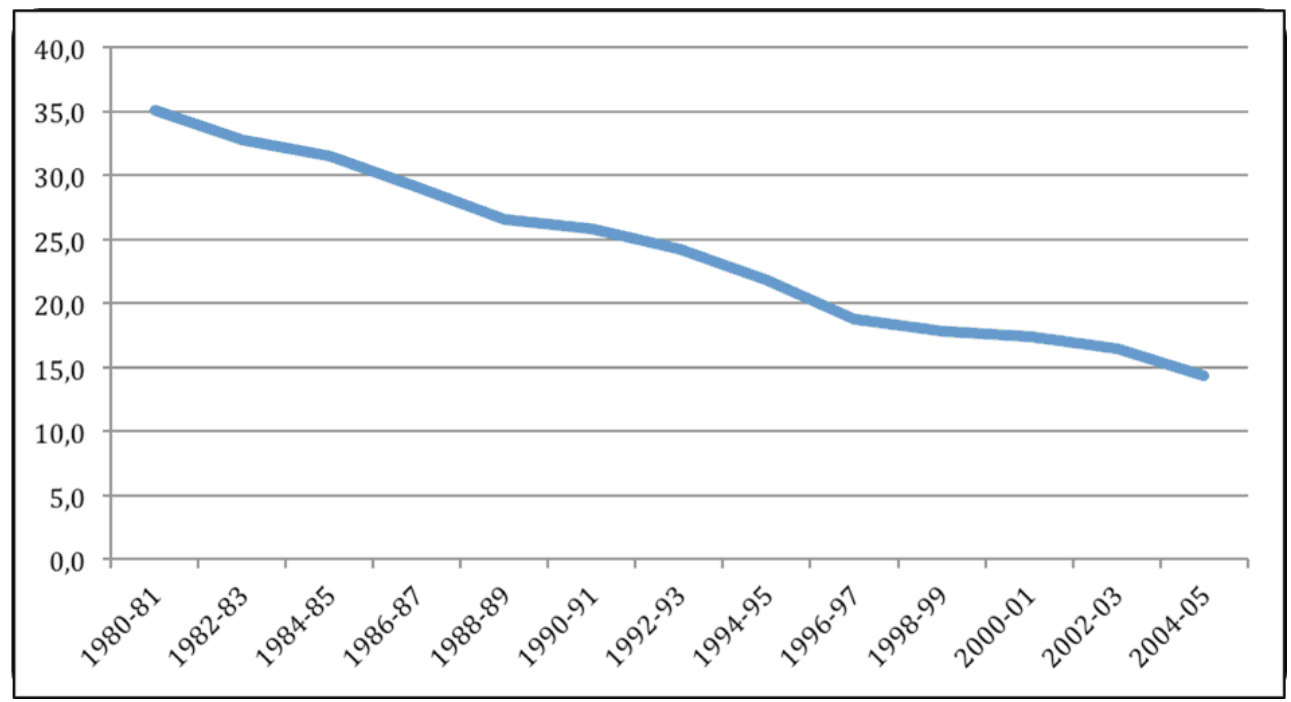

Figure 9. Percentage of Swedish men, 16-84 years old, smoking on a daily basis, 1980-2005.

From Statistics Sweden (SCB).

Family history is also a strong risk factor for AAA, as discussed previously on page 11, Family History. However, in our study, having a first-degree relative with AAA was not a significant pre-disposing factor for AAA. The explanation for this might be that in Sweden many AAA-patients are urged to encourage their first-degree relatives to have their aorta examined, which is in line with general recommendations (Chaikof et al. 2009, Kent et al. 2004). This might also be one reason for the high rate of previously known AAA in Studies II and III.

In the EVAR1, DREAM and OVER trials, a positive association between AAA and cancer was found, and mortality due to cancer was considerably higher than AAA-related or cardiovascular mortality (United Kingdom EVAR Trial Investigators et al. 2010, De Bruin et al. 2010, Lederle et al. 2009). The reason for the cancer-AAA association is probably due to the joint relation with smoking. 
To our surprise we found a tendency of a lower AAA-prevalence among men with cancer, OR 0.4 (95\% CI 0.1-1.1), $\mathrm{p}=0.079$. One explanation might be that those individuals who are diagnosed with cancer, almost always are subjected to a CT- or MRI-scan, which means that any existing AAA is discovered and hence would be found in the group of already discovered AAA prior to screening. It is unknown whether the 64 patients with an already known AAA in our cohort of 70-year-old men, actually had a higher cancer prevalence than the rest of the study population, since we did not have the ethical permission to review case-notes of individual patients.

Diabetes Mellitus has in prior works been shown to be a protector against AAA, as discussed on page 13, Diabetes Mellitus. In our cohort of 70-year-old men, the screening-detected AAA prevalence was not lower among diabetics. One reason for this might be that with increasing age, the protective effect of DM decreases, as other factors contributing to the development of AAA, e.g. atherosclerosis, become more dominant.

We also found an association between increased BMI and having an AAA, which is in line with previous findings, see page 13, Alcohol, low HDL, obesity, physical activity and diet.

The use of lipid lowering agents, treatment with angiotensin-convertingenzyme inhibitors and overall better regulation of hypertension has also been suggested as contributors to the declining AAA-prevalence (Anjum et al. 2012, Bergqvist 2011, Shantikumar et al. 2010). No associations pointing in this direction were found in our cohort; on the contrary, the use of lipid-lowering agents, thrombocyte inhibitors and beta-receptor blockers, already were significantly more common among those with a screening detected AAA, indicating an already known greater cardiovascular morbidity (Kent et al. 2010). The men with an AAA also were more affected by renal disease, COPD, CVD, and CHD (although CHD was only marginally statistically significant, $\mathrm{p}=0.053$ ). A bit surprising, diseases normally associated with atherosclerosis and smoking, for example claudication and hyperlipidaemia, were not statistically associated to AAA in the multivariable analysis in our study. Most likely, the diseases associated with smoking are also associated to each other and therefore may fail to show up in the multivariable analysis as independent risk factors for AAA. Thus, if patients with smoking associated diseases, other than AAA, use lipid-lowering agents, thrombocyte inhibitors and betareceptor blockers, this medication will also be associated with a higher prevalence of AAA. 


\section{Is screening at 70 years of age instead of 65 more effective?}

When a screening programme for AAA is designed, it is important to screen at an age where the prevalence is high enough for the programme to be cost-effective, but not at such a high age that a large number of AAA already have been discovered in other ways nor that the men screened are so old or frail that a large number of them would not be reasonable candidates for intervention. In order to answer this question, we also invited 65-year-old men that were not previously screened, from the same region in Sweden and screened them in about the same time-period as the 70-year-old men (Paper III).

The most important finding in Study III was that there was no significant difference in the screening-detected AAA-prevalence between the two age groups. Further, among the $65-$ and 70 -year-old men, $23.5 \%$ and $37.4 \%$ of all known AAA (i.e. both screening-detected and incidentally found) respectively, were already known at the time of screening. When adding these known AAA to the screening-detected ones, the total known AAA-prevalence in the two age groups was at least 2.1 and $3.0 \%$ respectively, $p<0.001$. In another contemporary Swedish study, $25.4 \%$ of the AAA were already known when screening 65-year-old men, thus in accordance with our results (Svensjo et al. 2011).

When a large proportion of individuals with AAA are already known at the time of screening, the efficacy of a screening-programme is reduced. One reason for the large share of incidentally detected AAA prior to screening might be the increasing use of advanced radiological methods, e.g. CT, as a routine-examination for most abdominal diseases, for example acute abdominal symptoms, as well as investigating the extent of a malignant disease (Brenner, Hall 2007). Another reason might be the recommendation of screening relatives to patients with AAA, as discussed above, page 69, Aspects on screening.

Further, as people get older, the risk of other diseases that demands radiological investigation increases, thus revealing any unknown AAA. This might be one possible explanation for the significantly higher rate of previously known AAA among the 70-year-old men, compared to the 65-yearold. 


\section{Surveillance of sub-aneurysmal aortas?}

There were no differences in the distribution of the aortic diameter between the two age groups, Paper III, Table 1. Recently some attention has been directed to the group of individuals with aortas with sub-aneurysmal dilatation (25-29 mm) (Wild et al. 2013). Wild et al. in their multicentre observational study found that $67.7 \%$ of 1696 men and women with a subaneurysmal dilatation in five years reached a diameter of $30 \mathrm{~mm}$ or more, and that $0.9 \%$ developed an AAA of $\geq 54 \mathrm{~mm}$. After ten years $26.2 \%$ had developed an $\mathrm{AAA} \geq 54 \mathrm{~mm}$. Other authors have found similar results; $\mathrm{d}$ 'Audiffret et al. followed 223 patients with sub-aneurysmal dilatation, comprising $1.8 \%$ of a population of 12,500 screened (d'Audiffret et al. 2002). In an average followup time of 5.9 years, $63 \%$ developed an AAA (i.e. diameter $\geq 30 \mathrm{~mm}$ ), and $1.3 \%$ grew to $>5 \mathrm{~cm}$. Devaraj et al. found similar results; $88 \%$ of aortas with a diameter of $2.6-2.9 \mathrm{~cm}$ dilated to $\geq 3 \mathrm{~cm}$ in a mean follow-up time of 5.4 years, and $2 \%$ expanded to $\geq 5.5 \mathrm{~cm}$ during the same time-period (Devaraj, Dodds 2008). Finally, Svensjö et al. recently found that of 40 sub-aneurysmal aortas at 65 years of age, $52.5 \%$ progressed to an AAA ( $\geq 30 \mathrm{~mm}$ ) when the men were re-screened at the age of 70 (Svensjö, Björck \& Wanhainen 2013).

We found no difference in the size of this subgroup when comparing 65and 70 -year-old men $-4.2 \%$ and $4.3 \%$ respectively had an aortic diameter of 25-29 mm, $\mathrm{m}=0.84$. Neither was there any statistical difference in the share of AAA $>54 \mathrm{~mm}$ between the two age groups. However, the prevalence of AAA $>54 \mathrm{~mm}$, was $53 \%$ higher among the 70-year-old men, which might represent a Type II error. All the same, most probably these large AAA would have been detected five years earlier as well, i.e. when the 70-year-old men were 65 .

Further, there was no difference in median-diameter between the two age groups, neither when studying all men with an aortic diameter $\geq 25 \mathrm{~mm}$, nor all men with an AAA (aortic diameter $\geq 30 \mathrm{~mm}$ ).

\section{Re-screening?}

From the four studies cited in the section above, a reasonable standpoint would be to re-screen the individuals with aortas with sub-aneurysmal dilatations after five years, which also is the conclusion of another author studying 345 patients with sub-aneurysmal aortas for a mean of 4.25 years (Gibbs et al. 2010). 
Re-screening the whole population after five years has been tested in a cost effectiveness analysis and found to be potentially attractive (Sogaard, Laustsen \& Lindholt 2012b). However, Svensjö et al. when re-screening 2041 men after five years (at the age of 70), with an initial aortic diameter $<25 \mathrm{~mm}$, found that only $0.7 \%$ had developed an AAA (diameter $\geq 30 \mathrm{~mm}$ ) (Svensjö, Björck \& Wanhainen 2013).

We found that at the age of 70 years, the number of men with already known AAAs was so large that there was no statistically significant difference in the screening-detected prevalence between 65- and 70-year old men, also speaking against the notion of re-screening the whole population, at least in health systems similar to the Swedish one.

Study III is not an actual re-screening study, but we have studied two three year-cohorts of men from the same part of the same country during almost the same time-period. Performing the study in this way increased the size of the study population three times; we invited almost 8000 and 6000 65and 70-year-old men respectively, resulting in more representative data, compared to re-screening only a one year-cohort.

\section{Still cost-effective to screen}

When updating a ten year old decision-analytical model - previously used to estimate cost-effectiveness when introducing screening for AAA (Henriksson, Lundgren 2005a) - to contemporary clinical practice, we found that the costs per life-year gained and QALY, were similar to those reported almost a decade ago, despite profound changes in disease-pattern and management of AAA (Paper IV).

However, these results are reached by a different mean with several counteracting aspects, discussed below.

\section{Decreased prevalence}

The prevalence of AAA today is substantially lower than the $4.9 \%$ that was applied in the previous model and what was actually found in the MASS (Henriksson, Lundgren 2005a, Thompson et al. 2012). The prevalence in Sweden today is less than half of this; we found a screening-detected prevalence of $1.9 \%$ among 65-year-old men (Paper III), comparable to other contemporary screening-studies, see page 9, Prevalence and Epidemiology. This 
is slightly higher than what has recently been reported from the NAAASP, reporting a prevalence of $1.5 \%$ for the 65 -year-old men examined in 2011-12 (NAAASP). The difference compared to England may however to a large extent be explained by the fact that in Sweden the aorta is measured according to the LELE-method and in the NAAASP the aorta is measured with the ITItechnique, see page 52, The ultrasound-examination and definition of an AAA. The aortas measured with the latter technique will be smaller, and hence a greater number of them will be classified as being non-diseased.

However, regarding AAA-prevalence and cost-effectiveness, screening has previously been found to be cost-effective down to around a prevalence of $1 \%$ in 65-year-old men (Spronk et al. 2011).

\section{Higher attendance rate}

One aspect counterbalancing the lower prevalence in the cost-effectiveness estimates is the higher-than-expected attendance rate to the screening program. The attendance rate was assumed to be $77.3 \%$ in the old model (Henriksson, Lundgren 2005a), which was in line with the rate found in both the MASS and the NAAASP, where $80.3 \%$ and $75.0 \%$ attended respectively (Thompson et al. 2012, NAAASP).

However, in our study, we experienced an even higher attendance rate of 85.7\% (Paper III).

\section{Decreased mortality, increased survival}

Another important counterbalancing aspect is the decreasing mortality rate after elective repair of AAA. Based on data from Swedish clinical practice during 2008-2012, we found a 90-day elective mortality rate of 3.8\%, Paper IV. This is substantially lower than what was found when retrieving information for the old model where the total 90-day mortality rate was $6.4 \%$ when analysing data from 4198 men $\geq 65$ years operated electively during 1987-2000 (Henriksson, Lundgren 2004).

Also, general survival in the population of Sweden has increased steadily since these measurements commenced (Statistics Sweden a). When the meanage increases, more life-years might be gained if death from rAAA can be prevented, but this requires that also men with rAAA gain from the increase in general survival. 
Furthermore, as discussed on page 31, in the section The systematic reviews and meta-analyses, the final follow-up of the MASS study and one meta-analysis have also shown that screening decreases over-all mortality in the population invited to screening, by 0.97 (in the 13-year follow up) and 0.973 respectively (Thompson et al. 2012, Takagi et al. 2013). Using the predicted overall mortality rates of the model for a screening and a no screening strategy yields an estimated Risk Ratio of 0.98 regarding over-all mortality (similar for 5 and 10 years of follow-up in our updated model).

\section{Increased efficacy}

In the now running screening programme, 125 men are invited to examination each day, which is far more than what was assumed in the old model where only 15 men were expected to be examined each day. With an attendance rate of $85.7 \%$, on average 107 men are examined daily, thus increasing the efficacy of the programme substantially compared with the previous estimates.

\section{Incidental discovery of AAA}

Another important issue determining the utility of a screening programme is how many of the participants that are already diagnosed at the time of screening. If a large proportion of men with AAA are already known when they are invited to screening, the efficacy of a screening-programme is reduced. We found that almost one fourth of the men with AAA already were known when screening 65-year-old men and this proportion rose to almost $40 \%$ when screening 70-year-old, previously not screened men for AAA (Paper III and II). The issue of opportunistically detected AAA has been raised and discussed also by others (Karnon et al. 2007). Karnon et al. estimated that of all men needing surgery for AAA in the MASS, 25\% were detected opportunistically in the control group at four-year follow up. In our cohort of 65-year-old men, 27 of 39 men (69\%) with an already known AAA were surgically treated prior to screening (Paper III). The reasons for the large share of opportunistically detected AAA before screening has been discussed previously, see page 70, Risk factors among 70-year-old men. 


\section{Selective screening}

Smoking is the most important risk factor associated to AAA (Paper II). Selective screening of ex- or current smokers has been discussed and rejected (Spencer et al. 2000), as have selective screening of high-risk groups, men with cardiovascular disease and COPD - both also strongly related to smoking (Lindholt, Juul \& Henneberg 2007). However, in the USA the US Preventive Services Task Force (USPSTF) recommends one-time AAA screening for men 65-75 years old who have ever smoked (defined as having smoked at least 100 (sic!) cigarettes in a persons lifetime) (U.S. Preventive Services Task Force 2005). Fleming et al. in a best-evidence review for the USPSTF found that inviting the $69 \%$ with a history of smoking would account for $89 \%$ of the expected reduction in AAA-related mortality from population-based screening of all men 65-74 years of age (Fleming et al. 2005).

In the screening program inviting 65-year-old men in Östergötland, Sweden, $9.4 \%$ of the men with AAA had never smoked, compared to $34.7 \%$ among those without, OR 0.2 (CI 0.1-0.4), p $<0.001$ (From the Screeningdatabase, The County Council of Östergötland). Whether a strategy of selective screening, e.g. inviting only "ever smokers", should be adopted needs to be addressed further. It should also be remembered that $19 \%$ of those men operated on for rAAA registered in Swedvasc 2006 were less than 65years-old (Wanhainen, Svensjo \& Mani 2008) and that one third of the rAAAs resulting in death in the USA, occur in women (Vouyouka, Kent 2007).

Further, the screening cost of $22.2 €$ per invited individual, in my view, is not a great amount of money, see Table 2 .

My belief is that inviting 60-year-old men and 70-year-old women, who have ever smoked, and men and women with a first-degree relative with AAA, probably is the most effective way to screen. 


\section{CONCLUSIONS}

The main conclusions of this thesis are:

I. When a two-stop referral pattern was used in the management of rAAA, the population-based survival rate for patients $\geq 45$ years of age was lower compared to patients handled with a one-stop referral pattern. This effect was greatest for patients 65-74 years old. On the other hand, the consequences of a generally accomplished one-stop referral pattern would be rather modest, probably due to the huge overall mortality from rAAA.

II. The contemporary screening-detected prevalence among 70-year-old men was $2.3 \%$, thus the lowest ever reported for this age and less than half the predicted, despite a high attendance rate. Almost $40 \%$ of the AAAs were already known by the time of screening. The most important risk factor for AAA was smoking. However, the previously welldocumented risk of having a first-degree relative with AAA was not significant in our study. Surprisingly, cancer was negatively associated with AAA, and further diabetes mellitus did not prove protective in this cohort. Other risk factors associated to AAA among 70-year-old men, were renal disease, COPD, CVD and CHD (CHD almost significant).

III. When comparing previously un-screened 65- and 70-year-old men, there was no difference in the screening-detected AAA-prevalence between the two age groups. The explanation for this probably was the fact that such a large share of the AAAs among 70-year-old men were already known at the time of screening. The attendance rate for AAA-screening was lower among the 70- compared to the 65-year-old men. Thus, neither screening men at 70 instead of 65 years of age, nor rescreening the whole 65-year-old male population after five years, would result in detection of substantially more unknown AAAs, and consequently no better prevention of rAAA.

IV. Despite profound changes in disease pattern and AAA-management during the last decade, screening 65-year-old men for AAA still appears to be cost-effective. 


\section{FUTURE PERSPECTIVES}

Ruptured AAA is a catastrophic condition killing the huge majority of the people struck. In a sparsely populated, vast country as Sweden, it seems futile to affect mortality from rAAA in any significant way by re-organising health care, for example by changing referral patterns or centralisation of services for AAA/rAAA. Other treatment modalities, e.g. eEVAR, do neither seem to be a solution. On the contrary, a 24-7 service for eEVAR requires even further centralisation. Hence, more patients would be subjected to two-stop referral, and in addition probably greater resource utilisation, e.g. the need of rapid transportation (airborne referral).

Thus, the most effective way to decrease mortality from rAAA is to prevent the rupture from happening. Screening risk-groups for AAA is a clinically- and cost-effective way to do that, e.g. by screening 65-year-old men, and men and women with a family history of rAAA/AAA. However, there will still be a substantial number of men younger than 65 years of age and women who will be struck by rAAA. Maybe it would be still more effective to change the target-groups for screening, for example 60-year-old men and 70year-old women who have ever smoked, besides the men and women with a family history? In my opinion these are the most important issues regarding AAA to study further.

In the long-run though, the most logical way to reduce, at least the smoking-related AAA - which represents the great majority - would be to set up an end date for smoking in Sweden, as has been done in other countries. But, do the decision-makers have the political will and guts to do so? 


\section{SUMMARY IN SWEDISH - SAMMANFATTNING PÅ SVENSKA}

Ett pulsåderbråck eller aneurysm, är en lokal utvidgning av en pulsåder artär. Den artär som oftast drabbas är stora kroppspulsådern - aorta - i buken nedanför avgången för njurartärerna. Man talar då om ett bukaortaaneurysm Abdominellt Aorta Aneurysm (AAA). Enligt en allmänt vedertagen definition föreligger ett AAA om aortas diameter är $\geq 30 \mathrm{~mm}$. Förekomsten - prevalensen - av AAA ökar med stigande ålder och AAA är mycket ovanligt hos män under 50 och kvinnor under 70 års ålder. Tillståndet är också cirka sex gånger vanligare hos män jämfört med kvinnor. Enligt äldre studier var prevalensen av AAA hos män över 65 år mellan 4 och $9 \%$.

Riskfaktorer för eller faktorer associerade med AAA är framför allt hög ålder, manligt kön, ärftlighet och rökning, men även högt blodtryck, kronisk obstruktiv lungsjukdom (KOL) och förhöjda blodfettsnivåer anses bidra till uppkomsten av AAA.

Faran med ett AAA är framför allt risken att det spricker - rupturerar. Ett rupturerat abdominellt aortaaneurysm - rAAA - är ett mycket allvarligt tillstånd med minst $80 \%$ total dödlighet - mortalitet. I Sverige uppskattas att cirka 600 män och 200 kvinnor årligen avlider av rAAA, vilket motsvarar ungefär $1,5 \%$ av den totala mortaliteten hos män och $0,5 \%$ hos kvinnor.

Behandlingen av ett AAA innebär att man ersätter eller fodrar den aneurysmatiskt omvandlade delen av aorta med en kärlprotes. Studier har visat att cirka $5,5 \mathrm{~cm}$ är en lämplig diameter vid vilken operationen bör äga rum. Risken är då större att aneurysmet rupturerar än vad risken för allvarliga komplikationer är med en planerad förebyggande operation.

I och med att ett AAA ytterst sällan ger symtom innan det rupturerar har olika strategier för att minska mortaliteten relaterat till rAAA diskuterats, bland annat centralisering/ändrad transportlogistik, screening, bättre kirurgisk behandling, politiska beslut - exempelvis stifta lagar om rökförbud. Jag har valt att i denna avhandling fokusera på aspekter rörande centralisering/ändrad transportlogistik samt screening för tidig upptäckt och behandling av AAA.

Centralisering av kirurgin för AAA/rAAA har av olika skäl redan i hög grad kommit till stånd och det har visats att sjukhus och kirurger som utför 
många operationer för detta tillstånd har bättre resultat avseende den operationsrelaterade mortaliteten. Forskning har också visat att operationsmortaliteten inte är högre hos patienter som överlever transporten till ett AAA/rAAA-opererande sjukhus via ett annat sjukhus jämfört med dem som anländer direkt till ett sådant sjukhus. Det finns emellertid undersökningar som visar att det är fördelaktigt att handläggas enligt onestop-principen, dvs. att patienten förs direkt till det sjukhus som behandlar AAA/rAAA.

Ovanstående gäller förstås bara de patienter som anländer levande till det AAA/rAAA opererande sjukhuset. Hur stor andel av patienterna med rAAA som dör på vägen från ruptur till operationsbordet är oklart. Det är inte heller känt hur många av dem som överlever transporten, som verkligen opereras $i$ slutänden. Eftersom vi har en låg obduktionsfrekvens i Sverige får dessa frågor besvaras på annat sätt.

Då AAA är relativt vanligt och ytterst sällan ger symtom innan ruptur, har man genomfört omfattande studier vilka visat nyttan av att med en enkel ultraljudsundersökning, till en hälsoekonomiskt acceptabel kostnad, screena 65-75 åriga män med avseende på förekomsten av AAA. Därför har man i flertalet landsting i Sverige och även i England infört screening för AAA bland 65-åriga män. De män som vid screening visar sig ha ett AAA följs med upprepade ultraljudsundersökningar och om eller när deras AAA har vuxit till cirka 5,5 cm i diameter, opereras de, om de efter utredning (av bland annat hjärt-lungfunktionen) bedöms klara den relativt stora operationen.

Resultat från de påbörjade screening-programmen i Sverige och England visar dock att prevalensen AAA är betydligt lägre än förväntat, 1,5-2 \% jämfört med de knappt $5 \%$ som redovisats i äldre prevalens-studier specifikt bland 65-åriga män. Sannolikt beror denna kraftiga minskning på att rökningen minskat i motsvarande grad de senaste årtiondena. Med anledning av denna prevalensminskning har dagens screening-program blivit ifrågasatta bland annat avseende val av åldersgrupp, samt om det fortfarande är hälsoekonomiskt försvarbart.

\section{Delarbete I}

Syftet med delarbete I var att undersöka om överlevnaden efter rAAA påverkades av om patienten anlände direkt till det rAAA-opererande sjukhuset (one-stop) eller transporterades dit via ett annat sjukhus (two-stop), där han/hon först sökt vård. Genom att göra en populationsbaserad 
retrospektiv studie, där vi fastställde överlevnaden efter 30 dagar, justerad mot den köns- och åldersmatchade populationsbasen kom vi förbi många faktorer som är svåra eller omöjliga att reda ut. Det kan gälla hur många patienter med rAAA som levande når sjukhus och hur många av dessa som vid behov verkligen skickas vidare och i slutändan opereras, om det är problem/förseningar vid diagnosställandet, om olika läkare/kliniker tänker olika när det gäller operationsbeslut, om det är kvalitetsskillnad på operationsteamet och dess metoder, kvalitet på eftervård etc.

Sammanlagt studerade vi 849 patienter som hade opererats för rAAA under åren 1987-2004. Vi fann att överlevnaden för åldersgruppen 65-74 år var $27 \%$ lägre om man handlades enligt two-stop jämfört med one-stop. Skillnaden var dock i numeriska termer relativt liten och för Sveriges del skulle det innebära cirka 12 räddade liv per år, om en one-stop handläggning kunde åstadkommas i hela landet dygnet runt, året runt. Detta fodrar dock antingen att det vid alla sjukhus som bedriver akut sjukvård ständigt fanns resurser för att kunna utföra kirurgi för rAAA, eller att det fanns en säker metod för att diagnosticera rAAA redan i ambulansen, så att patienten kunde transporteras direkt till ett sjukhus med sådana resurser. Sannolikt beror denna förvånansvärt lilla effekt vad gäller överlevnaden, på den extremt höga dödligheten, oavsett vad man gör, vid rAAA. Indirekt utgör denna studie således ytterligare ett belägg för nyttan med screening, dvs. att hitta ett AAA innan rupturen sker och förebygga den med en planerad operation.

\section{Delarbete II}

De pågående screening-programmen har visat betydligt lägre prevalens än förväntat bland 65-åriga män, och det har därför diskuterats om man bör höja screening-åldern till exempelvis 70 år.

I denna populationsbaserade screening-studie undersöktes AAAprevalensen och risk-faktorer för AAA hos 5623 tidigare oscreenade 70-åriga män.

Vi fann att den screeningupptäckta prevalensen av AAA i den 70-åriga manliga populationen var under hälften av den förväntade, endast 2,3\% och att nästan $40 \%$ av AAA redan var upptäckta/behandlade. Vi fann vidare att rökning var den starkaste riskfaktorn för AAA. 


\section{Delarbete III}

När ett screening-program för exempelvis AAA utformas, är det viktigt att man screenar vid en ålder när prevalensen är tillräckligt hög för att programmet ska vara kostnadseffektivt. Man ska dock inte screena vid en så hög ålder att en stor andel av patienterna med AAA redan har upptäckts på annat sätt, att patienterna har blivit så gamla och skröpliga att de inte klarar av den relativt stora förebyggande operationen, eller att aneurysmet redan rupturerat.

Även Delarbete III är en populationsbaserad screening-studie i vilken vi bjöd in 7951 tidigare oscreenade 65-åriga män, från samma landsting som de 70-åriga männen i Delarbete II, och screenade dem ungefär under samma tidsperiod.

Vi fann att den screening-upptäckta AAA-prevalensen inte skilde sig åt mellan 65- och 70-åringarna. Detta beroende på att en större andel AAA redan var upptäckta bland 70-åringarna före screening. Således är det inte effektivare att screena 70- i stället för 65-åringar i avsikten att finna tidigare okända AAA och därmed förebygga rAAA.

\section{Delarbete IV}

För snart tio år sedan genomförde Henriksson \& Lundgren en beslutsanalytisk modellstudie i vilken konstaterades att screening för AAA av 65-åriga män var kostnadseffektivt. Med tanke på att pågående screening-program nu visar ett antal förändrade förutsättningar, väcks frågan om detta fortfarande gäller.

I Delarbete IV gjorde vi därför en uppdatering av den gamla modellen och infogade data från implementerade screening-program, det svenska kärlregistret (Swedvasc) samt från aktuella vetenskapliga publikationer.

Vi fann att screening för AAA av 65-åriga män fortfarande är kostnadseffektivt, trots att prevalensen är lägre. Detta beror sannolikt på att medverkandegraden är högre, mortaliteten efter förebyggande operation är lägre, liksom den allmänna icke-AAA relaterade mortaliteten samt att screeningen kan genomföras betydligt mer effektivt (bland annat fler undersökta män/timme) än vad man hade räknat med i den snart tio år gamla modellstudien. 


\section{Sammanfattning}

En ändrad transportlogistik, dvs. ytterst centralisering av kirurgin för AAA/rAAA är ingen framkomlig väg för att minska dödligheten i rAAA. Man bör i stället använda resurserna till att förebygga att rupturen sker, exv. genom screening för AAA. Att screena 70-åriga män i stället för 65-åriga innebär ingen förbättring av screening-effekten, och screening bland 65-åriga män förefaller fortfarande vara hälsoekonomiskt rimligt, trots flera förändrade omständigheter under det senaste decenniet. 


\section{ACKNOWLEDGEMENTS}

I would never have been able to finish this thesis without the contribution of a lot of people. I therefore wish to express my sincerest gratitude and appreciation to the following:

My main-tutor, college and chief of the section for Vascular surgery, professor Toste Länne whom without hesitation tackled this project when asked. Although a very serious disease struck you, you safely brought the project to harbour, when the prospect of finishing it seemed futile due to the Regulations concerning the formal aspects of doctorial studies at the Linköping University. Without your steady navigation through this troubled Sea of Bureaucracy, I would probably have had to submerge this project...

My co-tutor, former college/chief of the section for Vascular surgery, mentor and dear friend, PhD Fredrik Lundgren - in reality this is your project! You persuaded me to jump into the boat of research already in 2003. We have now known each other for almost exactly twenty years, and from day one - when I began my internship at the Vrinnevihospital in Norrköping 1994, where you were chief consultant at the vascular section of the surgical department - your including attitude has been an ideal to me. You have always seen, listened to, trusted, encouraged and supported me and you have thus made me grow as a surgeon, a researcher and as a human being. You have always made yourself available, when I have felt an urge to discuss some matter with you, despite what you have been up to.

I sincerely hope that we will keep up this unique relation and I am looking forward to having many more fruitful discussions regarding clinical, scientific and ethical issues, literature, film, politics, and the latest of your projects/interests which we share in common - hunting!

My second co-tutor, professor Per Carlsson for making this project possible in terms of economic means. Without your support this would truly not have been possible! In a very kind way you have throughout the project supported me and contributed with valuable suggestions, most especially regarding Paper IV! 
I also wish to express my sincere appreciation to the following people, who directly have been involved in or have contributed to the research projects of this thesis:

PhD Martin Henriksson, co-author in Paper IV. Your enthusiasm, positive attitude and generous sharing of your knowledge regarding health-economic modelling, has been most important for this part of the project! I am very thankful for this and I look forward to future cooperation and, on occasion, maybe some beer and football!

Professor John Carstensen for wise statistical advice regarding Paper I and II! I am deeply impressed of your ability to immediately dissect complex statistical problems and make them understandable for a statistical novice like me!

Assistant professor Thomas Troëng for kindly providing us the data from Swedvasc to Paper I, II and III and also for critically reading Paper I before we submitted it!

The ultrasound technicians Pia Bjällander-Stenmark and Christina Svensson at the Department of Clinical Physiology in Linköping and Marie Jonsson and Anne Jelvehed at the Department of Clinical Physiology in Norrköping for great cooperation in the screening-programme, providing us with robust data to Paper II, III and IV!

Assistance-nurse Louise Kugelberg-Wärn for your meticulousness when entering the data from the screening-programme into the database. Your positive and responsible attitude in doing this is so admirable! I also wish to acknowledge assistance-nurses Ann-Louise Wickström-Wadell, Elisabet Ansell and nurse Jenny Häll for cooperating in the data-entering process! And thank you Bibbi Göransson, chief of the wards of Cardiology, for your very wise advice in choosing these excellent assistances and generously "lending" them to us!

Administrator Elin Wistrand at the Division of Cardiovascular Medicine, for excellent and professional help with all practical issues. You are definitely the right person in the right place! 
Maj-Britt Tornell, secretary of development, for your superb and rapid assistance in converting figures to various strange formats required by the publishers of the scientific journals! There is nothing you can't fix!

Hans Granfeldt, chief of the Department of Cardiovascular surgery in Linköping, for letting me stay away from clinical work to finish this thesis!

Further, I would like to acknowledge the Swedvasc Registry, for so generously providing us with data used for all four studies.

I would also like to express my sincere appreciation to the following:

My dear colleges and friends at the section for Vascular surgery at the Department of Cardiovascular surgery in Linköping; Jan Berglund, the perfect assistant and team-player; Lasse Isaksson, a very good friend and mentor since many years, for joyful discussions regarding absolutely everything when travelling to work together on the E4 or assisting each-others when operating; Björn Jönsson, for your upright attitude, brilliant humour and great cooperation in the angio-suite; and Martin Welander, for wise comments and shrewd humour giving me many good laughs! Thanks to you all and your never-ending appetite on surgery, I have been able to stay away from clinical work for a long time to finish this thesis!

Here, I would also like to mention and thank my former colleges at the section of Vascular surgery; Magnus Rydh, my ex-roomie for giving me some extremely good laughs and Joakim Starck for being such a pleasant colleague and hopefully future research partner!

All the highly professional staff at the Vascular-surgery outpatient clinics in Norrköping and Linköping, the 78:th ward, the ward of Thoracic operations and Lab 3 and 4 at the Seldinger Unit, Linköping University Hospital, for in such a high degree contributing to the joy of going to work!

My former but also in parts future colleagues at the department of Surgery and Urology at the Vrinnevihospital in Norrköping of whom I especially would like to mention; Lars Andåker, who as chief was the one who employed me as a puppyish wannabe-surgeon 1995, Hasse Krook, my excellent, super-straightforward tutor and good friend assuring that I got the very best surgical education possible; Gunnar Arbman, Monica Svensson and 
Kalev Teder for helping Hasse educating me; Staffan Haapaniemi for, as being the oldest senior registrar, giving me good advice and good laughs! You all are very good examples of brilliant surgeons in all aspects!

I would here also like to especially thank Lasse Isaksson, Monica Svensson and of course Fredrik for in Norrköping, recruiting me to the speciality of vascular surgery and so generously teaching me the art of open vascular surgery! With you as backup when I as a young surgeon was on duty, I was never worried of whatever difficult cases that would show up at the Surgical Emergency Department - if you couldn't help me handle it, no one could!

I also wish to express my gratitude to my present and former colleagues in the Swedvasc steering committee for great and inspiring cooperation - Björn Kragsterman, Katarina Björses, Lena Blomgren, Ken Eliasson, Marlene Hensäter, David Lindström, Anders Lundell, Joakim Nordanstig, Birgitta Sigvant, Erik Wellander, Ann Wigelius, and the senior advisory board of David Bergqvist, Lars Norgren, and Thomas Troëng. Thank you all! Keep up the good work!

Outside work I would like to thank my very dear parents Ann and Anders for endless patience and support - thanks for everything mum and dad! My sister and brothers; Torun, Markus and Hjalmar, with their respective families; my parents-in-law, Eva and Ingvar and my brother-in-law, Olof with family, for always being there...

I also wish to thank the families Abrahamsson, Digerfeldt, Lundin and Varenhorst for all happy and joyful moments we have spent together! You are truly the best friends one can wish for and a great support on all occasions!

Finally and above all - the light of my life, my own beloved family - Louise, Disa, Sixten and Anna, you are indisputably the very meaning of my life! Thank you so much for putting up with me and supporting me! Without you I'm nothing! I love you!

This work has been supported by generous grants from: The Centre for Medical Technology Assessment (CMT) - the County Council of Östergötland, The Swedvasc Registry, Gore-Medical, The Swedish Heart-Lung Foundation and The Foundation of King Gustav V and Queen Victoria. 


\section{REFERENCES}

Acosta, S., Ogren, M., Bengtsson, H., Bergqvist, D., Lindblad, B. \& Zdanowski, Z. 2006, "Increasing incidence of ruptured abdominal aortic aneurysm: a population-based study", Journal of vascular surgery : official publication, the Society for Vascular Surgery [and] International Society for Cardiovascular Surgery, North American Chapter, vol. 44, no. 2, pp. 237-243.

Ailawadi, G., Eliason, J.L. \& Upchurch, G.R.Jr 2003, "Current concepts in the pathogenesis of abdominal aortic aneurysm", Journal of vascular surgery : official publication, the Society for Vascular Surgery [and] International Society for Cardiovascular Surgery, North American Chapter, vol. 38, no. 3, pp. 584-588.

Ambler, G.K., Twine, C.P., Shak, J., Rollins, K., Varty, K., Hayes, P.D. \& Boyle, J.R. 2013, Survival following ruptured EVAR before and during the IMPROVE trial, ESVS, Budapest.

Andermann, A., Blancquaert, I., Beauchamp, S. \& Dery, V. 2008, "Revisiting Wilson and Jungner in the genomic age: a review of screening criteria over the past 40 years", Bulletin of the World Health Organization, vol. 86, no. 4, pp. 317-319.

Anjum, A. \& Powell, J.T. 2012, "Is the Incidence of Abdominal Aortic Aneurysm Declining in the 21 st Century? Mortality and Hospital Admissions for England \& Wales and Scotland", European Journal of Vascular and Endovascular Surgery, vol. 43, no. 2, pp. 161-166.

Anjum, A., von Allmen, R., Greenhalgh, R. \& Powell, J.T. 2012, "Explaining the decrease in mortality from abdominal aortic aneurysm rupture", British Journal of Surgery, vol. 99, no. 5, pp. 637-645.

Antoniou, G.A., Georgiadis, G.S., Antoniou, S.A., Pavlidis, P., Maras, D., Sfyroeras, G.S., Georgakarakos, E.I. \& Lazarides, M.K. 2013, "Endovascular repair for ruptured abdominal aortic aneurysm confers an early survival benefit over open repair", Journal of Vascular Surgery, vol. 58, no. 4, pp. 1091-1105.

Ashton, H.A., Buxton, M.J., Day, N.E., Kim, L.G., Marteau, T.M., Scott, R.A., Thompson, S.G., Walker, N.M. \& Multicentre Aneurysm Screening Study Group 2002, "The Multicentre Aneurysm Screening Study (MASS) into the effect of abdominal aortic aneurysm screening on mortality in men: a randomised controlled trial", Lancet, vol. 360, no. 9345, pp. 1531-1539.

Ashton, H.A., Gao, L., Kim, L.G., Druce, P.S., Thompson, S.G. \& Scott, R.A. 2007, "Fifteen-year follow-up of a randomized clinical trial of ultrasonographic screening for abdominal aortic aneurysms", The British journal of surgery, vol. 94, no. 6, pp. 696-701.

Astrand, H., Ryden-Ahlgren, A., Sundkvist, G., Sandgren, T. \& Lanne, T. 2007, "Reduced aortic wall stress in diabetes mellitus", European journal of vascular and endovascular surgery : the official journal of the European Society for Vascular Surgery, vol. 33, no. 5, pp. 592-598.

Azizzadeh, A., Miller Iii, C.C., Villa, M.A., Estrera, A.L., Coogan, S.M., Meiner, S.T. \& Safi, H.J. 2009, "Effect of patient transfer on outcomes after open repair of ruptured abdominal aortic aneurysms", Vascular, vol. 17, no. 1, pp. 9-14. 
Badger, S.A., O'Donnell, M.E., Sharif, M.A., Boyd, C.S., Hannon, R.J., Lau, L.L., Lee, B . \& Soong, C.V. 2008, "Risk factors for abdominal aortic aneurysm and the influence of social deprivation", Angiology, vol. 59, no. 5, pp. 559-566.

Beales, L., Wolstenhulme, S., Evans, J.A., West, R. \& Scott, D.J. 2011, "Reproducibility of ultrasound measurement of the abdominal aorta", The British journal of surgery, vol. 98, no. 11, pp. 15171525 .

Becquemin, J.P., Pillet, J.C., Lescalie, F., Sapoval, M., Goueffic, Y., Lermusiaux, P., Steinmetz, E., Marzelle, J. \& ACE trialists 2011, "A randomized controlled trial of endovascular aneurysm repair versus open surgery for abdominal aortic aneurysms in low- to moderate-risk patients", Journal of vascular surgery : official publication, the Society for Vascular Surgery [and] International Society for Cardiovascular Surgery, North American Chapter, .

Bengtsson, H. \& Bergqvist, D. 1993, "Ruptured abdominal aortic aneurysm: a population-based study", Journal of vascular surgery : official publication, the Society for Vascular Surgery [and] International Society for Cardiovascular Surgery, North American Chapter, vol. 18, no. 1, pp. $74-80$

Bengtsson, H., Bergqvist, D., Ekberg, O. \& Janzon, L. 1991, "A population based screening of abdominal aortic aneurysms (AAA)", European journal of vascular surgery, vol. 5, no. 1, pp. 5357.

Bengtsson, H., Sonesson, B. \& Bergqvist, D. 1996, "Incidence and prevalence of abdominal aortic aneurysms, estimated by necropsy studies and population screening by ultrasound", Annals of the New York Academy of Sciences, vol. 800, pp. 1-24.

Bengtsson, H., Sonesson, B., Länne, T., Nilsson, P., Solvig, J., Loren, I. \& Bergqvist, D. 1992, "Prevalence of abdominal aortic aneurysm in the offspring of patients dying from aneurysm rupture", British Journal of Surgery, vol. 79, no. 11, pp. 1142-1143.

Bergqvist, D. 2011, "Pharmacological Interventions to Attenuate the Expansion of Abdominal Aortic Aneurysm (AAA) - A Systematic Review", European Journal of Vascular and Endovascular Surgery, vol. 41, no. 5; it possible by pharmacological methods to attenuate the expansion rate of abdominal aortic aneurysms? Method, pp. 663-667.

Bergqvist, D., Bjorck, M. \& Wanhainen, A. 2013, "Abdominal aortic aneurysm and new WHO criteria for screening", International angiology : a journal of the International Union of Angiology, vol. 32 , no. 1 , pp. 37-41.

Berterö, C., Carlsson, P. \& Lundgren, F. 2010, "Screening for abdominal aortic aneurysm, a one-year follow up: An interview study", Journal of Vascular Nursing, vol. 28, no. 3, pp. 97-101.

Björck, M. \& Wanhainen, A. 2013, "Pathophysiology of AAA: Heredity vs Environment", Progress in cardiovascular diseases, vol. 56, no. 1, pp. 2-6.

Blanchard, J.F. 1999, "Epidemiology of abdominal aortic aneurysms", Epidemiologic reviews, vol. 21, no. 2, pp. 207-221.

Blankensteijn, J.D., de Jong, S.E., Prinssen, M., van der Ham, A.C., Buth, J., van Sterkenburg, S.M., Verhagen, H.J., Buskens, E., Grobbee, D.E. \& Dutch Randomized Endovascular Aneurysm Management (DREAM) Trial Group 2005, "Two-year outcomes after conventional or 
endovascular repair of abdominal aortic aneurysms", The New England journal of medicine, vol. 352 , no. 23 , pp. 2398-2405.

Bown, M.J., Sutton, A.J., Bell, P.R. \& Sayers, R.D. 2002, "A meta-analysis of 50 years of ruptured abdominal aortic aneurysm repair", The British journal of surgery, vol. 89, no. 6, pp. 714-730.

Brady, A.R., Thompson, S.G., Fowkes, F.G., Greenhalgh, R.M., Powell, J.T. \& UK Small Aneurysm Trial Participants 2004, "Abdominal aortic aneurysm expansion: risk factors and time intervals for surveillance", Circulation, vol. 110, no. 1, pp. 16-21.

Brenner, D.J. \& Hall, E.J. 2007, "Computed Tomography - An Increasing Source of Radiation Exposure", N Engl J Med, vol. 357, no. 22, pp. 2277-2284.

Briggs, A.H., Claxton, K. \& Sculpher, M.J. 2006, Decision modelling for health economic evaluation, Oxford University Press, Oxford.

Brinton, E.A. 2012, "Effects of ethanol intake on lipoproteins", Current atherosclerosis reports, vol. 14, no. 2, pp. 108-114.

Brown, L.C. \& Powell, J.T. 1999, "Risk factors for aneurysm rupture in patients kept under ultrasound surveillance. UK Small Aneurysm Trial Participants", Annals of Surgery, vol. 230, no. 3, pp. 28996; discussion 296-7.

Brown, P.M., Zelt, D.T. \& Sobolev, B. 2003, "The risk of rupture in untreated aneurysms: The impact of size, gender, and expansion rate", Journal of Vascular Surgery, vol. 37, no. 2, pp. 280-284.

Burström \& Rehnberg 2006, Burström,Kristina;Rehnberg,Clas;Centrum för folkhälsa. Enheten för socialmedicin och Hälsoekonomi; $<$ br />Hälsorelaterad livskvalitet $i$ Stockholms län 2002: resultat per åldersgrupp och kön, utbildningsnivå, födelseland samt sysselsättningsgrupp : en befolkningsundersökning med EQ-5D, Centrum för folkhälsa, Stockholm.

Cao, P., De Rango, P., Verzini, F., Parlani, G., Romano, L. \& Cieri, E. 2011, "Comparison of Surveillance Versus Aortic Endografting for Small Aneurysm Repair (CAESAR): Results from a Randomised Trial", European Journal of Vascular and Endovascular Surgery, vol. 41, no. 1, pp. $13-25$.

Chaikof, E.L., Brewster, D.C., Dalman, R.L., Makaroun, M.S., Illig, K.A., Sicard, G.A., Timaran, C.H., Upchurch Jr, G.R. \& Veith, F.J. 2009, "The care of patients with an abdominal aortic aneurysm: The Society for Vascular Surgery practice guidelines", Journal of Vascular Surgery, vol. 50, no. 4, Supplement 1, pp. S2-S49.

Cho, J., Kim, J.Y., Rhee, R.Y., Gupta, N., Marone, L.K., Dillavou, E.D. \& Makaroun, M.S. 2008, "Contemporary results of open repair of ruptured abdominal aortoiliac aneurysms: Effect of surgeon volume on mortality", Journal of Vascular Surgery, vol. 48, no. 1, pp. 10-18.

Choksy, S.A., Wilmink, A.B. \& Quick, C.R. 1999, "Ruptured abdominal aortic aneurysm in the Huntingdon district: a 10-year experience", Annals of the Royal College of Surgeons of England, vol. 81 , no. 1 , pp. 27-31.

Collett, D. 2003a, "Modelling Binary data" in, 2nd edn, Chapman \& Hall / CRC, , pp. 45-101.

Collett, D. 2003b, Modelling survival data in medical research, 2nd edn, Chapman \& Hall/CRC, Boca Raton, Fla. ; London. 
Collin, J., Araujo, L., Walton, J. \& Lindsell, D. 1988, "Oxford screening programme for abdominal aortic aneurysm in men aged 65 to 74 years", Lancet, vol. 2, no. 8611, pp. 613-615.

Collin, J., Heather, B. \& Walton, J. 1991, "Growth rates of subclinical abdominal aortic aneurysms-implications for review and rescreening programmes", European journal of vascular surgery, vol. 5, no. 2, pp. 141-144.

Conway, A.M., Malkawi, A.H., Hinchliffe, R.J., Holt, P.J., Murray, S., Thompson, M.M. \& Loftus, I.M. 2012, "First-year results of a national abdominal aortic aneurysm screening programme in a single centre", The British journal of surgery, vol. 99, no. 1, pp. 73-77.

Cosford, P.A. \& Leng, G.C. 2007, "Screening for abdominal aortic aneurysm", Cochrane database of systematic reviews (Online), vol. (2), no. 2, pp. CD002945.

Coughlin, P.A., Jackson, D., White, A.D., Bailey, M.A., Farrow, C., Scott, D.J.A. \& Howell, S.J. 2013, "Meta-analysis of prospective trials determining the short- and mid-term effect of elective open and endovascular repair of abdominal aortic aneurysms on quality of life", British Journal of Surgery, vol. 100, no. 4, pp. 448-455.

Dabare, D., Lo, T.T., McCormack, D.J. \& Kung, V.W. 2012, "What is the role of screening in the management of abdominal aortic aneurysms?", Interactive cardiovascular and thoracic surgery, .

Darwood, R., Earnshaw, J.J., Turton, G., Shaw, E., Whyman, M., Poskitt, K., Rodd, C. \& Heather, B. 2012, "Twenty-year review of abdominal aortic aneurysm screening in men in the county of Gloucestershire, United Kingdom", Journal of Vascular Surgery, vol. 56, no. 1, pp. 8-13.

Davis, M., Harris, M. \& Earnshaw, J.J. 2013, "Implementation of the National Health Service Abdominal Aortic Aneurysm Screening Program in England", Journal of Vascular Surgery, vol. 57, no. 5, pp. 1440-1445.

De Bruin, J.L., Baas, A.F., Buth, J., Prinssen, M., Verhoeven, E.L.G., Cuypers, P.W.M., van Sambeek, M.R.H.M., Balm, R., Grobbee, D.E. \& Blankensteijn, J.D. 2010, "Long-Term Outcome of Open or Endovascular Repair of Abdominal Aortic Aneurysm", N Engl J Med, vol. 362, no. 20, pp. 1881-1889.

De Martino, R.R., Brooke, B.S., Robinson, W., Schanzer, A., Indes, J.E., Wallaert, J.B., Nolan, B.W., Cronenwett, J.L. \& Goodney, P.P. 2013, "Designation as "Unfit for Open Repair" Is Associated With Poor Outcomes After Endovascular Aortic Aneurysm Repair", Circulation.Cardiovascular quality and outcomes, .

De Rango, P., Cao, P., Cieri, E., Parlani, G., Lenti, M., Simonte, G. \& Verzini, F. 2012, "Effects of diabetes on small aortic aneurysms under surveillance according to a subgroup analysis from a randomized trial", Journal of Vascular Surgery, vol. 56, no. 6, pp. 1555-1563.

Di Castelnuovo, A., Rotondo, S., Iacoviello, L., Donati, M.B. \& De Gaetano, G. 2002, "Meta-analysis of wine and beer consumption in relation to vascular risk", Circulation, vol. 105, no. 24, pp. 2836-2844.

Dillon, M., Cardwell, C., Blair, P.H., Ellis, P., Kee, F. \& Harkin, D.W. 2007, "Endovascular treatment for ruptured abdominal aortic aneurysm", Cochrane database of systematic reviews (Online), vol. (1), no. 1, pp. CD005261. 
Dimick, J.B., Pronovost, P.J., Cowan, J.A., Ailawadi, G. \& Upchurch, G.R.,Jr 2002, "The volumeoutcome effect for abdominal aortic surgery: differences in case-mix or complications?", Archives of surgery (Chicago, Ill.: 1960), vol. 137, no. 7, pp. 828-832.

Dimick, J.B., Pronovost, P.J., Cowan Jr., J.A., Lipsett, P.A., Stanley, J.C. \& Upchurch Jr., G.R. 2003, "Variation in postoperative complication rates after high-risk surgery in the United States", Surgery, vol. 134, no. 4, pp. 534-540.

Diwan, A., Sarkar, R., Stanley, J.C., Zelenock, G.B. \& Wakefield, T.W. 2000, "Incidence of femoral and popliteal artery aneurysms in patients with abdominal aortic aneurysms", Journal of Vascular Surgery, vol. 31, no. 5, pp. 863-869.

Donnelly, R. \& London, N.J.M. 2009, ABC of Arterial and Venous Disease, Second edn, .

Drott, C., Arfvidsson, B., Ortenwall, P. \& Lundholm, K. 1992, "Age-standardized incidence of ruptured aortic aneurysm in a defined Swedish population between 1952 and 1988: mortality rate and operative results", The British journal of surgery, vol. 79, no. 2, pp. 175-179.

Dueck, A.D., Kucey, D.S., Johnston, K.W., Alter, D. \& Laupacis, A. 2004, "Survival after ruptured abdominal aortic aneurysm: effect of patient, surgeon, and hospital factors", Journal of vascular surgery : official publication, the Society for Vascular Surgery [and] International Society for Cardiovascular Surgery, North American Chapter, vol. 39, no. 6, pp. 1253-1260.

Eckstein, H.-., Bruckner, T., Heider, P., Wolf, O., Hanke, M., Niedermeier, H.-., Noppeney, T., Umscheid, T.\& Wenk, H. 2007, "The Relationship Between Volume and Outcome Following Elective Open Repair of Abdominal Aortic Aneurysms (AAA) in 131 German Hospitals", European Journal of Vascular and Endovascular Surgery, vol. 34, no. 3, pp. 260-266.

EVAR trial participants 2005, "Endovascular aneurysm repair versus open repair in patients with abdominal aortic aneurysm (EVAR trial 1): randomised controlled trial", Lancet, vol. 365, no. 9478, pp. 2179-2186.

Faraway, J.J. 2006, "Extending the Linear Model with R - Generalized Linear Mixed Effects and Nonparametric Regression Models" in Chapman \& Hall / CRC, , pp. 55-67.

Ferguson, C.D., Clancy, P., Bourke, B., Walker, P.J., Dear, A., Buckenham, T., Norman, P. \& Golledge, J. 2010, "Association of statin prescription with small abdominal aortic aneurysm progression", American Heart Journal, vol. 159, no. 2, pp. 307-313.

Filardo, G., Powell, J.T., Martinez, M.A. \& Ballard, D.J. 2012, "Surgery for small asymptomatic abdominal aortic aneurysms", Cochrane database of systematic reviews (Online), vol. 3, pp. CD001835.

Fink, H.A., Lederle, F.A., Roth, C.S., Bowles, C.A., Nelson, D.B. \& Haas, M.A. 2000, "The accuracy of physical examination to detect abdominal aortic aneurysm", Archives of Internal Medicine, vol. 160, no. 6, pp. 833-836.

Fleming, C., Whitlock, E.P., Beil, T.L. \& Lederle, F.A. 2005, "Screening for abdominal aortic aneurysm: A best-evidence systematic review for the U.S. Preventive Services Task Force", Annals of Internal Medicine, vol. 142, no. 3, pp. 203-211.

Forsdahl, S.H., Singh, K., Solberg, S. \& Jacobsen, B.K. 2009, "Risk Factors for Abdominal Aortic Aneurysms. A 7-Year Prospective Study: The Tromso Study, 1994-2001", Circulation, . 
Freiberg, M.S., Arnold, A.M., Newman, A.B., Edwards, M.S., Kraemer, K.L. \& Kuller, L.H. 2008, "Abdominal aortic aneurysms, increasing infrarenal aortic diameter, and risk of total mortality and incident cardiovascular disease events: 10-year follow-up data from the Cardiovascular Health Study", Circulation, vol. 117, no. 8, pp. 1010-1017.

Frydman, G., Walker, P.J., Summers, K., West, M., Xu, D., Lightfoot, T., Codd, C., Dique, T. \& Nataatmadja, M. 2003, "The Value of Screening in Siblings of Patients with Abdominal Aortic Aneurysm", European Journal of Vascular and Endovascular Surgery, vol. 26, no. 4, pp. 396400 .

Gibbs, D.M., Bown, M.J., Hussey, G. \& Naylor, A.R. 2010, "The ectatic aorta: no benefit in surveillance", Annals of Vascular Surgery, vol. 24, no. 7, pp. 908-911.

Golledge, J., Clancy, P., Jamrozik, K. \& Norman, P.E. 2007, "Obesity, Adipokines, and Abdominal Aortic Aneurysm: Health in Men Study", Circulation, vol. 116, no. 20, pp. 2275-2279.

Hafez, H., Owen, L.W., Lorimer, C.F. \& Bajwa, A. 2009, "Advantage of a one-stop referral and management service for ruptured abdominal aortic aneurysms", The British journal of surgery, vol. 96 , no. 12 , pp. 1416-1421.

Hager, J. 2013, The Swedvasc Annual Report 2013. Accessed 3 September 2013, http://www.ucr.uu.se/swedvasc/index.php/arsrapporter.

Hager, J., Länne, T., Carlsson, P. \& Lundgren, F. 2013, "Lower Prevalence than Expected when Screening 70-year-old Men for Abdominal Aortic Aneurysm", European Journal of Vascular and Endovascular Surgery, vol. 46, no. 4, pp. 453-459.

Hames, H., Forbes, T.L., Harris, J.R., Lawlor, D.K., DeRose, G. \& Harris, K.A. 2007, "The effect of patient transfer on outcomes after rupture of an abdominal aortic aneurysm", Canadian Journal of Surgery, vol. 49, no. 7, pp. 43-47.

Hartshorne, T.C., McCollum, C.N., Earnshaw, J.J., Morris, J. \& Nasim, A. 2011, "Ultrasound Measurement of Aortic Diameter in a National Screening Programme", European Journal of Vascular and Endovascular Surgery, vol. 42, no. 2, pp. 195-199.

Henriksen, N.A., Sorensen, L.T., Jorgensen, L.N. \& Lindholt, J.S. 2013, "Lack of association between inguinal hernia and abdominal aortic aneurysm in a population-based male cohort", British Journal of Surgery, vol. 100, no. 11, pp. 1478-1482.

Henriksson, M. \& Lundgren, F. 2005a, "Decision-analytical model with lifetime estimation of costs and health outcomes for one-time screening for abdominal aortic aneurysm in 65-year-old men", The British journal of surgery, vol. 92, no. 8, pp. 976-983.

Henriksson, M. \& Lundgren, F. 2005b, One-time Screening for Abdominal Aortic Aneurysm in 65year old Men, Center for Medical Technology Assessment, Linköping University, Sweden.

Henriksson, M. \& Lundgren, F. 2004, Screening för pulsåderbråck i buken: en hälsoekonomisk utvärdering; $<b r />$ Centrum för utvärdering av medicinsk teknologi; $\mathrm{Cmt}$, Linköping.

Hinchliffe, R.J., Bruijstens, L., MacSweeney, S.T.R. \& Braithwaite, B.D. 2006, "A Randomised Trial of Endovascular and Open Surgery for Ruptured Abdominal Aortic Aneurysm - Results of a Pilot Study and Lessons Learned for Future Studies", European Journal of Vascular and Endovascular Surgery, vol. 32, no. 5, pp. 506-513. 
Hollander, M. \& Wolfe, D.A. 1973, Nonparametric statistical methods, Wiley, New York.

Holt, P.J., Poloniecki, J.D., Gerrard, D., Loftus, I.M. \& Thompson, M.M. 2007a, "Meta-analysis and systematic review of the relationship between volume and outcome in abdominal aortic aneurysm surgery", The British journal of surgery, vol. 94, no. 4, pp. 395-403.

Holt, P.J., Poloniecki, J.D., Loftus, I.M., Michaels, J.A. \& Thompson, M.M. 2007b, "Epidemiological study of the relationship between volume and outcome after abdominal aortic aneurysm surgery in the UK from 2000 to 2005", The British journal of surgery, vol. 94, no. 4, pp. 441-448.

Holt, P.J.E. \& Michaels, J.A. 2007, "Does Volume Directly Affect Outcome in Vascular Surgical Procedures?", European Journal of Vascular and Endovascular Surgery, vol. 34, no. 4, pp. 386389.

Hoornweg, L.L., Storm-Versloot, M.N., Ubbink, D.T., Koelemay, M.J.W., Legemate, D.A. \& Balm, R. 2008, "Meta Analysis on Mortality of Ruptured Abdominal Aortic Aneurysms", European Journal of Vascular and Endovascular Surgery, vol. 35, no. 5, pp. 558-570.

Humphrey, J.D. \& Taylor, C.A. 2008, "Intracranial and abdominal aortic aneurysms: similarities, differences, and need for a new class of computational models", Annual Review of Biomedical Engineering, vol. 10, pp. 221-246.

IMPROVE 2013, . Available: http://www.improvetrial.org November 27].

Israelsson, L.A. 1999, "Incisional Hernias in Patients with Aortic Aneurysmal Disease: the Importance of Suture Technique", European Journal of Vascular and Endovascular Surgery, vol. 17, no. 2, pp. 133-135.

Jack, S., West, M. \& Grocott, M.P. 2011, "Perioperative exercise training in elderly subjects", Best practice \& research.Clinical anaesthesiology, vol. 25, no. 3, pp. 461-472.

Jamrozik, K., Norman, P.E., Spencer, C.A., Parsons, R.W., Tuohy, R., Lawrence-Brown, M.M. \& Dickinson, J.A. 2000, "Screening for abdominal aortic aneurysm: Lessons from a populationbased study", Medical Journal of Australia, vol. 173, no. 7, pp. 345-350.

Johnston, K.W., Rutherford, R.B., Tilson, M.D., Shah, D.M., Hollier, L. \& Stanley, J.C. 1991, "Suggested standards for reporting on arterial aneurysms. Subcommittee on Reporting Standards for Arterial Aneurysms, Ad Hoc Committee on Reporting Standards, Society for Vascular Surgery and North American Chapter, International Society for Cardiovascular Surgery", Journal of vascular surgery : official publication, the Society for Vascular Surgery [and] International Society for Cardiovascular Surgery, North American Chapter, vol. 13, no. 3, pp. 452-458.

Kakafika, A.I. \& Mikhailidis, D.P. 2007, "Smoking and aortic diseases", Circulation journal : official journal of the Japanese Circulation Society, vol. 71, no. 8, pp. 1173-1180.

Karnon, J., Goyder, E., Tappenden, P., McPhie, S., Towers, I., Brazier, J. \& Madan, J. 2007, "A review and critique of modelling in prioritising and designing screening programmes", Health technology assessment (Winchester, England), vol. 11, no. 52, pp. iii-iv, ix-xi, 1-145.

Kennedy, N.A., Flynn, L.M., Berg, R.M., Lorelli, D.R., Rama, K. \& Rizk, Y. 2010, "The evaluation of morbidity and mortality in abdominal aortic aneurysm repair patients as related to body mass index", The American Journal of Surgery, vol. 199, no. 3, pp. 369-371. 
Kent, K.C., Zwolak, R.M., Jaff, M.R., Hollenbeck, S.T., Thompson, R.W., Schermerhorn, M.L., Sicard, G.A., Riles, T.S. \& Cronenwett, J.L. 2004, "Screening for abdominal aortic aneurysm: A consensus statement", Journal of Vascular Surgery, vol. 39, no. 1, pp. 267-269.

Kent, K.C., Zwolak, R.M., Egorova, N.N., Riles, T.S., Manganaro, A., Moskowitz, A.J., Gelijns, A.C. \& Greco, G. 2010, "Analysis of risk factors for abdominal aortic aneurysm in a cohort of more than 3 million individuals", Journal of Vascular Surgery, vol. 52, no. 3, pp. 539-548.

Kertai, M.D., Boersma, E., Westerhout, C.M., Domburg, R.v., Klein, J., Bax, J.J., Urk, H.v. \& Poldermans, D. 2004, "Association between long-term statin use and mortality after successful abdominal aortic aneurysm surgery", The American Journal of Medicine, vol. 116, no. 2, pp. 96 103.

Kiev, J., Eckhardt, A. \& Kerstein, M.D. 1997, "Reliability and Accuracy of Physical Examination in Detection of Abdominal Aortic Aneurysms", Vascular and Endovascular Surgery, vol. 31, no. 2, pp. 143-146.

Lanne, T., Sandgren, T. \& Sonesson, B. 1998, "A dynamic view on the diameter of abdominal aortic aneurysms", European journal of vascular and endovascular surgery : the official journal of the European Society for Vascular Surgery, vol. 15, no. 4, pp. 308-312.

Larsson, E., Granath, F., Swedenborg, J. \& Hultgren, R. 2009, "A population-based case-control study of the familial risk of abdominal aortic aneurysm", Journal of Vascular Surgery, vol. 49, no. 1, pp. 47-51.

Law, M.R., Morris, J. \& Wald, N.J. 1994, "Screening for abdominal aortic aneurysms", Journal of medical screening, vol. 1, no. 2, pp. 110-5; discussion 115-6.

Lederle, F.A. 2011, "The rise and fall of abdominal aortic aneurysm", Circulation, vol. 124, no. 10, pp. 1097-1099.

Lederle, F.A., Freischlag, J.A., Kyriakides, T.C., Padberg, F.T.Jr, Matsumura, J.S., Kohler, T.R., Lin, P.H., Jean-Claude, J.M., Cikrit, D.F., Swanson, K.M., Peduzzi, P.N. \& Open Versus Endovascular Repair (OVER) Veterans Affairs Cooperative Study Group 2009, "Outcomes following endovascular vs open repair of abdominal aortic aneurysm: a randomized trial", JAMA : the journal of the American Medical Association, vol. 302, no. 14, pp. 1535-1542.

Lederle, F.A., Johnson, G.R., Wilson, S.E., Ballard, D.J., Jordan, W.D.,Jr, Blebea, J., Littooy, F.N., Freischlag, J.A., Bandyk, D., Rapp, J.H., Salam, A.A. \& Veterans Affairs Cooperative Study \#417 Investigators 2002a, "Rupture rate of large abdominal aortic aneurysms in patients refusing or unfit for elective repair", JAMA : the journal of the American Medical Association, vol. 287, no. 22, pp. 2968-2972.

Lederle, F.A., Johnson, G.R., Wilson, S.E., Chute, E.P., Hye, R.J., Makaroun, M.S., Barone, G.W ., Bandyk, D., Moneta, G.L. \& Makhoul, R.G. 2000a, "The Aneurysm Detection and Management study screening program: Validation cohort and final results", Archives of Internal Medicine, vol. 160, no. 10, pp. 1425-1430.

Lederle, F.A., Johnson, G.R., Wilson, S.E., Chute, E.P., Littooy, F.N., Bandyk, D., Krupski, W.C., Barone, G.W., Acher, C.W. \& Ballard, D.J. 1997, "Prevalence and associations of abdominal aortic aneurysm detected through screening. Aneurysm Detection and Management (ADAM) Veterans Affairs Cooperative Study Group", Annals of Internal Medicine, vol. 126, no. 6, pp. 441-449. 
Lederle, F.A., Johnson, G.R., Wilson, S.E., Littooy, F.N., Krupski, W.C., Bandyk, D., Acher, C.W., Chute, E.P., Hye, R.J., Gordon, I.L., Freischlag, J., Averbook, A.W . \& Makaroun, M.S. 2000b, "Yield of repeated screening for abdominal aortic aneurysm after a 4-year interval. Aneurysm Detection and Management Veterans Affairs Cooperative Study Investigators", Archives of Internal Medicine, vol. 160, no. 8, pp. 1117-1121.

Lederle, F.A., Walker, J.M. \& Reinke, D.B. 1988, "Selective screening for abdominal aortic aneurysms with physical examination and ultrasound", Archives of Internal Medicine, vol. 148, no. 8, pp. 1753-1756.

Lederle, F.A., Wilson, S.E., Johnson, G.R., Reinke, D.B., Littooy, F.N., Acher, C.W., Ballard, D.J., Messina, L.M., Gordon, I.L., Chute, E.P., Krupski, W.C., Busuttil, S.J., Barone, G.W., Sparks, S., Graham, L.M., Rapp, J.H., Makaroun, M.S., Moneta, G.L., Cambria, R.A., Makhoul, R.G., Eton, D., Ansel, H.J., Freischlag, J.A., Bandyk, D. \& Aneurysm Detection and Management Veterans Affairs Cooperative Study Group 2002b, "Immediate repair compared with surveillance of small abdominal aortic aneurysms", The New England journal of medicine, vol. 346, no. 19, pp. 14371444 .

Lederle, F.A. 2008, "Comment on "Screening for Abdominal Aortic Aneurysm Reduces Overall Mortality in Men"", European Journal of Vascular and Endovascular Surgery, vol. 36, no. 5, pp. 620-621.

Lederle, F.A., Freischlag, J.A., Kyriakides, T.C., Matsumura, J.S., Padberg, F.T., Kohler, T.R., Kougias, P., Jean-Claude, J., Cikrit, D.F. \& Swanson, K.M. 2012, "Long-Term Comparison of Endovascular and Open Repair of Abdominal Aortic Aneurysm", N Engl J Med, vol. 367, no. 21, pp. 1988-1997.

Lederle, F.A., Nelson, D.B. \& Joseph, A.M. 2003, "Smokers' relative risk for aortic aneurysm compared with other smoking-related diseases: a systematic review", Journal of Vascular Surgery, vol. 38, no. 2, pp. 329-334.

Liddington, M.I. \& Heather, B.P. 1992, "The relationship between aortic diameter and body habitus", European journal of vascular surgery, vol. 6, no. 1, pp. 89-92.

Limet, R., Sakalihassan, N. \& Albert, A. 1991, "Determination of the expansion rate and incidence of rupture of abdominal aortic aneurysms", Journal of Vascular Surgery, vol. 14, no. 4, pp. 540-548.

Lindholt, J.S., Heegaard, N.H.H., Vammen, S., Fasting, H., Henneberg, E.W . \& Heickendorff, L. 2001, "Smoking, but not Lipids, Lipoprotein (a) and Antibodies Against Oxidised LDL, is Correlated to the Expansion of Abdominal Aortic Aneurysms", European Journal of Vascular and Endovascular Surgery, vol. 21, no. 1, pp. 51-56.

Lindholt, J.S., Juul, S., Fasting, H. \& Henneberg, E.W. 2005, "Screening for abdominal aortic aneurysms: Single centre randomised controlled trial", British medical journal, vol. 330, no. 7494, pp. 750-752.

Lindholt, J.S., Juul, S. \& Henneberg, E.W. 2007, "High-risk and Low-risk Screening for Abdominal Aortic Aneurysm Both Reduce Aneurysm-related Mortality. A Stratified Analysis from a Singlecentre Randomised Screening Trial", European Journal of Vascular and Endovascular Surgery, vol. 34, no. 1, pp. 53-58.

Lindholt, J.S. \& Norman, P. 2008, "Screening for Abdominal Aortic Aneurysm Reduces Overall Mortality in Men. A Meta-analysis of the Mid- and Long-term Effects of Screening for 
Abdominal Aortic Aneurysms", European Journal of Vascular and Endovascular Surgery, vol. 36, no. 2, pp. 167-171.

Lindholt, J.S. \& Norman, P.E. 2011, "Meta-analysis of postoperative mortality after elective repair of abdominal aortic aneurysms detected by screening", The British journal of surgery, vol. 98, no. 5, pp. 619-622.

Lindholt, J.S., Sorensen, J., Sogaard, R. \& Henneberg, E.W. 2010, "Long-term benefit and costeffectiveness analysis of screening for abdominal aortic aneurysms from a randomized controlled trial", The British journal of surgery, vol. 97, no. 6, pp. 826-834.

Lindholt, J.S., Vammen, S., Fasting, H. \& Henneberg, E.W. 2000, "Psychological consequences of screening for abdominal aorticaneurysm and conservative treatment of small abdominal aortic aneurysms", European Journal of Vascular and Endovascular Surgery, vol. 20, no. 1, pp. 79-83.

Lindholt, J.S., Vammen, S., Juul, S., Henneberg, E.W. \& Fatsing, H. 1999, "The validity of ultrasonographic scanning as screening method for abdominal aortic aneurysm", Eur J Vasc Endovasc, vol. 17,pp. 472-475.

Lindstrom, D., Sadr Azodi, O., Wladis, A., Tonnesen, H., Linder, S., Nasell, H., Ponzer, S. \& Adami, J. 2008, "Effects of a perioperative smoking cessation intervention on postoperative complications: a randomized trial", Annals of Surgery, vol. 248, no. 5, pp. 739-745.

Liss, P.E. \& Lundgren, F. 2005, "Ethical reasons motivate screening for abdominal aortic aneurysm in 65 -year-old men. Aneurysm-related mortality can be halved", Lakartidningen, vol. 102, no. 3233, pp. 2216-2219.

Ljungberg, L.U., De Basso, R., Alehagen, U., Björck, H.M., Persson, K., Dahlström, U. \& Länne, T. 2011, "Impaired Abdominal aortic wall Integrity in Elderly Men Carrying the Angiotensinconverting Enzyme D Allele", European Journal of Vascular and Endovascular Surgery, vol. 42, no. 3, pp. 309-316.

Lloyd, G.M., Bown, M.J., Norwood, M.G.A., Deb, R., Fishwick, G., Bell, P.R.F. \& Sayers, R.D. 2004, "Feasibility of preoperative computer tomography in patients with ruptured abdominal aortic aneurysm: a time-to-death study in patients without operation", Journal of Vascular Surgery, vol. 39, no. 4, pp. 788-791.

Lopez-Candales, A., Holmes, D.R., Liao, S., Scott, M.J., Wickline, S .A. \& Thompson, R.W. 1997, "Decreased vascular smooth muscle cell density in medial degeneration of human abdominal aortic aneurysms", The American journal of pathology, vol. 150, no. 3, pp. 993-1007.

Luft, H.S., Bunker, J.P. \& Enthoven, A.C. 1979, "Should operations be regionalized? The empirical relation between surgical volume and mortality", The New England journal of medicine, vol. 301, no. 25 , pp. 1364-1369.

MacSweeney, S.T.R., Ellis, M., Worrell, P.C., Greenhalgh, R.M. \& Powell, J.T. 1994, "Smoking and growth rate of small abdominal aortic aneurysms", The Lancet, vol. 344, no. 8923, pp. 651-652.

Mani, K., Bjorck, M., Lundkvist, J. \& Wanhainen, A. 2008, "Similar cost for elective open and endovascular AAA repair in a population-based setting", Journal of endovascular therapy : an official journal of the International Society of Endovascular Specialists, vol. 15, no. 1, pp. 1-11. 
Mani, K., Wanhainen, A., Lundkvist, J. \& Lindström, D. 2011, "Cost-effectiveness of intensive smoking cessation therapy among patients with small abdominal aortic aneurysms", Journal of Vascular Surgery, vol. 54, no. 3, pp. 628-636.

Maybury, R.S., Chang, D.C. \& Freischlag, J.A. 2011, "Rural Hospitals Face a Higher Burden of Ruptured Abdominal Aortic Aneurysm and Are More Likely to Transfer Patients for Emergent Repair", Journal of the American College of Surgeons, vol. 212, no. 6, pp. 1061-1067.

McGregor, J.C., Pollock, J.G. \& Anton, H.C. 1975, "The value of ultrasonography in the diagnosis of abdominal aortic aneurysm", Scottish medical journal, vol. 20, no. 3, pp. 133-137.

Moll, F.L., Powell, J.T., Fraedrich, G., Verzini, F., Haulon, S., Waltham, M., van Herwaarden, J.A., Holt, P.J.E., van Keulen, J.W., Rantner, B., Schlösser, F.J.V., Setacci, F. \& Ricco, J.-. 2011, "Management of Abdominal Aortic Aneurysms Clinical Practice Guidelines of the European Society for Vascular Surgery", European Journal of Vascular and Endovascular Surgery, vol. 41 , no. Supplement 1, pp. S1-S58.

Moore, C.L., Holliday, R.S., Hwang, J.Q. \& Osborne, M.R. 2008, "Screening for abdominal aortic aneurysm in asymptomatic at-risk patients using emergency ultrasound", The American Journal of Emergency Medicine, vol. 26, no. 8, pp. 883-887.

Mureebe, L., Egorova, N., Giacovelli, J.K., Gelijns, A., Kent, K.C. \& McKinsey, J.F. 2008, "National trends in the repair of ruptured abdominal aortic aneurysms", Journal of vascular surgery : official publication, the Society for Vascular Surgery [and] International Society for Cardiovascular Surgery, North American Chapter, vol. 48, no. 5, pp. 1101-1107.

Mureebe, L., Egorova, N., McKinsey, J.F. \& Kent, K.C. 2010, "Gender trends in the repair of ruptured abdominal aortic aneurysms and outcomes", Journal of Vascular Surgery, vol. 51, no. 4, Supplement 1, pp. S9-S13.

NAAASP , The National Health Services Abdominal Aortic Aneurysm Screening Programme [Homepage of NHS Abdominal Aortic Aneurysm Screening Programme], [Online]. Available: http://aaa.screening.nhs.uk.

NICE , National Institute for Health and Clinical Excellence (NICE). Guide to methods of technology appraisal 2013. Available: www.nice.org.uk.

Nordon, I.M., Hinchliffe, R.J., Loftus, I.M. \& Thompson, M.M. 2011, "Pathophysiology and epidemiology of abdominal aortic aneurysms", Nature reviews.Cardiology, vol. 8, no. 2, pp. 92102.

Norman, P.E., Jamrozik, K., Lawrence-Brown, M.M., Le, M.T., Spencer, C.A., Tuohy, R.J., Parsons, R.W. \& Dickinson, J.A. 2004, "Population based randomised controlled trial on impact of screening on mortality from abdominal aortic aneurysm", BMJ (Clinical research ed.), vol. 329, no. 7477 , pp. 1259.

Norman, P.E. \& Powell, J.T. 2007, "Abdominal aortic aneurysm: the prognosis in women is worse than in men", Circulation, vol. 115, no. 22, pp. 2865-2869.

Norman, P.E., Spilsbury, K. \& Semmens, J.B. 2011, "Falling rates of hospitalization and mortality from abdominal aortic aneurysms in Australia", Journal of Vascular Surgery, vol. 53, no. 2, pp. 274-277. 
Noronen, K., Laukontaus, S., Kantonen, I., Lepäntalo, M. \& Venermo, M. 2013, "The Natural Course of Abdominal Aortic Aneurysms that Meet the Treatment Criteria but not the Operative Requirements", European Journal of Vascular and Endovascular Surgery, vol. 45, no. 4, pp. 326-331.

Ouriel, K., Clair, D.G., Kent, K.C. \& Zarins, C.K. 2010, "Endovascular repair compared with surveillance for patients with small abdominal aortic aneurysms", Journal of Vascular Surgery, vol. 51, no. 5, pp. 1081-1087.

Parodi, J.C., Palmaz, J.C. \& Barone, H.D. 1991, "Transfemoral intraluminal graft implantation for abdominal aortic aneurysms", Annals of Vascular Surgery, vol. 5, no. 6, pp. 491-499.

Petrie, A. \& Sabin, C. 2005, Medical statistics at a glance, 2nd edn, Blackwell, Malden, Mass.

Powell, J.T. 2003, "Familial clustering of abdominal aortic aneurysm?smoke signals, but no culprit genes", British Journal of Surgery, vol. 90, no. 10, pp. 1173-1174.

Powell, J.T., Brown, L.C., Greenhalgh, R.M. \& Thompson, S.G. 2008, "The rupture rate of large abdominal aortic aneurysms: is this modified by anatomical suitability for endovascular repair?", Annals of Surgery, vol. 247, no. 1, pp. 173-179.

Prinssen, M., Verhoeven, E.L., Buth, J., Cuypers, P.W., van Sambeek, M.R., Balm, R., Buskens, E., Grobbee, D.E., Blankensteijn, J.D. \& Dutch Randomized Endovascular Aneurysm Management (DREAM)Trial Group 2004, "A randomized trial comparing conventional and endovascular repair of abdominal aortic aneurysms", The New England journal of medicine, vol. 351, no. 16, pp. 1607-1618.

Rayt, H.S., Sutton, A.J., London, N.J., Sayers, R.D. \& Bown, M.J. 2008, "A systematic review and meta-analysis of endovascular repair (EVAR) for ruptured abdominal aortic aneurysm", European journal of vascular and endovascular surgery: the official journal of the European Society for Vascular Surgery, vol. 36, no. 5, pp. 536-544.

Reimerink, J.J., Hoornweg, L.L., Vahl, A.C., Wisselink, W., van den Broek, T.A., Legemate, D.A., Reekers, J.A., Balm, R. \& Amsterdam Acute Aneurysm Trial Collaborators 2013a, "Endovascular repair versus open repair of ruptured abdominal aortic aneurysms: a multicenter randomized controlled trial", Annals of Surgery, vol. 258, no. 2, pp. 248-256.

Reimerink, J.J., van der Laan, M.J., Koelemay, M.J., Balm, R. \& Legemate, D.A. 2013b, "Systematic review and meta-analysis of population-based mortality from ruptured abdominal aortic aneurysm", British Journal of Surgery, vol. 100, no. 11, pp. 1405-1413.

RESCAN Collaborators, Bown, M.J., Sweeting, M.J., Brown, L.C., Powell, J.T. \& Thompson, S.G. 2013, "Surveillance intervals for small abdominal aortic aneurysms: a meta-analysis", JAMA : the journal of the American Medical Association, vol. 309, no. 8, pp. 806-813.

Rosenthal, R., von Kanel, O., Eugster, T., Stierli, P. \& Gurke, L. 2005, "Does specialization improve outcome in abdominal aortic aneurysm surgery?", Vascular, vol. 13, no. 2, pp. 107-113.

Rudarakanchana, N. \& Powell, J.T. 2013, "Advances in Imaging and Surveillance of AAA: When, How, How Often?", Progress in cardiovascular diseases, vol. 56, no. 1, pp. 7-12.

Rughani, G., Robertson, L. \& Clarke, M. 2012, "Medical treatment for small abdominal aortic aneurysms", The Cochrane database of systematic reviews, vol. 9, pp. CD009536. 
Rutherford, R.B. 2000, Vascular surgery, 5th edn, Saunders, Philadelphia ; London.

Sadat, U., Boyle, J.R., Walsh, S.R., Tang, T., Varty, K. \& Hayes, P.D. 2008, "Endovascular vs open repair of acute abdominal aortic aneurysms-A systematic review and meta-analysis", Journal of Vascular Surgery, vol. 48, no. 1, pp. 227-236.

Sakalihasan, N., Limet, R. \& Defawe, O. "Abdominal aortic aneurysm", The Lancet, vol. 365, no. 9470, pp. 1577-1589.

Sandiford, P., Mosquera, D. \& Bramley, D. 2011, "Trends in incidence and mortality from abdominal aortic aneurysm in New Zealand", The British journal of surgery, vol. 98, no. 5, pp. 645-651.

SBU, The Swedish Council on Health Technology Assessment , SBU, The Swedish Council on Health Technology Assessment. Available: http://www.sbu.se/200804e [2012, June].

Schlösser, F.J.V., Tangelder, M.J.D., Verhagen, H.J.M., van der Heijden, G.J.M.G., Muhs, B.E., van der Graaf, Y. \& Moll, F.L. 2008, "Growth predictors and prognosis of small abdominal aortic aneurysms", Journal of Vascular Surgery, vol. 47, no. 6, pp. 1127-1133.

Schouten, O., Boersma, E., Hoeks, S.E., Benner, R., van Urk, H., van Sambeek, M.R., Verhagen, H.J., Khan, N.A., Dunkelgrun, M., Bax, J.J., Poldermans, D. \& Dutch Echocardiographic Cardiac Risk Evaluation Applying Stress Echocardiography Study Group 2009, "Fluvastatin and perioperative events in patients undergoing vascular surgery", The New England journal of medicine, vol. 361, no. 10 , pp. $980-989$.

Schouten, O., van Laanen, J.H.H., Boersma, E., Vidakovic, R., Feringa, H.H.H., Dunkelgrün, M., Bax, J.J., Koning, J., van Urk, H. \& Poldermans, D. 2006, "Statins are Associated with a Reduced Infrarenal Abdominal Aortic Aneurysm Growth", European Journal of Vascular and Endovascular Surgery, vol. 32, no. 1, pp. 21-26.

Scott, R.A.P., Bridgewater, S.G. \& Ashton, H.A. 2002, "Randomized clinical trial of screening for abdominal aortic aneurysm in women", British Journal of Surgery, vol. 89, no. 3, pp. 283-285.

Shackley, P., Slack, R. \& Michaels, J. 2001, "Vascular patients' preferences for local treatment: an application of conjoint analysis", Journal of health services research \& policy, vol. 6, no. 3, pp. 151-157.

Shantikumar, S., Ajjan, R., Porter, K.E. \& Scott, D.J.A. 2010, "Diabetes and the Abdominal Aortic Aneurysm", European Journal of Vascular and Endovascular Surgery, vol. 39, no. 2, pp. 200207.

Sharp, M.A. \& Collin, J. 2003, "A Myth Exposed: Fast Growth in Diameter does not Justify Precocious Abdominal Aortic Aneurysm Repair", European Journal of Vascular and Endovascular Surgery, vol. 25, no. 5, pp. 408-411.

Simoni, G., Pastorino, C., Perrone, R., Ardia, A., Gianrossi, R., Decian, F., Cittadini, j., G., Baiardi, A. \& Bachi, V. 1995, "Screening for abdominal aortic aneurysms and associated risk factors in a general population", European Journal of Vascular and Endovascular Surgery, vol. 10, no. 2, pp. 207-210.

Singh, K., Bonaa, K.H., Jacobsen, B.K., Bjork, L. \& Solberg, S. 2001, "Prevalence of and risk factors for abdominal aortic aneurysms in a population-based study : The Tromso Study", American Journal of Epidemiology, vol. 154, no. 3, pp. 236-244. 
Singh, K., Bønaa, K.H., Solberg, S., Sørlie, D.G. \& Bjørk, L. 1998, "Intra- and interobserver variability in ultrasound measurements of abdominal aortic diameter. The Troms $\varnothing$ study", European Journal of Vascular and Endovascular Surgery, vol. 15, no. 6, pp. 497-504.

Sogaard, R., Laustsen, J. \& Lindholt, J.S. 2012a, "Cost effectiveness of abdominal aortic aneurysm screening and rescreening in men in a modern context: evaluation of a hypothetical cohort using a decision analytical model", BMJ (Clinical research ed.), vol. 345, pp. e4276.

Sogaard, R., Laustsen, J. \& Lindholt, J.S. 2012b, "Cost effectiveness of abdominal aortic aneurysm screening and rescreening in men in a modern context: evaluation of a hypothetical cohort using a decision analytical model", BMJ (Clinical research ed.), vol. 345, pp. e4276.

Sonesson, B., Ahlgren, A.R., Lazer, L. \& Lanne, T. 1997, "Does long-term smoking affect aortic stiffness more in women than in men?", Clinical physiology (Oxford, England), vol. 17, no. 5, pp. 439-447.

Sonesson, B., Lanne, T., Hansen, F. \& Sandgren, T. 1994, "Infrarenal aortic diameter in the healthy person", European journal of vascular surgery, vol. 8, no. 1, pp. 89-95.

Spencer, C.A., Jamrozik, K., Norman, P.E. \& Lawrence-Brown, M.M. 2000, "The potential for a selective screening strategy for abdominal aortic aneurysm", Journal of medical screening, vol. 7 , no. 4 , pp. 209-211.

Spronk, S., van Kempen, B.J., Boll, A.P., Jorgensen, J.J., Hunink, M.G. \& Kristiansen, I.S. 2011, "Cost-effectiveness of screening for abdominal aortic aneurysm in the Netherlands and Norway", The British journal of surgery, vol. 98, no. 11, pp. 1546-1555.

Stackelberg, O., Björck, M., Sadr-Azodi, O., Larsson, S.C., Orsini, N. \& Wolk, A. 2013, "Obesity and abdominal aortic aneurysm", British Journal of Surgery, vol. 100, no. 3, pp. 360-366.

Stather, P.W., Sidloff, D., Dattani, N., Choke, E., Bown, M.J. \& Sayers, R.D. 2013, "Systematic review and meta-analysis of the early and late outcomes of open and endovascular repair of abdominal aortic aneurysm", The British journal of surgery, .

Statistics Sweden a, , Statistics Sweden. Available: www.scb.se.

Statistics Sweden b, , Statistics Sweden. Life tables during 2008-2012, for men and women. Available: www.scb.se.

Sterpetti, A.V., Schultz, R.D., Feldhaus, R.J., Cheng, S.E. \& Peetz, D.J.,Jr 1987, "Factors influencing enlargement rate of small abdominal aortic aneurysms", The Journal of surgical research, vol. 43 , no. 3, pp. 211-219.

Svensjo, S., Bjorck, M., Gurtelschmid, M., Djavani Gidlund, K., Hellberg, A. \& Wanhainen, A. 2011, "Low prevalence of abdominal aortic aneurysm among 65-year-old Swedish men indicates a change in the epidemiology of the disease", Circulation, vol. 124, no. 10, pp. 1118-1123.

Svensjö, S., Björck, M. \& Wanhainen, A. 2013, "Five-year outcomes in men screened for abdominal aortic aneurysm at 65 years of age - a population-based cohort study", European Journal of Vascular and Endovascular Surgery, , no. 0.

Svensjö, S., Björck, M. \& Wanhainen, A. 2012, "Current prevalence of abdominal aortic aneurysm in 70-year-old women", British Journal of Surgery, , pp. n/a-n/a. 
Swedvasc, http://www.ucr.uu.se/swedvasc [2012, June].

Sweeting, M.J., Thompson, S.G., Brown, L.C., Powell, J.T. \& RESCAN collaborators 2012, "Metaanalysis of individual patient data to examine factors affecting growth and rupture of small abdominal aortic aneurysms", The British journal of surgery, vol. 99, no. 5, pp. 655-665.

Takagi, H., Kawai, N. \& Umemoto, T. 2007, "Abdominal aortic aneurysm: Screening reduces all cause mortality in men", BMJ (Clinical research ed.), vol. 335, no. 7626, pp. 899.

Takagi, H., Niwa, M., Mizuno, Y., Goto, S.N., Umemoto, T. \& All-Literature Investigation of Cardiovascular Evidence Group 2013, "The Last Judgment upon abdominal aortic aneurysm screening", International journal of cardiology, vol. 167, no. 5, pp. 2331-2332.

Takagi, H., Goto, S., Matsui, M., Manabe, H. \& Umemoto, T. 2010, "A further meta-analysis of population-based screening for abdominal aortic aneurysm", Journal of Vascular Surgery, vol. 52, no. 4, pp. 1103-1108.

The National board of health and welfare, Centre of epidemiology, Official statistics of Sweden 2009, Causes of death 2007, Socialstyrelsen, Stockholm.

The National Board of Health and Welfare, Sweden, The National Board of Health and Welfare, Sweden [Homepage of The National Board of Health and Welfare, Sweden], [Online]. Available: http://www.socialstyrelsen.se/english.

The R-project for Statistical Computing, http://www.r-project.org/ [2012, January-December].

The United Kingdom EVAR Trial Investigators, 2010, "Endovascular Repair of Aortic Aneurysm in Patients Physically Ineligible for Open Repair", The New England journal of medicine, .

Thompson, S.G., Ashton, H.A., Gao, L., Buxton, M.J., Scott, R.A. \& Multicentre Aneurysm Screening Study (MASS) Group 2012, "Final follow-up of the Multicentre Aneurysm Screening Study (MASS) randomized trial of abdominal aortic aneurysm screening", The British journal of surgery, vol. 99, no. 12, pp. 1649-1656.

Thompson, S.G., Ashton, H.A., Gao, L., Scott, R.A. \& Multicentre Aneurysm Screening Study Group 2009, "Screening men for abdominal aortic aneurysm: 10 year mortality and cost effectiveness results from the randomised Multicentre Aneurysm Screening Study", BMJ (Clinical research ed.), vol. 338, pp. b2307.

Troëng, T., Malmstedt, J. \& Björck, M. 2008, "External Validation of the Swedvasc Registry: A Firsttime Individual Cross-matching with the Unique Personal Identity Number", European Journal of Vascular and Endovascular Surgery, vol. 36, no. 6, pp. 705-712.

Twine, C.P. \& Williams, I.M. 2011, "Systematic review and meta-analysis of the effects of statin therapy on abdominal aortic aneurysms", British Journal of Surgery, vol. 98, no. 3, pp. 346-353.

U.S. Preventive Services Task Force 2005, "Screening for abdominal aortic aneurysm: Recommendation statement", Annals of Internal Medicine, vol. 142, no. 3, pp. 198-202.

UKSAT Participants 2002, "Long-term outcomes of immediate repair compared with surveillance of small abdominal aortic aneurysms", The New England journal of medicine, vol. 346, no. 19, pp. $1445-1452$. 
UKSAT participants 2000, "Smoking, lung function and the prognosis of abdominal aortic aneurysm. The UK Small Aneurysm Trial Participants", European journal of vascular and endovascular surgery : the official journal of the European Society for Vascular Surgery, vol. 19, no. 6, pp. 636-642.

UKSAT Participants 1998, "Mortality results for randomised controlled trial of early elective surgery or ultrasonographic surveillance for small abdominal aortic aneurysms. The UK Small Aneurysm Trial Participants", Lancet, vol. 352, no. 9141, pp. 1649-1655.

United Kingdom EVAR Trial Investigators, Greenhalgh, R.M., Brown, L.C., Powell, J.T., Thompson, S.G., Epstein, D. \& Sculpher, M.J. 2010, "Endovascular versus open repair of abdominal aortic aneurysm", The New England journal of medicine, vol. 362, no. 20, pp. 1863-1871.

Vardulaki, K.A., Walker, N.M., Day, N.E., Duffy, S.W., Ashton, H.A. \& Scott, R.A.P. 2000, "Quantifying the risks of hypertension, age, sex and smoking in patients with abdominal aortic aneurysm", British Journal of Surgery, vol. 87, no. 2, pp. 195-200.

Veith, F.J., Lachat, M., Mayer, D., Malina, M., Holst, J., Mehta, M., Verhoeven, E.L., Larzon, T., Gennai, S., Coppi, G., Lipsitz, E.C., Gargiulo, N.J., van der Vliet, J.A., Blankensteijn, J., Buth, J., Lee, W.A., Biasi, G., Deleo, G., Kasirajan, K., Moore, R., Soong, C.V., Cayne, N.S., Farber, M.A., Raithel, D., Greenberg, R.K., van Sambeek, M.R., Brunkwall, J.S., Rockman, C.B., Hinchliffe, R.J. \& RAAA Investigators 2009, "Collected world and single center experience with endovascular treatment of ruptured abdominal aortic aneurysms", Annals of Surgery, vol. 250, no. 5 , pp. 818-824.

Verloes, A., Sakalihasan, N., Koulischer, L. \& Limet, R. 1995, "Aneurysms of the abdominal aorta: familial and genetic aspects in three hundred thirteen pedigrees", Journal of Vascular Surgery, vol. 21, no. 4, pp. 646-655.

Vogel, T.R., Nackman, G.B., Brevetti, L.S., Crowley, J.G., Bueno, M.M., Banavage, A., Odroniec, K., Ciocca, R.G. \& Graham, A.M. 2005, "Resource utilization and outcomes: effect of transfer on patients with ruptured abdominal aortic aneurysms", Annals of Vascular Surgery, vol. 19, no. 2, pp. 149-153.

Volodos', N.L., Shekhanin, V.E., Karpovich, I.P., Troian, V.I. \& Gur'ev, I. 1986, "A self-fixing synthetic blood vessel endoprosthesis", Vestnik khirurgii imeni I.I.Grekova, vol. 137, no. 11, pp. 123-125.

Von Allmen, R.S. \& Powell, J.T. 2012, "The management of ruptured abdominal aortic aneurysms: screening for abdominal aortic aneurysm and incidence of rupture", The Journal of cardiovascular surgery, vol. 53, no. 1, pp. 69-76.

Vouyouka, A.G. \& Kent, K.C. 2007, "Arterial vascular disease in women", Journal of Vascular Surgery, vol. 46, no. 6, pp. 1295-1302.

Wahlgren, C.M., Larsson, E., Magnusson, P.K., Hultgren, R. \& Swedenborg, J. 2010, "Genetic and environmental contributions to abdominal aortic aneurysm development in a twin population", Journal of vascular surgery : official publication, the Society for Vascular Surgery [and] International Society for Cardiovascular Surgery, North American Chapter, vol. 51, no. 1, pp. 37; discussion 7. 
Wanhainen, A. 2011, "Comments regarding 'Ultrasound Measurement of Aortic Diameter in a National Screening Programme'", European journal of vascular and endovascular surgery: the official journal of the European Society for Vascular Surgery, vol. 42, no. 2, pp. 200-201.

Wanhainen, A. \& Bjorck, M. 2011, "The Swedish experience of screening for abdominal aortic aneurysm", Journal of vascular surgery : official publication, the Society for Vascular Surgery [and] International Society for Cardiovascular Surgery, North American Chapter, vol. 53, no. 4, pp. 1164-1165.

Wanhainen, A., Svensjo, S. \& Mani, K. 2008, "Screening for abdominal aortic aneurysm--areas where information is still inadequate", Scandinavian journal of surgery : SJS : official organ for the Finnish Surgical Society and the Scandinavian Surgical Society, vol. 97, no. 2, pp. 131-135.

Wanhainen, A., Lundkvist, J., Bergqvist, D. \& Björck, M. 2005, "Cost-effectiveness of different screening strategies for abdominal aortic aneurysm", Journal of Vascular Surgery, vol. 41, no. 5, pp. 741-751.

Wild, J.B., Stather, P.W., Biancari, F., Choke, E.C., Earnshaw, J.J., Grant, S.W., Hafez, H., Holdsworth, R., Juvonen, T., Lindholt, J., McCollum, C., Parvin, S., Sayers, R.D. \& Bown, M.J. 2013, "A Multicentre Observational Study of the Outcomes of Screening Detected Subaneurysmal Aortic Dilatation", European journal of vascular and endovascular surgery: the official journal of the European Society for Vascular Surgery, vol. 45, no. 2, pp. 128-134.

Wilmink, T.B.M., Quick, C.R.G. \& Day, N.E. 1999, "The association between cigarette smoking and abdominal aortic aneurysms", Journal of Vascular Surgery, vol. 30, no. 6, pp. 1099-1105.

Wilson, J.M.G., Jungner, G. \& World Health Organization 1968, Principles and practice of screening for disease, World Health Organization, Geneva.

Wong, D.R., Willett, W.C. \& Rimm, E.B. 2007, "Smoking, hypertension, alcohol consumption, and risk of abdominal aortic aneurysm in men", American Journal of Epidemiology, vol. 165, no. 7, pp. 838-845.

Wong, J., Lam, D.P., Abrishami, A., Chan, M.T. \& Chung, F. 2012, "Short-term preoperative smoking cessation and postoperative complications: a systematic review and meta-analysis", Canadian journal of anaesthesia = Journal canadien d'anesthesie, vol. 59, no. 3, pp. 268-279.

Zarrouk, M., Holst, J., Malina, M., Lindblad, B., Wann-Hansson, C., Rosvall, M. \& Gottsater, A. 2013, "The importance of socioeconomic factors for compliance and outcome at screening for abdominal aortic aneurysm in 65-year-old men", Journal of vascular surgery, .

Zdanowski, Z., Danielsson, G., Jonung, T., Kaij, J., Ribbe, E., Sahlin, C., Schatz, P., Thorne, J. \& Norgren, L. 2002, "Outcome of treatment of ruptured abdominal aortic aneurysms depending on the type of hospital", The European journal of surgery = Acta chirurgica, vol. 168, no. 2, pp. 96100 . 


\section{APPENDIX}

\section{Health Questionnaire}

Prior to the examination of your aorta, we kindly ask you to complete this Health Questionnaire and bring it to the investigation - this is optional but the information is needed for our research concerning abdominal aortic aneurysms - whether you complete the questionnaire or not, does not in any way affect your opportunity to have your aorta examined by ultrasound.

Our purpose is to get a picture of your health. All information will be handled with the same secrecy as medical records in general and may be used for scientific research.

Place of birth

Country of birth

What has been your main occupation?

Have you got any relative who has or has had an aneurysm? $\square$ No $\square$ Yes If your answer is Yes:

How are/were you related?

Where was the aneurysm located?

$\square$ The Chest $\square$ The Abdomen $\square$ Elsewhere $\square$ Don't know

Do you already know that you have an aneurysm or have you been operated for this disorder? $\square$ No $\square$ Yes

If your answer is Yes:

Where is/was the aneurysm located?

$\square$ The Chest $\square$ The Abdomen $\square$ Elsewhere $\square$ Don't know

Is the aneurysm operated? $\square$ No $\quad \square$ Yes

If your answer is Yes:

Was the operation done due to a ruptured aneurysm? $\square$ No $\quad \square$ Yes

At which hospital was the operation performed? 
Do you smoke? $\square$ No $\square$ Yes

Are you an ex-smoker? $\square$ No $\square$ Yes

If your answer is Yes on any of the two questions above:

For how long have you been smoking?.........years.

How many cigarettes did you smoke each day on average?.........

If you used another type of tobacco, how many grams did you smoke each week on average?.........g

Have you been using snuff during a longer time-period regularly? $\square$ No $\quad \square$ Yes

Do you have or have you previously had any of the following diseases?

\begin{tabular}{|c|c|c|c|c|}
\hline Disease & No & Yes & Don't know & What year did you get sick? \\
\hline \multicolumn{5}{|l|}{ Hypertension } \\
\hline \multicolumn{5}{|l|}{ Hyperlipidemia } \\
\hline \multicolumn{5}{|l|}{$\begin{array}{l}\text { Diabetes, } \\
\text { If Yes, what treatment are you undertaking? } \\
\square \text { Diet } \square \text { Tabletts } \square \text { Insulin }\end{array}$} \\
\hline \multicolumn{5}{|l|}{$\begin{array}{l}\text { Asthma/COPD (Chronic Obstructive } \\
\text { Pulmonary Disease) }\end{array}$} \\
\hline \multicolumn{5}{|l|}{$\begin{array}{l}\text { Any other pulmonary disease, } \\
\text { If Yes, what? }\end{array}$} \\
\hline \multicolumn{5}{|l|}{ Renal failure } \\
\hline \multicolumn{5}{|l|}{ Stroke/TIA/CVD (CerebroVascularDisease) } \\
\hline \multicolumn{5}{|l|}{ Claudication } \\
\hline \multicolumn{5}{|l|}{ Amputation } \\
\hline \multicolumn{5}{|l|}{ Previous vascular surgery } \\
\hline \multicolumn{5}{|l|}{ Angina } \\
\hline \multicolumn{5}{|l|}{ Myocardial infarction } \\
\hline \multicolumn{5}{|l|}{ Previous cardiac surgery } \\
\hline \multicolumn{5}{|l|}{$\begin{array}{l}\text { Any other cardiovascular disease, } \\
\text { If Yes, what? }\end{array}$} \\
\hline \multicolumn{5}{|l|}{$\begin{array}{l}\text { Rheumatic disease, } \\
\text { If Yes, what? }\end{array}$} \\
\hline \multicolumn{5}{|l|}{$\begin{array}{l}\text { Cancer, } \\
\text { If Yes, what?..................................... }\end{array}$} \\
\hline $\begin{array}{l}\text { Anything else, } \\
\text { If Yes, what? }\end{array}$ & & & & \\
\hline
\end{tabular}


The following information is completed by the medical personnel at the time of the examination.

Date:

Height:

Weight:

Aorta

Diameter: . $\mathrm{mm}$

Localized swelling $\square$ No $\square$ Yes Difficult to examine 



\section{Articles}

The articles associated with this thesis have been removed for copyright reasons. For more details about these see:

http://urn.kb.se/resolve?urn=urn:nbn:se:liu:diva-102482 